NATIONAL LABORATORY

\title{
Additional EIPC Study Analysis: Interim Report on Medium Priority Topics
}

\section{March 2014}

\section{Prepared by}

\section{Stanton W. Hadley}

Oak Ridge National Laboratory

Douglas J. Gotham

Purdue University

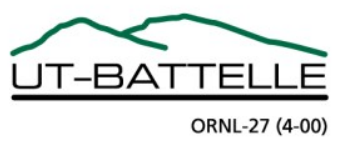




\title{
DOCUMENT AVAILABILITY
}

Reports produced after January 1, 1996, are generally available free via US Department of Energy (DOE) SciTech Connect.

Website http://www.osti.gov/scitech/

Reports produced before January 1, 1996, may be purchased by members of the public from the following source:

\author{
National Technical Information Service \\ 5285 Port Royal Road \\ Springfield, VA 22161 \\ Telephone 703-605-6000 (1-800-553-6847) \\ TDD 703-487-4639 \\ Fax 703-605-6900 \\ E-mail info@ntis.gov \\ Website http://www.ntis.gov/support/ordernowabout.htm
}

Reports are available to DOE employees, DOE contractors, Energy Technology Data Exchange representatives, and International Nuclear Information System representatives from the following source:

Office of Scientific and Technical Information

PO Box 62

Oak Ridge, TN 37831

Telephone 865-576-8401

Fax 865-576-5728

E-mail reports@osti.gov

Website http://www.osti.gov/contact.html

This report was prepared as an account of work sponsored by an agency of the United States Government. Neither the United States Government nor any agency thereof, nor any of their employees, makes any warranty, express or implied, or assumes any legal liability or responsibility for the accuracy, completeness, or usefulness of any information, apparatus, product, or process disclosed, or represents that its use would not infringe privately owned rights. Reference herein to any specific commercial product, process, or service by trade name, trademark, manufacturer, or otherwise, does not necessarily constitute or imply its endorsement, recommendation, or favoring by the United States Government or any agency thereof. The views and opinions of authors expressed herein do not necessarily state or reflect those of the United States Government or any agency thereof. 
Electrical and Electronics Systems Research Division

Additional EIPC Study Analysis: Interim Report on Medium Priority Topics

Stanton W. Hadley (ORNL)

Douglas J. Gotham (Purdue University)

March 2014

Prepared by

OAK RIDGE NATIONAL LABORATORY

Oak Ridge, Tennessee 37831-6283

managed by

UT-BATTELLE, LLC

for the

US DEPARTMENT OF ENERGY

under contract DE-AC05-00OR22725 



\section{CONTENTS}

Page

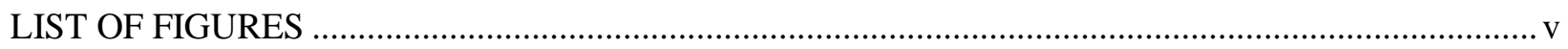

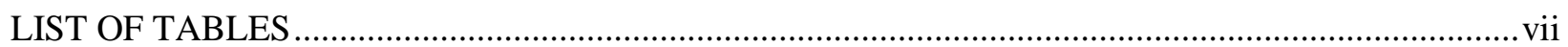

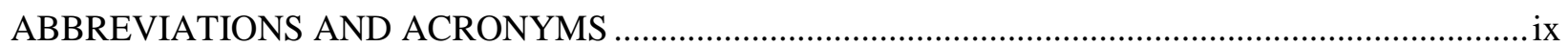

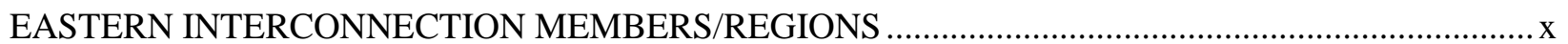

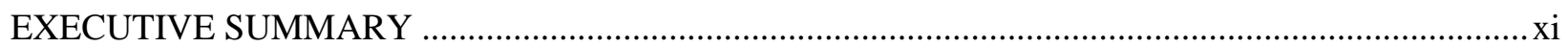

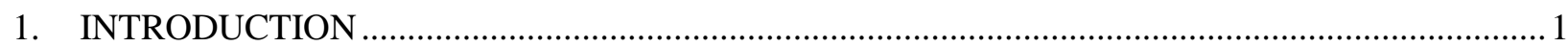

2. TOPIC 6: OPERATING AND PLANNING RESERVES ........................................................ 6

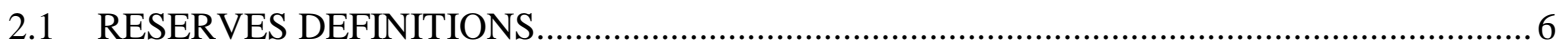

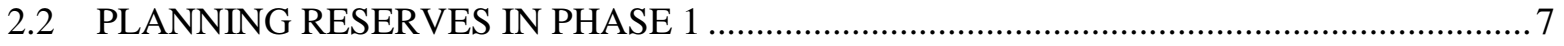

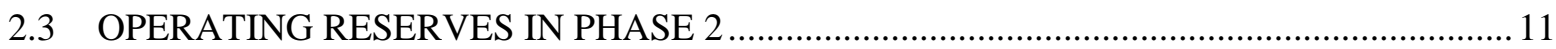

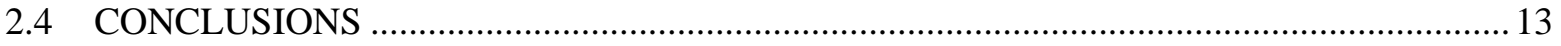

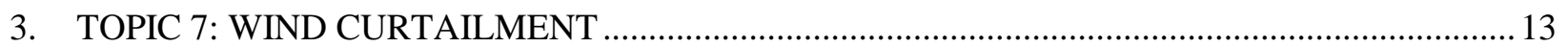

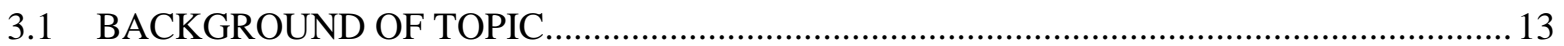

3.2 ESTIMATION OF HOURLY WIND SCHEDULE AND CURTAILMENTS ....................... 14

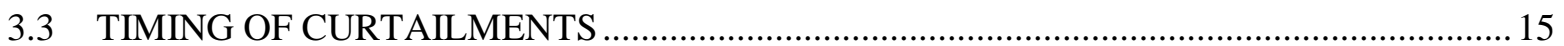

3.4 EXPLORATION OF PEAK CURTAILMENT DAY ......................................................... 16

3.5 EFFECT OF REDUCED SPIN REQUIREMENTS AND FLEXIBLE COMBINED

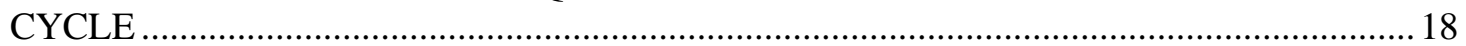

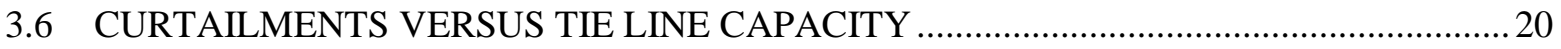

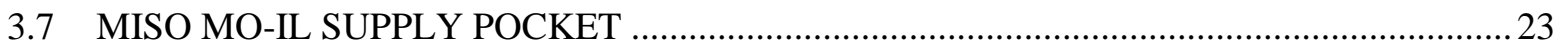

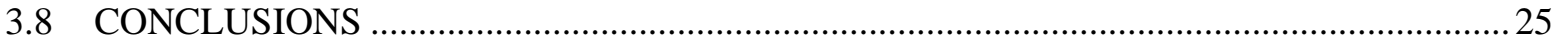

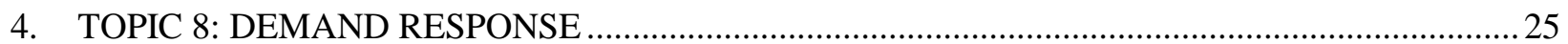

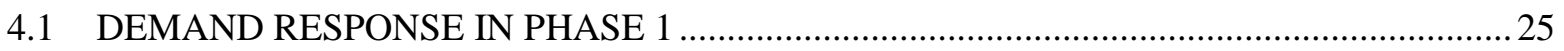

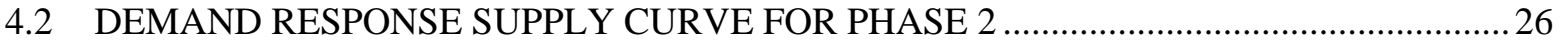

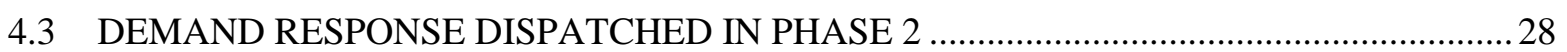

4.4 SOUTHEAST DEMAND RESPONSE USE AND PRICE IMPACTS ................................... 30

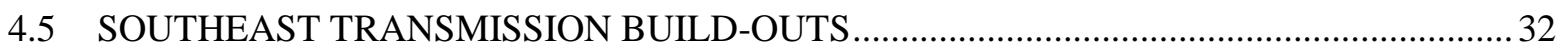

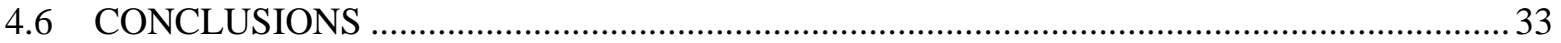

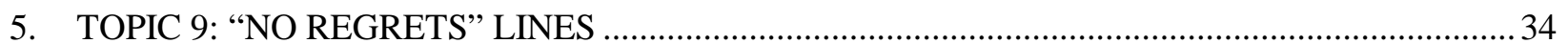

5.1 TRANSMISSION ELEMENTS COMMON TO MULTIPLE SCENARIOS .......................... 34

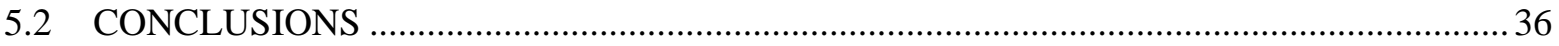

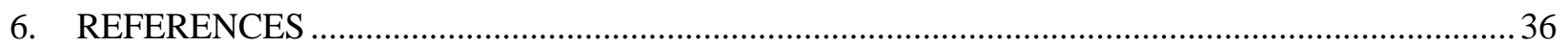

APPENDIX: LINES AND TRANSFORMERS COMMON TO ALL SCENARIOS ................................ 1 



\section{LIST OF FIGURES}

Figure $\quad$ Page

Fig. ES-1. Map of NEEM regions (EI includes the multicolored, non-gold regions).................................xi

Fig. ES-2. Phase 1 ratio of capacities to peak demand in the $\mathrm{CO}_{2}+$ scenario............................................

Fig. ES-3. Potential wind generation, curtailments, and actual wind generation in the $\mathrm{CO}+$

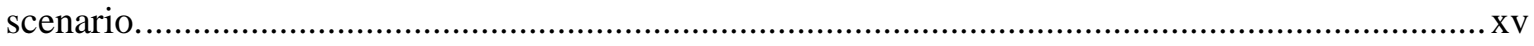

Fig. ES-4. Curtailed region April 1 morning generation levels in the $\mathrm{CO}_{2}+$ scenario and $\mathrm{Hi}$ Spin

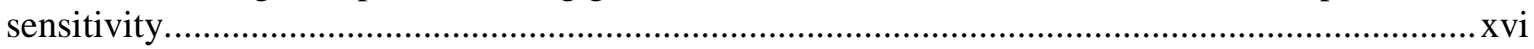

Fig. ES-5. Net transfer vs. wind curtailment in the curtailed regions in the Hi Spin sensitivity. ...............xvi

Fig. ES-6. VACAR generation, load, and marginal price on August 1 in the $\mathrm{CO}_{2}+$ scenario..................xviii

Fig. ES-7. Marginal prices at six balancing areas versus the corresponding demand response (DR) demand for all of VACAR in the business as usual (BAU) scenario...............................................iii

Fig. ES-8. Locations of buses with upgrades common to all three scenarios. ...........................................

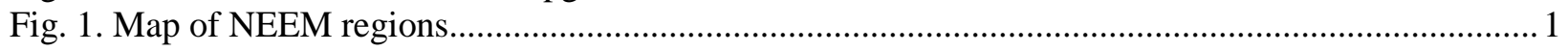

Fig. 2. Phase 1 ratio of capacities to peak demand in the $\mathrm{CO}_{2}+$ scenario............................................... 10

Fig. 3. Phase 1 ratio of capacities to peak demand in the RPS/R scenario. ............................................... 10

Fig. 4. Phase 1 ratio of capacities to peak demand in the BAU scenario.................................................. 10

Fig. 5. Potential wind generation, curtailments, and actual wind generation in the $\mathrm{CO}_{2}+$ scenario.......... 15

Fig. 6. Supply and demand for major curtailed regions on April 1 in the $\mathrm{CO}_{2}+$ scenario........................ 16

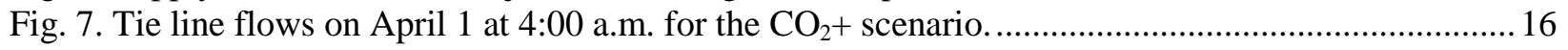

Fig. 8. Generation and loads for PJM regions on April 1 in the $\mathrm{CO}_{2}+$ scenario...................................... 17

Fig. 9. Locational marginal prices for balancing areas across the EI on April 1 at 4:00 a.m. for the

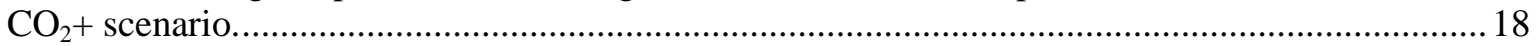

Fig. 10. Generation on April 1 in the curtailed regions in the Hi Spin sensitivity.................................... 19

Fig. 11. Generation on April 1 in PJM in the Hi Spin sensitivity........................................................... 19

Fig. 12. Tie line flows on April 1 at 4:00 a.m. in the Hi Spin sensitivity. ............................................... 20

Fig. 13. Net transfer vs. curtailment in the curtailed regions for the $\mathrm{CO}_{2}+$ scenario................................ 21

Fig. 14. Net transfer vs. curtailment in the curtailed regions for the Hi Spin sensitivity........................... 21

Fig. 15. Percent of year that curtailments in curtailed regions were at different levels..............................22

Fig. 16. Net transfer vs. wind curtailment in the curtailed regions in the Hi Spin sensitivity. ................... 23

Fig. 17. Locational marginal prices on April 1 at 10:00 a.m. in the $\mathrm{CO}_{2}+$ scenario..................................2

Fig. 18. MISO MO-IL generation and load on April 1 in the $\mathrm{CO}_{2}+$ scenario...........................................2

Fig. 19. ORNL NADR runs with variation in critical peak price. .................................................... 27

Fig. 20. Supply curve for pricing-related DR programs in 2030. Five-tier approximation and

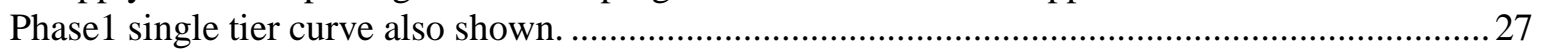

Fig. 21. Six-tier supply curve and model curve with allocated nonprice DR in 2030 for Phase 2.............28

Fig. 22. Capacities and peak demand for each region for the $\mathrm{CO}_{2}+$ scenario.........................................29

Fig. 23. VACAR generation, load and marginal prices on August 1 under the $\mathrm{CO}_{2}+$ scenario................. 30

Fig. 24. SOCO generation, load, and marginal prices on August 1 under the $\mathrm{CO}_{2}+$ scenario.................... 30

Fig. 25. Eastern Interconnection tie line loads on August 1 at 4:00 p.m. for the $\mathrm{CO}_{2}+$ scenario. .............. 31

Fig. 26. Marginal prices at six balancing areas versus the corresponding DR demand for all of

VACAR in the BAU scenario. ............................................................................................ 32

Fig. 27. Phase $1 \mathrm{CO}_{2}$ + flow duration curves for the "soft" tie line between PJM ROR and

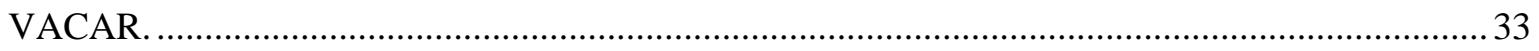

Fig. 28. Locations of buses with upgrades common to all three scenarios............................................. 35 



\section{LIST OF TABLES}

Table

Page

Table ES-1. NEEM Regions and Territories in the Eastern Interconnection............................................xii

Table ES-2. Topics to Be Studied as Part of Analysis of EIPC Cases......................................................iii

Table 1. NEEM Regions and Territories in the Eastern Interconnection................................................... 2

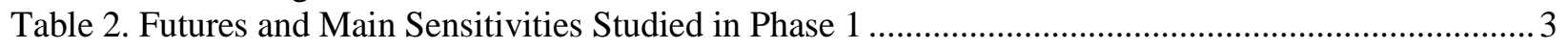

Table 3. Topics to Be Studied as Part of Analysis of EIPC Cases.............................................................. 5

Table 4. NERC Definitions of Reserves (NERC 2013) .................................................................... 7

Table 5. Reserve Margin Regions, Reserve Requirements, and NEEM Regions (CRA 2010).................... 8

Table 6. Intermittent Resource Contributions (CRA 2010) .................................................................... 9

Table 7. Phase 1 Reserve Requirement and 2030 Reserve Margins by Region ........................................ 11

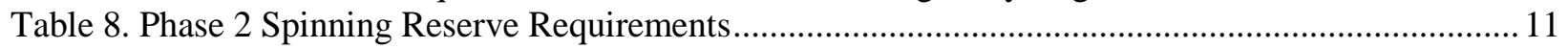

Table 9. Regional Average Spin Requirements and Contributions from Hydro ...................................... 12

Table 10. Phase 2 Wind Curtailment Amounts and Percent of Potential Generation................................ 14

Table 11. Curtailments and Net Transfers April 1 at 4:00 a.m. for curtailed regions................................ 21

Table 12. Curtailment and Transfer Quadrants for the Hi Spin Sensitivity ............................................. 23

Table 13. Demand Response Supply Curve as Proportion of Total DR Available in Regions for EIPC Study 28

Table 14. Phase 2 Demand Response Capacity (in gigawatts and percent of demand) and Generation in NEEM Regions.... 29

Table 15. Elements in Common Across All Scenarios by Region ............................................................ 34

Table 16. Overnight Capital Costs (billions of 2010 dollars) ….................................................................35

Table 17. Elements in Common with Different Methods by Region ......................................................... 36 



\section{ABBREVIATIONS AND ACRONYMS}

BA

BAU

CC

$\mathrm{CO}_{2}+$

CPP

CRA

CT

DG

DOE

DR

EE

EI

EIPC

EISPC

FERC

GE MAPS

GW

HVDC

MRN-NEEM

NADR

NEEM

NERC

ORNL

PSS/E

RPS

RPS/R

RTO

SCE\&G

SSC

SSI

SVC

TWh balancing area

business as usual

combined cycle

high $\mathrm{CO}_{2}$ cost + aggressive EE, DR, and DG + national RPS scenario

critical peak price

Charles Rivers Associates

combustion turbine

distributed generation

US Department of Energy

demand response

energy efficiency

Eastern Interconnection

Eastern Interconnection Planning Collaborative

Eastern Interconnection States’ Planning Council

Federal Energy Regulatory Commission

General Electric Multi-Area Production Simulation (software)

gigawatt $=1,000$ megawatts or $10^{6}$ kilowatts

high voltage direct current

Multi-Region National-North American Electricity and Environment Model

A National Assessment of Demand Response Potential (FERC study)

North American Electricity and Environment Model

North American Electric Reliability Corporation

Oak Ridge National Laboratory

Power System Simulator for Engineering (from Siemens)

renewable portfolio standard

RPS, implemented regionally

Regional Transmission Operator

South Carolina Electric and Gas

stakeholder steering committee

Stakeholder-Specified Infrastructure

static var controller

terawatt-hour $=1,000$ gigawatt-hours $=10^{6}$ megawatt-hours $=10^{9}$ kilowatt-hours 


\section{EASTERN INTERCONNECTION MEMBERS/REGIONS (also referred to as NEEM regions in this report)}

\section{ENT}

FRCC

IESO

MAPP CA

MAPP US

MISO IN

MISO MI

MISO MO-IL

MISO W

MISO WUMS

NE

NEISO

Non-RTO Midwest

NYISO A-F

NYISO G-I

NYISO J-K

PJM

PJM E

PJM ROM

PJM ROR

SOCO

SPP N

SPP S

TVA

VACAR
Entergy Corp. plus other utilities in central Missouri, Arkansas, Louisiana, Mississippi, east Texas

Florida Reliability Coordinating Council—Florida minus the panhandle

Independent Electricity System Operator, Ontario Canada

Mid-Continent Area Power Pool—Canada (Manitoba-Saskatchewan)

Mid-Continent Area Power Pool-US (non-MISO regions in Montana, North Dakota, South Dakota, Minnesota, Iowa)

Midcontinent Independent System Operator-Indiana

Midcontinent Independent System Operator-Michigan

Midcontinent Independent System Operator-Missouri-Illinois (eastern Missouri, much of Illinois)

Midcontinent Independent System Operator-West (parts of Montana, North Dakota, South Dakota, Minnesota, Iowa, Wisconsin)

Mid-continent Independent System Operator—Wisconsin-Upper Michigan

Nebraska

New England Independent System Operator

Non-Regional Transmission Operator Midwest (most Kentucky, some Ohio public utilities)

New York Independent System Operator-Upstate

New York Independent System Operator-lower Hudson Valley

New York Independent System Operator—New York City-Long Island

Independent System Operator for territory from Chicago to Virginia (formerly the Pennsylvania-New Jersey-Maryland power pool)

PJM Eastern Mid-Atlantic Area Council (New Jersey, Delaware, eastern Maryland)

PJM Rest of Mid-Atlantic Area Council (eastern Pennsylvania, DC, eastern Maryland)

PJM Rest of Region (northern Illinois, Ohio, western Pennsylvania, western Maryland, West Virginia, Virginia, eastern North Carolina)

Southern Company plus other utilities in Georgia, Alabama, eastern Mississippi, western Florida

Southwest Power Pool—North (Kansas, western Missouri)

Southwest Power Pool—South (Oklahoma, north Texas, eastern New Mexico, western Arizona, western Louisiana)

Tennessee Valley Authority (Tennessee, northern Mississippi, northern Alabama, southern Kentucky)

Virginia-Carolina Subregion—South Carolina, western North Carolina 


\section{EXECUTIVE SUMMARY}

Between 2010 and 2012 the Eastern Interconnection Planning Collaborative (EIPC) conducted a major long-term resource and transmission study of the Eastern Interconnection (EI). With guidance from a stakeholder steering committee (SSC) that included representatives from the Eastern Interconnection States' Planning Council (EISPC) among others, the project was conducted in two phases. The first was a 2015-2040 analysis that looked at a broad array of possible future scenarios, while the second focused on a more detailed examination of the grid in 2030. The studies provided a wealth of information on possible future generation, demand, and transmission alternatives. However, at the conclusion there were still unresolved questions and issues. The US Department of Energy, which had sponsored the study, asked Oak Ridge National Laboratory researchers and others who worked on the project to conduct an additional study of the data to provide further insights for stakeholders and the industry. This report documents the second part of that follow-on study [an earlier report (Hadley 2013) covered the first part, and a subsequent report will address the last part].

The EI covers most of the electricity grid east of the Rockies. High voltage transmission lines interconnect the regions in the EI so power can be transferred readily between them. The EI consists of the multicolored (non-gold) regions in the map in Fig. 1. The regions used in the EIPC study (both EI and non-EI) are referred to as NEEM regions throughout this report because of the model (the North American Electricity and Environment Model) used for analysis in Phase 1 of the study. These NEEM regions are based on the boundaries of organizations such as utilities, regional transmission operators, coordinating authorities, independent system operators, and other natural groupings of the grid. Table ES1 gives a more detailed description of each region in the EI.

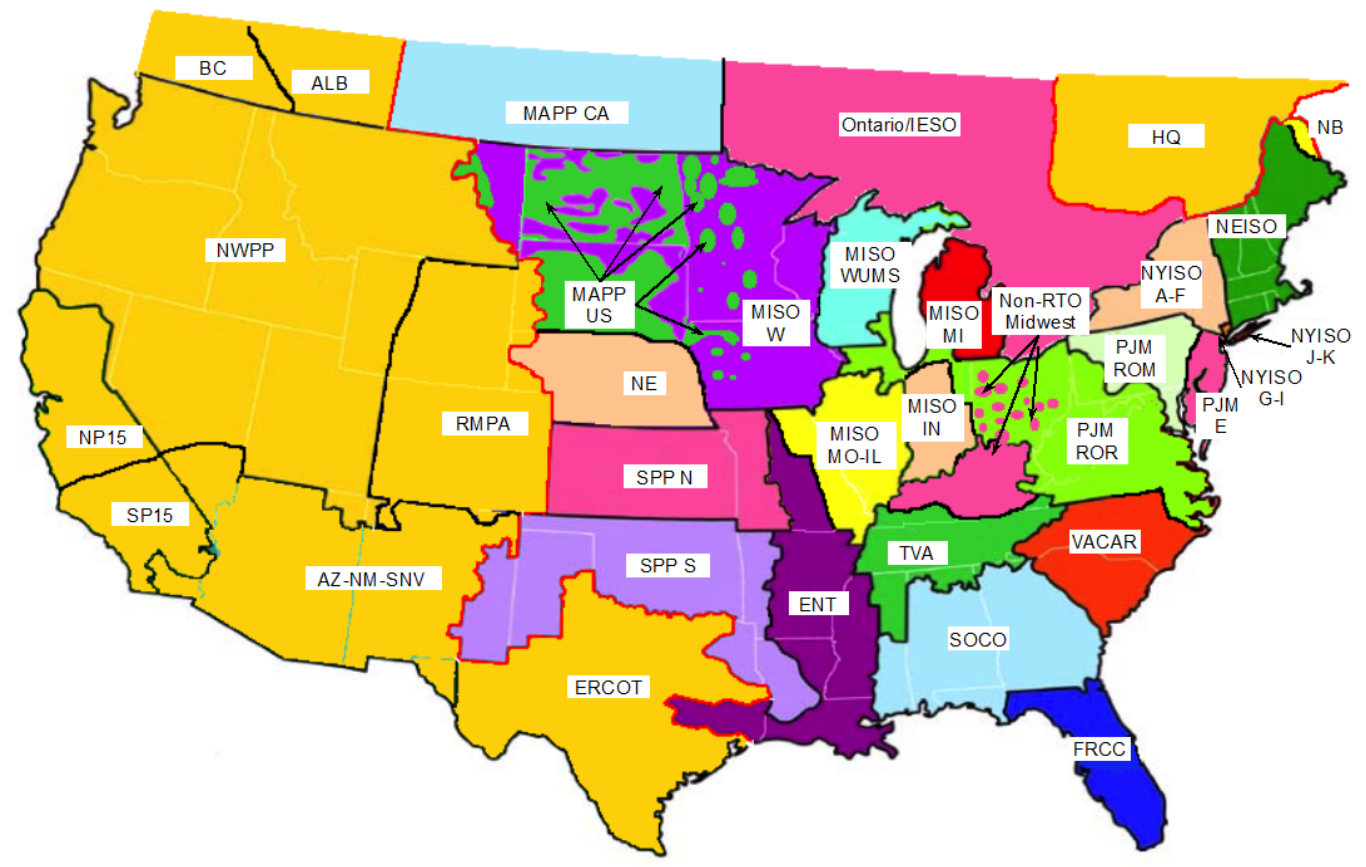

Fig. ES-1. Map of NEEM regions (EI includes the multicolored, non-gold regions).

For this report, results are presented at the level of the entire EI, the individual NEEM regions, or collections of NEEM regions into larger “territories” based on similar characteristics or transmission relationships. 
Table ES-1. NEEM Regions and Territories in the Eastern Interconnection

\begin{tabular}{|c|c|c|}
\hline Region & Description & Territory \\
\hline MAPP CA & Mid-Continent Area Power Pool (MAPP) Canada (Manitoba-Saskatchewan) & Northwest \\
\hline MAPP US & MAPP US (non-MISO regions in MT, ND, SD, MN, IA) & Northwest \\
\hline MISO W & Midcontinent Independent System Operator (MISO) in Michigan & Northwest \\
\hline MISO MO-IL & MISO Missouri-Illinois (eastern MO, much of IL) & Northwest \\
\hline MISO WUMS & MISO Wisconsin-Upper Michigan & Northwest \\
\hline MISO IN & MISO Indiana & Northwest \\
\hline MISO MI & MISO West (parts of MT, ND, SD, MN, IA, MN, WI) & Northwest \\
\hline Non-RTO Midwest & Non-Regional Transmission Operator (RTO) in Midwest (most KY, some OH) & Central \\
\hline PJM ROR & PJM Rest of Region (north IL, OH, west PA, west MD, WV, VA, east NC) & Central \\
\hline PJM ROM & PJM Rest of Mid-Atlantic Area Council (MAAC) (east PA, DC, east MD) & Central \\
\hline PJM E & PJM Eastern MAAC (NJ, DE, east MD) & Central \\
\hline IESO & Independent Electricity System Operator in Ontario & Northeast \\
\hline NYISO A-F & New York Independent System Operator in Upstate NY & Northeast \\
\hline NYISO G-I & New York Independent System Operator in lower Hudson Valley & Northeast \\
\hline NYISO J-K & New York Independent System Operator in New York City-Long Island & Northeast \\
\hline NEISO & New England Independent System Operator & Northeast \\
\hline NE & Nebraska & Southwest \\
\hline SPP N & Southwest Power Pool (SPP) North (Kansas, western Missouri) & Southwest \\
\hline SPP S & SPP South (Oklahoma, north TX, east NM, west AR, west LA) & Southwest \\
\hline ENT & Entergy Corp. + other utilities in central MO, AR, LA, MS, east TX & Southwest \\
\hline TVA & Tennessee Valley Authority (TN, north MS, north AL, south $\mathrm{KY}$ ) & Southeast \\
\hline SOCO & Southern Company + other utilities in $\mathrm{GA}, \mathrm{AL}$, east MS, west FL & Southeast \\
\hline VACAR & South Carolina, west North Carolina & Southeast \\
\hline FRCC & Florida minus panhandle & Southeast \\
\hline
\end{tabular}

The Phase 1 analysis used a capacity expansion model belonging to Charles Rivers Associates (CRA) called MRN-NEEM (Multi-Region National-North American Electricity and Environment Model). A capacity expansion model evaluates energy supply and demand over multiple decades and will build or retire capacity as needed or economic. The MRN-NEEM document on the EIPC website provides more detail on the models used (CRA 2010).

In Phase 1 of the study, the term "futures" was used to define a consistent set of input assumptions on technologies, policies, and costs. Eight futures were defined by the SSC in an attempt to cover a wide range of possible policies. A set of sensitivities was defined for each future, but first a base case using the general equilibrium economic model MRN had to be run to establish economy-wide, energy-related demands and prices. The results of these base cases could then be used to expand the transmission system between regions. Following that, other sensitivities allowed the EIPC and SSC to explore a variety of changes to technologies, costs, demands, or policies.

Three scenarios representing transmission needs under a broad array of hypothetical futures were selected for more extensive transmission-focused evaluation in Phase 2: a business as usual scenario (labeled BAU in this report); a scenario with a national renewable portfolio standard that is implemented on a regional basis (labeled RPS/R here); and a combined policies scenario with a high $\mathrm{CO}_{2}$ cost, a national renewable portfolio standard, and aggressive energy efficiency/demand response/distributed generation (labeled $\mathrm{CO}_{2}+$ here).

In Phase 2 the EI was modeled at a very detailed level (70,000 buses, 9,900 generators) using the Power System Simulator for Engineering (PSS'E) model for a peak hour and off-peak hour in each case (only the peak hour in the BAU case.) Transmission lines and other upgrades were added to ensure reliability criteria were met in those hours. The resulting build-outs of the transmission system in these scenarios 
were then used as inputs in the General Electric Multi-Area Production Simulation software (GE MAPS) model run by CRA. GE MAPS is a detailed economic dispatch and production cost model that simulates electric power system operation, taking into account transmission topology. The GE MAPS model projected energy production costs, constraints limiting dispatch and interregional transactions, anticipated emissions, renewable energy production, and other pertinent factors.

Additional information regarding the EIPC modeling can be found in Sect. 1 of this report, the EIPC Phase 1 Report (EIPC 2011), and the EIPC Phase 2 Report (EIPC 2012).

The results from Phases 1 and 2 provided a wealth of data that could be examined further to address energy-related questions. In January 2013, a small group of members of the EIPC, EISPC, and SSC were contacted to determine the need for additional analysis and topics of interest. Based on this, a list of 13 possible study topics was developed and ranked by the group in terms of relative priority (Table ES-2). The topics are ranked by priority (high, medium, low) and arranged such that the lower numbered/higher ranked items in each category contribute to the later items within the same category.

Table ES-2. Topics to Be Studied as Part of Analysis of EIPC Cases

\begin{tabular}{|rl|}
\hline \multicolumn{2}{|l|}{ High Priority Topics } \\
\hline $\mathbf{1}$ & How do Phase 2 results compare to Phase 1 \\
\hline $\mathbf{2}$ & Were there significant changes in earlier years within various regions? \\
\hline $\mathbf{3}$ & When all costs are integrated, how do results compare between scenarios? \\
\hline $\mathbf{4}$ & Do some regions face over-reliance on certain fuels or technologies? \\
\hline $\mathbf{5}$ & What are the gas sector Interrelationships in the different regions? \\
\hline & Medium Priority Topics \\
\hline $\mathbf{6}$ & How did regional operating and planning reserves definitions affect the results? \\
\hline $\mathbf{7}$ & Why was there so much wind curtailment in the RPS/R and $\mathrm{CO}_{2}+$ scenarios? \\
\hline $\mathbf{8}$ & How much did Demand Response as defined in the models affect results? \\
\hline $\mathbf{9}$ & What transmission lines were of value in all scenarios? \\
\hline & Low Priority Topics \\
\hline $\mathbf{1 0}$ & Regional vs national implementation of policies \\
\hline $\mathbf{1 1}$ & Load growth sensitivities on resource mix and cost \\
\hline $\mathbf{1 2}$ & Environmental Policy sensitivity impacts \\
\hline $\mathbf{1 3}$ & Technology sensitivity impacts \\
\hline
\end{tabular}

The first five topics were discussed in the report Additional EIPC Study Analysis: Interim Report on High Priority Topics (Hadley 2013). The second set of topics is covered in this report.

\section{Topic 6: How did regional operating and planning reserves definitions affect the results?}

Reserves represent an amount of capacity above demand available to provide adequate electricity at the correct voltage and frequency to maintain the grid under unusual or abnormal circumstances. There are two main types of reserves used in the EIPC study: planning reserves and operating reserves. Planning reserves are used for long-term resource planning, while operating reserves are used for day-to-day operations.

Phase 1 of the study used planning reserves, with values between $12-18 \%$ for the various regions. All generating capacity could be used to meet the reserve margin, including DR. However, the EIPC derated intermittent (solar and wind) technologies by applying a fractional "resource contribution credit." The installed capacity of the technology was multiplied by this fraction to represent the amount of capacity that would be available during peak hours. This credit ranged from $11 \%$ to $30 \%$ depending on the region 
and technology. Because the capacity factors for these technologies were higher than the credit, there was often a large amount of extra generation from these intermittent sources, which affected the curtailment quantities discussed under Topic 7. Even after the credit was applied, the modeling in Phase 1 built capacity in excess of the reserve margin in some regions to lower the overall cost of generation through export to others.

Fig. ES-2 presents the capacities in each region as a fraction of their peak demands in the $\mathrm{CO}_{2}+$ scenario. It shows both the technologies that qualify for the reserve calculation plus the intermittent capacity that is not credited. All regions meet their minimum reserve margins, but those with high wind capacity have significant capacity above internal reserve requirements and will have this capacity available for export to other regions when wind production is high. Another observation is that the $\mathrm{CO}_{2}+$ scenario included significant DR. Because the DR fully qualified for the reserve margin calculation, it lowered the amount of traditional generation required. Many regions required DR to meet their peak demand (the $100 \%$ line crosses DR in the chart) unless they could import from the regions with excess production. In Phase 1, only the southeast regions, notably VACAR ${ }^{*}$ and FRCC, ${ }^{*}$ called on DR for a small portion of their needs.

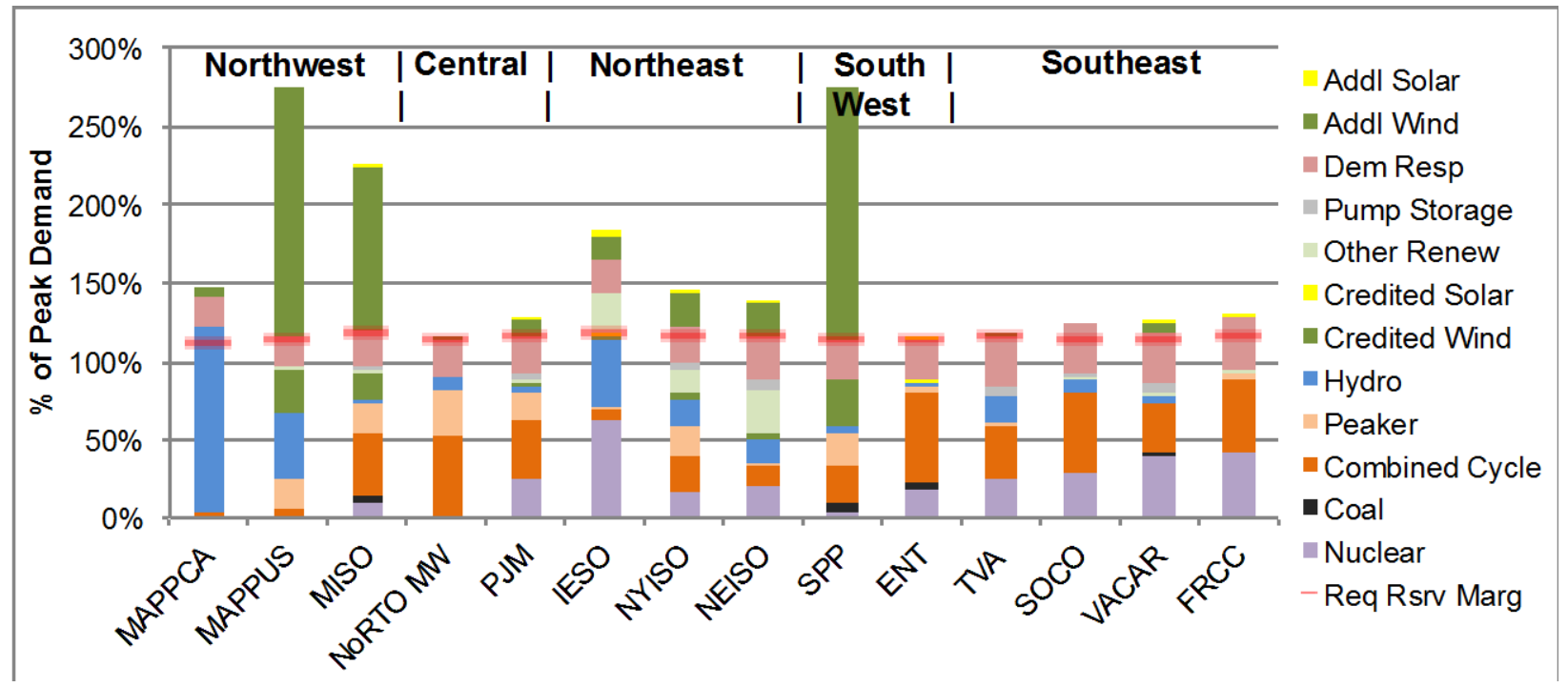

Fig. ES-2. Phase 1 ratio of capacities to peak demand in the $\mathrm{CO}_{2}+$ scenario.

The Phase 2 calculations used operating reserves in their calculations. The required reserve quantities varied greatly by region, with PJM having the largest requirements both in megawatts and as a percentage of demand. In the modeling, only thermal fossil plants [coal, gas steam, and combined cycle (CC)] and hydroelectric plants could provide reserves; these plants had to be running at least at their minimum dispatch points and could only provide limited quantities based on their ramp rates. While many regions had sufficient hydro to cover most of their reserves requirement, other regions were forced by their reserves requirements to increase output from the committed thermal units while other lower-cost units (most notably wind) were curtailed. A sensitivity was run that cut the reserves requirement in half (to represent DR supply of reserves in some of the regions) and enhanced CC flexibility (minimum power levels, minimum up/down times, and ramp rates). This led to a reduction in the amount of low cost power curtailed, and is more fully discussed under Topic 7. During peak times, some regions had to back down their more efficient CC plants to provide reserves and call on more expensive CT units and DR to provide energy, as discussed under Topic 8.

*Note: Refer to Table ES-1 or the Eastern Interconnection regions list at the front for complete definitions of region identifiers used in the text. 


\section{Topic 7: Why was there so much wind curtailment in the RPS/R and $\mathrm{CO}_{2}+$ scenarios?}

Wind power is a resource that can provide large amounts of electrical power at very low marginal cost. The variable operating cost is near zero, and when production tax credits are available the net variable cost to wind producers is actually negative. Generally, it is most economic for the sector to take all generation provided from wind. However, there are various reasons why at times the system cannot accept all the wind power available, and some wind farms have to reduce power levels. There can be multiple contributing factors to curtailment: there is simply more production than consumers demand at the time; there is insufficient transmission to carry the power to other regions where there is demand; and/or there are other factors such as local reserve requirements, transmission impedance, ramping limitations, environmental regulations, or other low cost resources are available. These factors become more of an issue as the fraction of power from wind increases.

In Phase 1 of the study there was little issue with curtailment, primarily for two reasons. First, the wind generation and loads were aggregated and averaged into just 20 periods to cover each year, rather than the 8,760 hours used in Phase 2. Extremes of high wind generation and/or very low demand, when curtailment would be most pronounced, were not evaluated. Phase 2 provided a more detailed view, resulting in large curtailments, most notably in the high wind regions of MISO and SPP, especially in the $\mathrm{CO}_{2}+$ scenario. Second, operating reserves, which could force higher cost generators to run instead of the wind generators, were not modeled in Phase 1 of the study.

The results from the GE MAPS model included the annual total curtailments by region but did not include the hourly amounts, which are necessary to evaluate the causes. We used the results from multiple scenarios with differing amounts of curtailment to create a close approximation of the hourly curtailments for the five regions with the highest levels of curtailment (MISO_MO-IL, MISO_W, NE, SPP_N, and SPP_S). These regions accounted for 122 out of $131 \mathrm{TWh}$ of curtailment in the EI for the $\mathrm{CO}_{2}+$ scenario. Our first analysis showed that curtailments were highest in the morning hours for each region (Fig. ES-3), which indicates that low demand levels played an important role in curtailments.
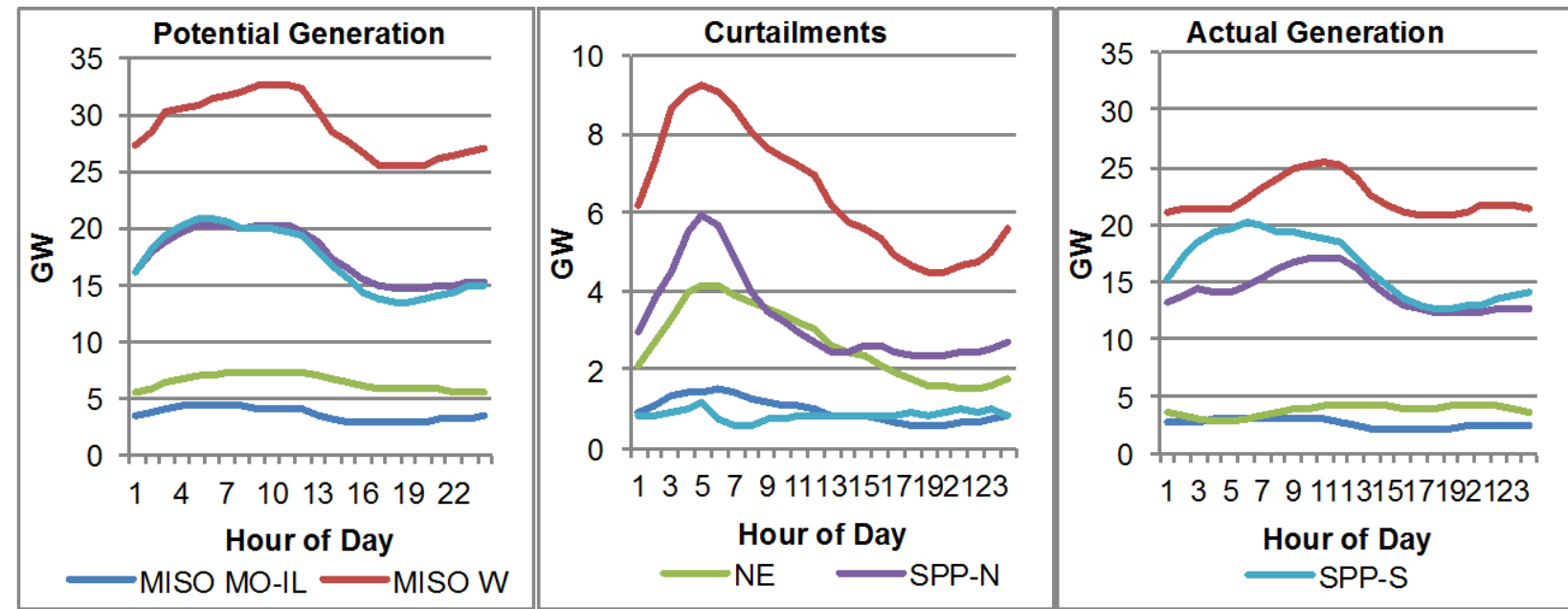

Fig. ES-3. Potential wind generation, curtailments, and actual wind generation in the CO2+ scenario. (Refer to Table ES-1 or the acronym list for region explanations.)

The peak curtailment day of April 1 was analyzed in depth (Fig. ES-4). The high curtailments at 4 a.m. occurred even though interregional tie lines were not heavily loaded, so low demand must have played a role. Another factor was that CC production occurred, especially in PJM, despite prices below cost of production. When the ramp rates were increased for CCs and minimum up/down times were reduced to 
increase the flexibility of these units in the "Hi Spin" sensitivity, CC production was greatly reduced in the early hours, resulting in more transfers from the windy regions and less curtailment.

The modifications in the Hi Spin sensitivity reduced curtailments significantly in some hours, but there were still many hours with large curtailments. Plotting the level of curtailments versus the net exports from the curtailed regions shows that most of the curtailments, especially the high levels of curtailment, occurred when transfers from the region were near their peak amounts (Fig. ES-5). The red lines in Fig. ES-5 indicate the median values for net transfers and curtailments. Each point represents a different hour in the year. Most points reside in quadrants I and III, where both transfers and curtailments are either high or low together.

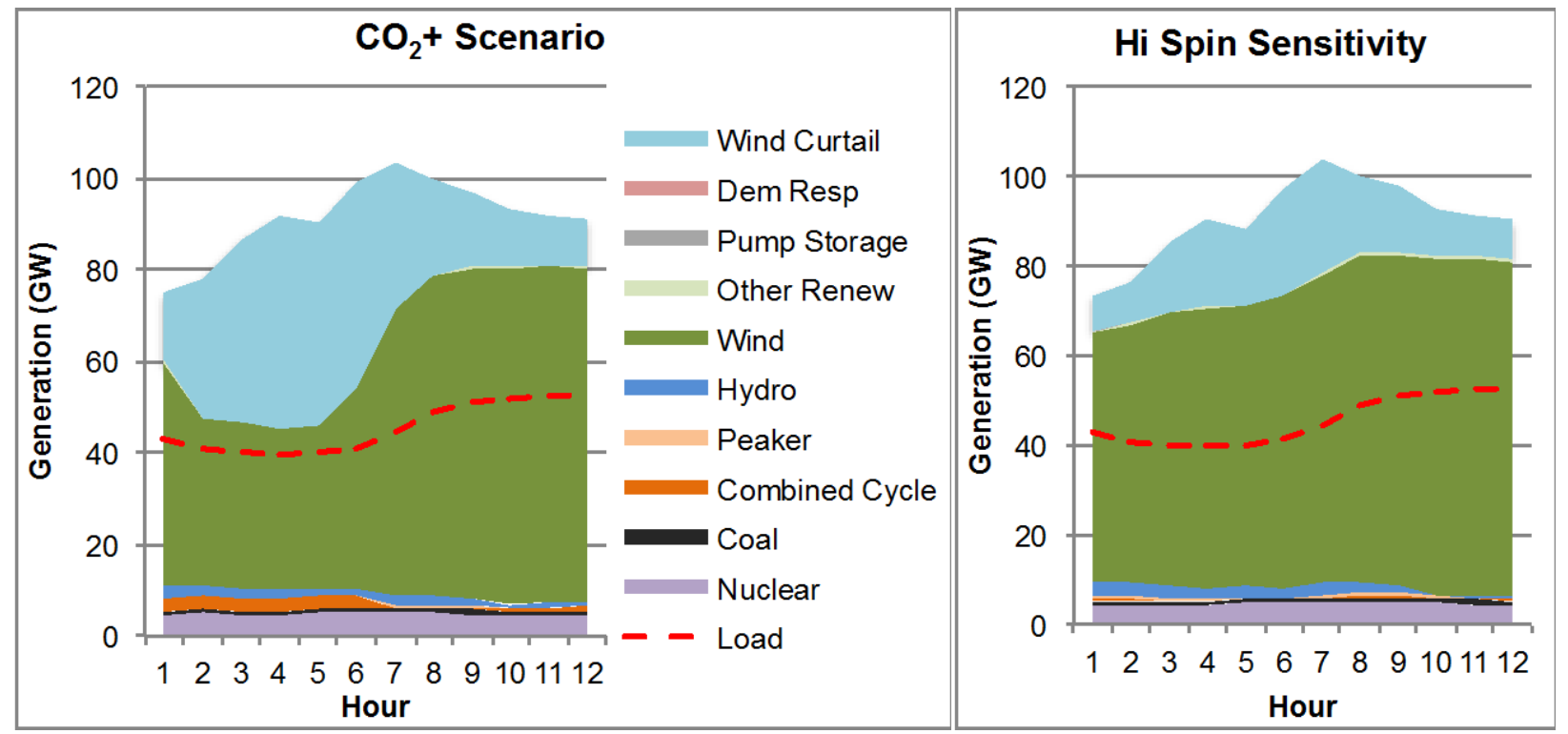

Fig. ES-4. Curtailed region April 1 morning generation levels in the $\mathrm{CO}_{2}+$ scenario and $\mathrm{Hi}$ Spin sensitivity.

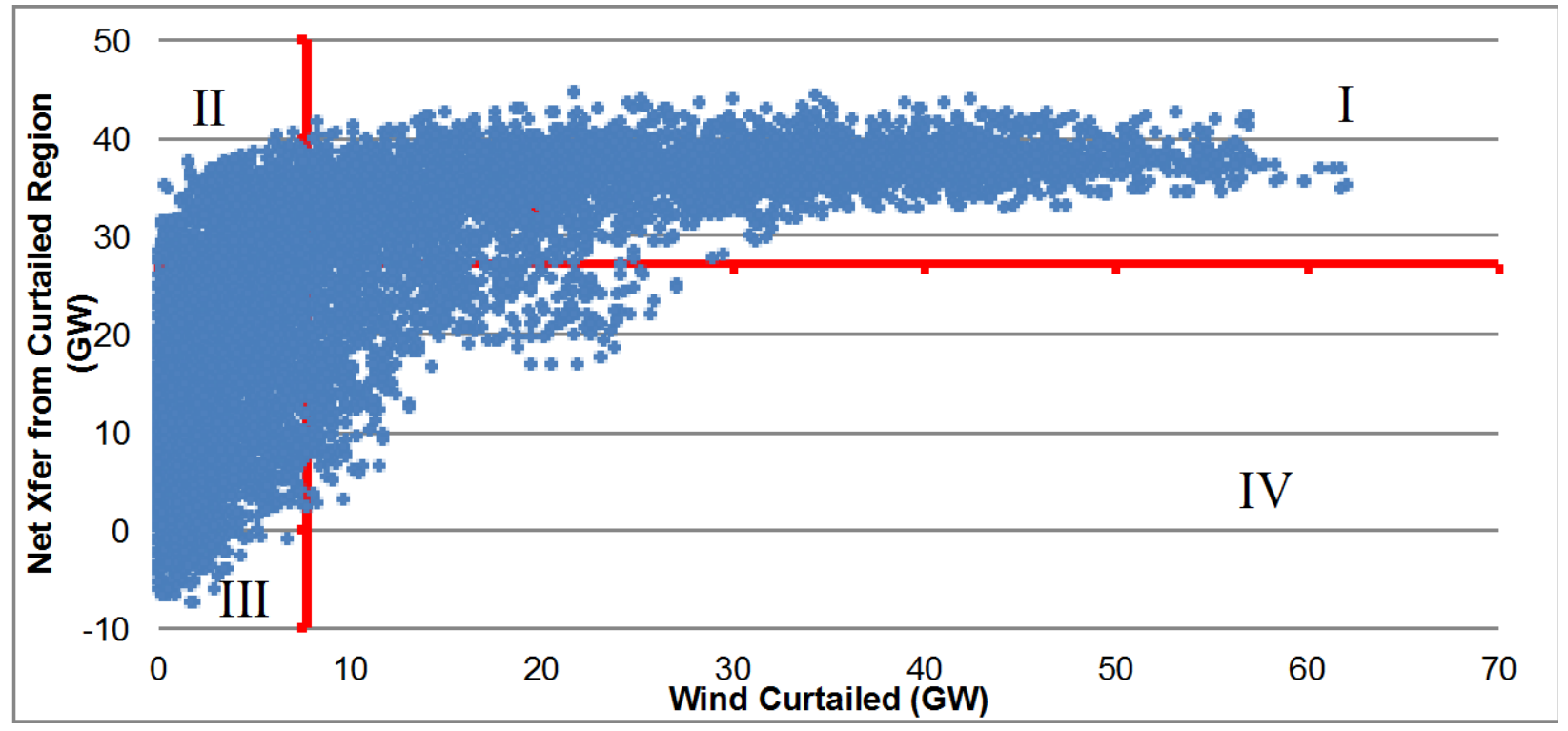

Fig. ES-5. Net transfer vs. wind curtailment in the curtailed regions in the Hi Spin sensitivity. 
A final point is that the vast majority of curtailed energy occurs in quadrant I when both curtailments and transfers are above the median. More than 96 TWh of curtailment from these five regions occurred in quadrant I in the Hi Spin sensitivity. In the $\mathrm{CO}_{2}+$ scenario, quadrant I contained more than $101 \mathrm{TWh}$. The Hi Spin sensitivity only reduced curtailment by 9 TWh overall, so clearly, the dominant reason for the curtailments was the transfer limitations. However, it would require more than $60 \mathrm{GW}$ of additional transfer capacity (more than 17 high voltage direct current lines) to ease the peak amount of curtailment shown in Fig. ES-5. There did appear to be some generation pockets such as in MISO_MO-IL, MAPP_US, and VACAR where wind was curtailed because nearby transmission elements were not sufficiently built out.

\section{Topic 8: How much did Demand Response as defined in the models affect results?}

DR is a complex collection of programs and technologies that allows demand to respond to supply, mainly through reduction of demand in the face of supply shortages. In June 2009, the Federal Energy Regulatory Commission (FERC) released a study on DR, A National Assessment of Demand Response Potential (FERC 2009), referred to in this report as the NADR. The amount of DR for each region was calculated using the state-by-state projections of DR from the FERC NADR model. The model projects both future DR and future peak demand through 2019 for four different scenarios: BAU, expanded BAU, achievable amounts, and full participation. The state-weighted average ratio of DR amounts to peak demand were found for each region in the study.

The SSC assumed a DR growth rate based on a combination of these scenarios. In the models used, this amount of DR capacity was forced in as pseudo power plants at relatively high variable costs (price) to generate. In Phase 1 only a single cost could be used so it was set at $\$ 750 / \mathrm{MWh}$, roughly the maximum amount from the FERC study. DR energy was dispatched in just the VACAR and FRCC regions, but DR capacity reduced the quantity of ordinary capacity needed to meet reserve requirements in all regions.

In Phase 2, the SSC created a DR supply curve for each region based on the amounts used in Phase 1 and the FERC model. DR was used more frequently because variations in demands and supplies were greater than in Phase 1, along with reserve requirements limiting CC production, similar rationales to the wind curtailments described above. Load pockets in MISO_MO-IL and MAPP_US led to frequent, but low levels of, DR dispatch in the $\mathrm{CO}_{2}+$ scenario.

DR use was more extensive in the Southeast: SOCO, VACAR, and FRCC. Lack of surplus renewables meant little cushion during peak times, as for example in the August 1 scenario depicted in Fig. ES-6. Operating reserve requirements also contributed as CC capacity had to be reduced during periods of peak demand to provide needed spinning reserves. If DR was allowed to provide reserves, the CC may have provided more power and reduced the need to call on DR energy. The figure also shows the price impact as DR gets dispatched. If DR had been allowed to qualify for reserves, then less would have been dispatched and prices would have been lower.

The DR capacity was scattered across a region in line with the demands. Transmission congestion issues both within a region and between regions could cause DR to be called upon in some parts of a region but not in others. This can be seen in the different marginal prices reported by the balancing areas. Within VACAR, the areas within the southern part of South Carolina (Santee Cooper, Central Electric Coop, and SC Electric \& Gas) called upon DR more often at higher levels, resulting in higher marginal prices than other areas in the region (in Fig. ES-7).

One question was why the Southeast did not build out more transmission capacity if it was going to be faced with more capacity issues than other regions. This can be partly explained because in the Phase 1 modeling the potential added transmission was only used during peak times, less than $20 \%$ of the year, and so did not meet the SSC usage criteria for these lines to be built. There could be several reasons why 
they were only used during peak times, including hurdle rates between regions or the "peakiness" in the Southeast, with higher summer demands.

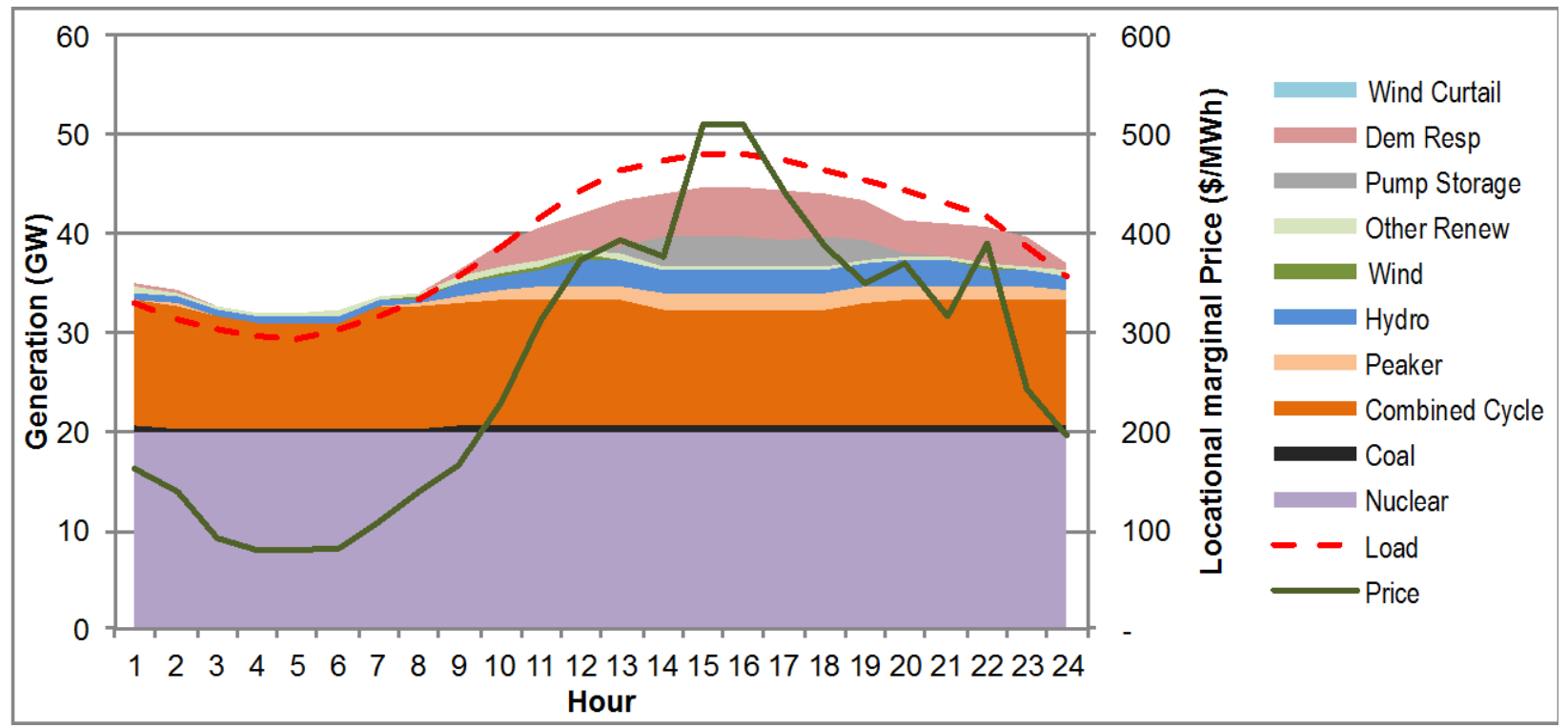

Fig. ES-6. VACAR generation, load, and marginal price on August 1 in the $\mathrm{CO}_{2}+$ scenario.

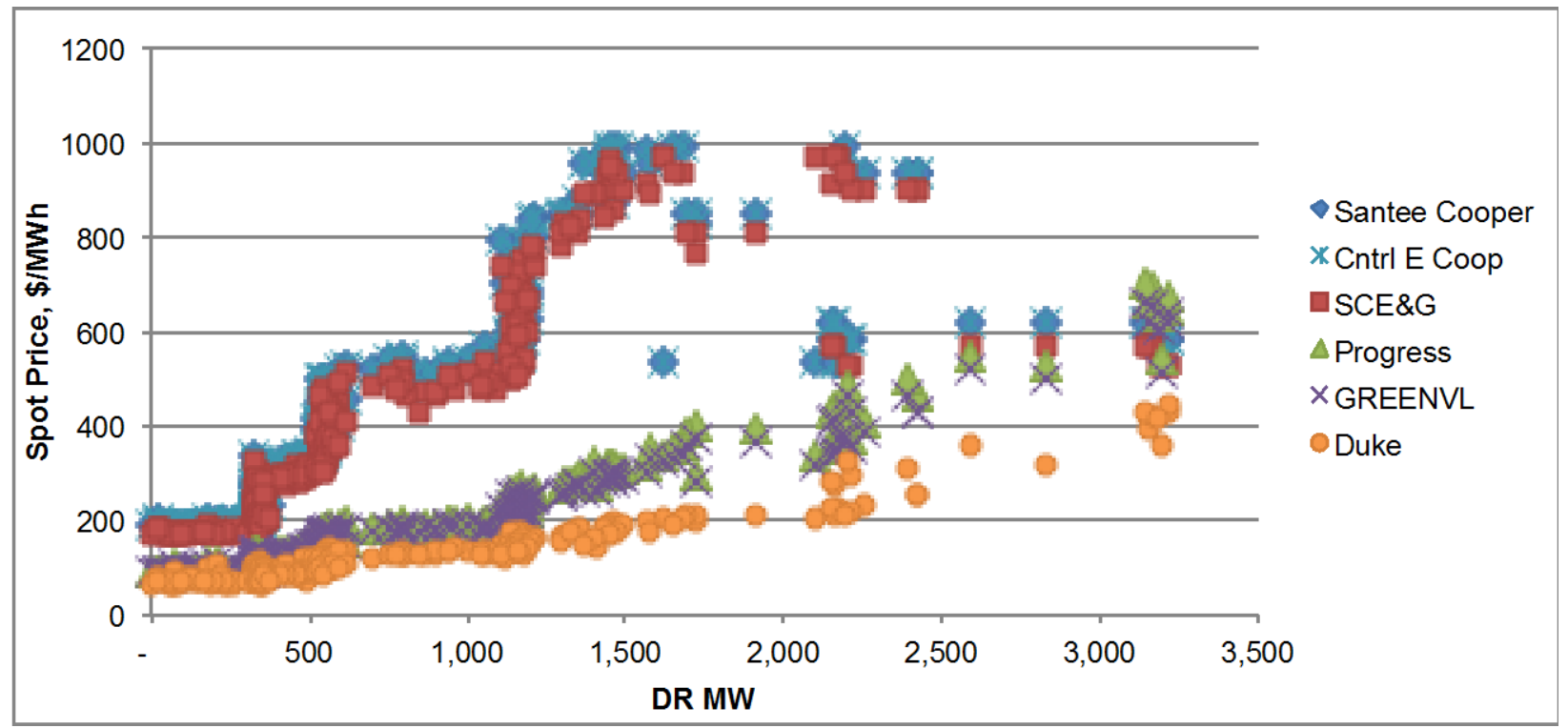

Fig. ES-7. Marginal prices at six balancing areas versus the corresponding demand response (DR) demand for all of VACAR in the business as usual (BAU) scenario.

DR can be a vital contributor to balancing supply and demand, but modeling efforts for this study were rough approximations. The resource had to be modeled as a pseudo generator with a price set high to model its limited availability. In Phase 1, only a single price for all DR could be applied, and so it was set at roughly what the available models represented for the total potential supply. In Phase 2, a more complex supply curve with six price steps provided a more nuanced approach. Because DR was used in meeting the minimum planning reserve margin, some regions relied on it to meet their peak demand. In the $\mathrm{CO}_{2}+$ scenario DR capacity was highest and those regions without access to surplus wind (most 
notably VACAR) used higher levels of DR at consequent high prices. Some of this was due to the differences in the geographic, transmission, and time step detail in Phase 1 and Phase 2 modeling. At times, DR was called on because of transmission constraints that limited the availability to import power from other regions or elsewhere within a region.

\section{Topic 9: What transmission lines were of value in all scenarios?}

Before any scenarios were run, a base transmission grid was defined, including both existing elements and new elements proposed by the EIPC and approved by the SSC. Each scenario then had elements (transmission lines, transformers, autotransformers, reactive support devices, or other upgrades) added as needed to interconnect new generation, prevent overloads, or prevent low voltage situations. Of these added elements, 89 were common to all three scenarios (Fig. ES-8). Many of these additions were in the NEISO region to support new wind farms that were added in the SSC process. In addition to these, there were 26 elements that were modified in all three scenarios, but in different ways (e.g., added circuit, reconductoring, or higher rating on new equipment).

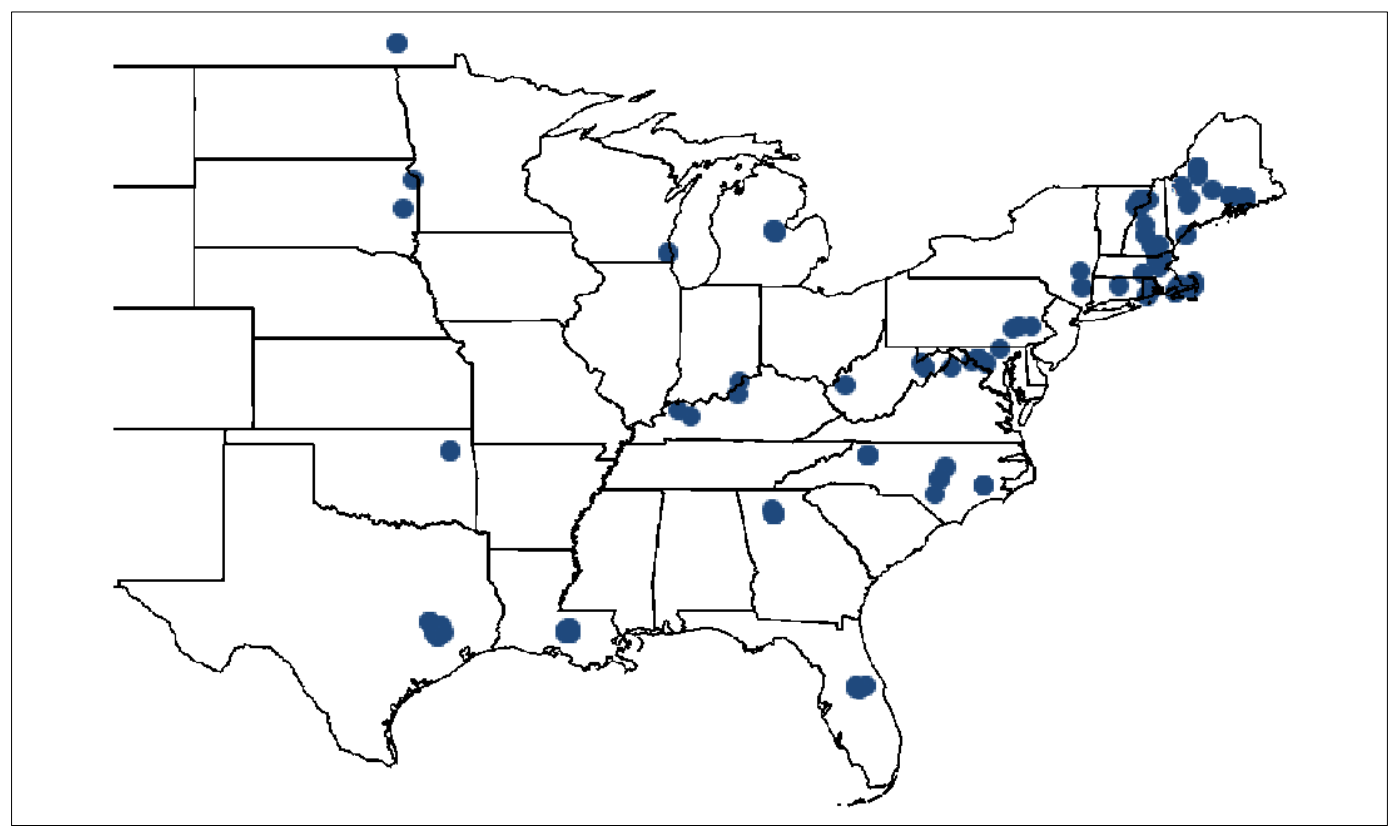

Fig. ES-8. Locations of buses with upgrades common to all three scenarios. 



\section{INTRODUCTION}

Between 2010 and 2012 the Eastern Interconnection Planning Collaborative (EIPC) conducted a major long-term resource and transmission study of the Eastern Interconnection (EI). With guidance from a stakeholder steering committee (SSC) that included representatives from the Eastern Interconnection States' Planning Council (EISPC) among others, the project was conducted in two phases. The first was a 2015-2040 analysis that looked at a broad array of possible future scenarios, while the second focused on a more detailed examination of the grid in 2030. The studies provided a wealth of information on possible future generation, demand, and transmission alternatives; however, at the conclusion there were still unresolved questions and issues. The US Department of Energy (DOE), which had sponsored the study, asked Oak Ridge National Laboratory (ORNL) researchers and others who had worked on the project to conduct an additional study of the data to provide further insights for stakeholders and the industry. This report documents the second part of that follow-on study [an earlier report (Hadley 2013) covered the first part, and a subsequent report will address the last part].

The EI covers most of the electricity grid east of the Rockies. High voltage transmission lines interconnect the regions in the EI so power can be transferred readily between them. The EI consists of the multicolored (non-gold) regions in the map in Fig. 1. The regions used in the EIPC study (both EI and non-EI) are referred to as NEEM regions throughout this report because of the model (the North American Electricity and Environment Model) used for analysis in Phase 1 of the study. These NEEM regions are based on the boundaries of organizations such as utilities, regional transmission operators, coordinating authorities, independent system operators, and other natural groupings based on the structure of the grid. Table 1 gives a more detailed description of each region in the EI.

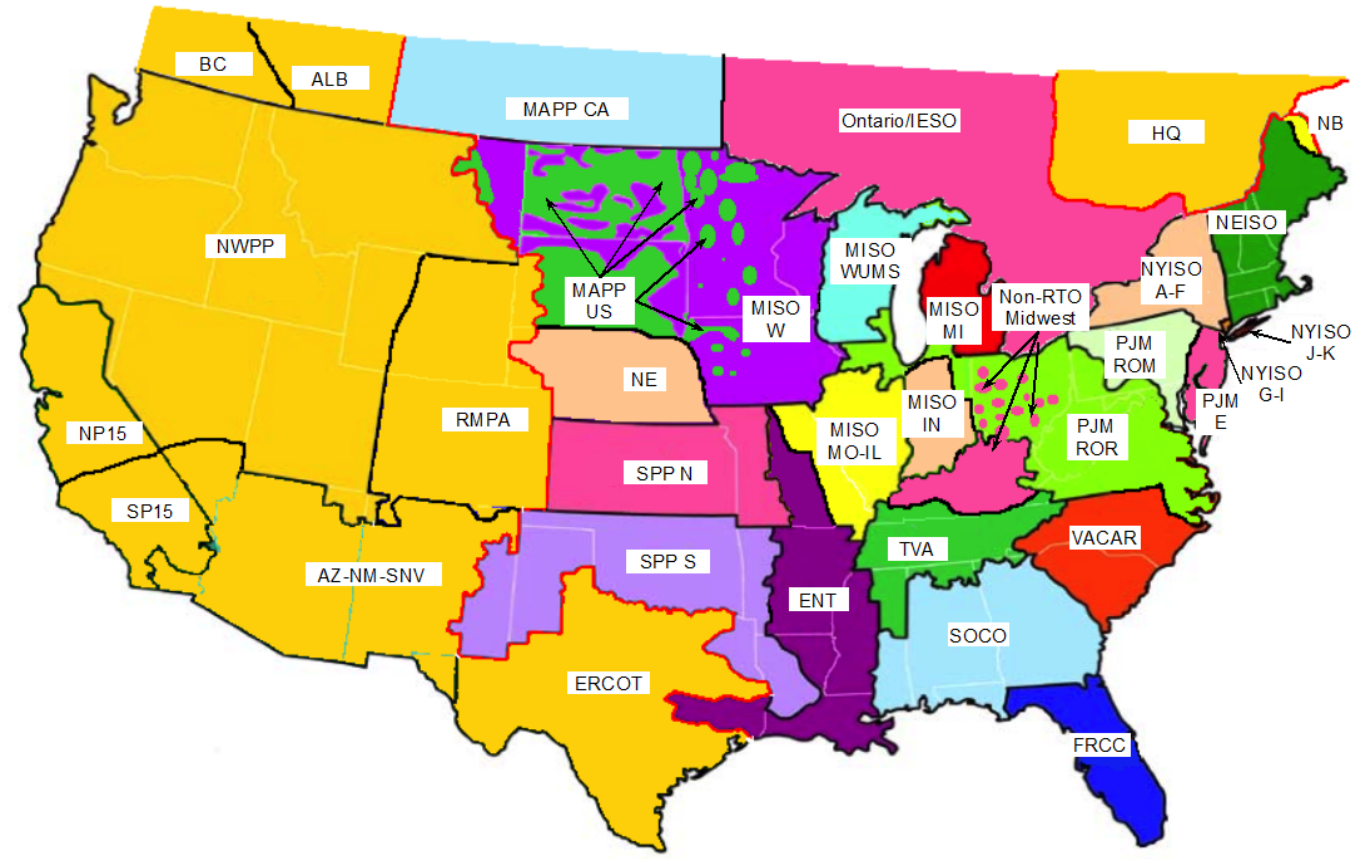

Fig. 1. Map of NEEM regions (EI includes the multicolored, non-gold regions).

For this report, results are presented at the level of the entire EI, the individual NEEM regions, or collections of NEEM regions into larger "territories" based on transmission relationships. 
Table 1. NEEM Regions and Territories in the Eastern Interconnection

\begin{tabular}{|c|c|c|}
\hline Region & Description & Territory \\
\hline MAPP CA & Mid-Continent Area Power Pool (MAPP) Canada (Manitoba-Saskatchewan) & Northwest \\
\hline MAPP US & MAPP US (non-MISO regions in MT, ND, SD, MN, IA) & Northwest \\
\hline MISO W & Midcontinent Independent System Operator (MISO) in Michigan & Northwest \\
\hline MISO MO-IL & MISO Missouri-Illinois (eastern MO, much of IL) & Northwest \\
\hline MISO WUMS & MISO Wisconsin-Upper Michigan & Northwest \\
\hline MISO IN & MISO Indiana & Northwest \\
\hline MISO MI & MISO West (parts of MT, ND, SD, MN, IA, MN, WI) & Northwest \\
\hline Non-RTO Midwest & Non-Regional Transmission Operator (RTO) in Midwest (most KY, some OH) & Central \\
\hline PJM ROR & PJM Rest of Region (north IL, OH, west PA, west MD, WV, VA, east NC) & Central \\
\hline PJM ROM & PJM Rest of Mid-Atlantic Area Council (MAAC) (east PA, DC, east MD) & Central \\
\hline PJM E & PJM Eastern MAAC (NJ, DE, east MD) & Central \\
\hline IESO & Independent Electricity System Operator in Ontario & Northeast \\
\hline NYISO A-F & New York Independent System Operator in Upstate NY & Northeast \\
\hline NYISO G-I & New York Independent System Operator in lower Hudson Valley & Northeast \\
\hline NYISO J-K & New York Independent System Operator in New York City-Long Island & Northeast \\
\hline NEISO & New England Independent System Operator & Northeast \\
\hline NE & Nebraska & Southwest \\
\hline SPP N & Southwest Power Pool (SPP) North (Kansas, western Missouri) & Southwest \\
\hline SPP S & SPP South (Oklahoma, north TX, east NM, west AR, west LA) & Southwest \\
\hline ENT & Entergy Corp. + other utilities in central MO, AR, LA, MS, east TX & Southwest \\
\hline TVA & Tennessee Valley Authority (TN, north MS, north AL, south KY) & Southeast \\
\hline SOCO & Southern Company + other utilities in GA, AL, east MS, west FL & Southeast \\
\hline VACAR & South Carolina, west North Carolina & Southeast \\
\hline FRCC & Florida minus panhandle & Southeast \\
\hline
\end{tabular}

The Phase 1 analysis used a capacity expansion model belonging to Charles Rivers Associates (CRA) called MRN-NEEM (Multi-Region National-North American Electricity and Environment Model). A capacity expansion model evaluates energy supply and demand over multiple decades and will build or retire capacity as needed or economic. The MRN-NEEM document on the EIPC website provides more detail on the models used (CRA 2010). The following are some of the key characteristics of the Phase 1 modeling.

- Each region was treated as a single point or "bubble," with no transmission modeled internally.

- Each region was connected to other regions by single "pipes” for transferring electricity rather than physical transmission lines operating at different voltages.

- Transfer capacities between regions were initially calculated by the EIPC; however, a method was created to use model results to determine how much to expand the capacity in the different scenarios.

- The model calculated the supply, demand, and consequent generation capacity needed for each 5-year point between 2010 and 2050; however, only results for 2015-2040 were reported.

- The model attempted to minimize costs over the period, taking into account various reliability and policy constraints such as minimum reserve margins and environmental regulations.

- The hours of each year were aggregated into 20 "blocks" of different durations: 10 blocks covered the summer hours, while five blocks each covered the winter and "shoulder" seasons.

CRA and the EIPC members formulated some of the initial inputs for the model, with final values determined by the SSC. This group pulled in information from utilities, DOE sources, and others to establish such factors as growth rates, cost projections, technology changes, etc. The inputs used and outputs from the model are available on the EIPC website (http://www.eipconline.com/). In addition, the EIPC prepared preliminary estimates of the cost of transmission expansion under each of the scenarios. Results of the Phase 1 analysis are in the EIPC Phase 1 Report (EIPC 2011). 
In Phase 1 of the study, the term "futures" was used to define a consistent set of input assumptions on technologies, policies, and costs. Eight futures were defined by the SSC in an attempt to cover a wide range of possible policies. A set of sensitivities was defined for each future, but first a base case using the general equilibrium economic model MRN had to be run to establish economy-wide energy-related demands and prices for each of the futures. The results of these base cases could then be used to expand the transmission system between regions. Following that, other sensitivities allowed the EIPC and SSC to explore a variety of changes to technologies, costs, demands, or policies. Table 2 summarizes the different futures and sensitivities analyzed.

Table 2. Futures and Main Sensitivities Studied in Phase 1

\begin{tabular}{|c|c|c|c|c|c|c|c|c|}
\hline Sensitivities & $\begin{array}{l}\text { Future } \\
\text { 1: BAU }\end{array}$ & $\begin{array}{l}\text { Future 2: } \\
\mathrm{CO}_{2} \text { Cost } \\
\text { /National } \\
\text { Implement }\end{array}$ & $\begin{array}{l}\text { Future 3: } \\
\mathrm{CO}_{2} \text { Cost } \\
\text { /Regional } \\
\text { Implement }\end{array}$ & $\begin{array}{l}\text { Future 4: } \\
\text { Aggressive } \\
\text { EE/DR/DG }\end{array}$ & $\begin{array}{c}\text { Future 5: } \\
\text { National } \\
\text { RPS/National } \\
\text { Implement }\end{array}$ & $\begin{array}{c}\text { Future 6: } \\
\text { National } \\
\text { RPS/Regional } \\
\text { Implement }\end{array}$ & $\begin{array}{l}\text { Future 7: } \\
\text { Nuclear } \\
\text { Resurgence }\end{array}$ & $\begin{array}{c}\text { Future 8: } \\
\mathrm{CO}_{2} \text { Cost + } \\
\text { RPS + } \\
\text { EE/DR/DG }\end{array}$ \\
\hline $\begin{array}{l}\text { Expand } \\
\text { transmission }\end{array}$ & $\sqrt{ }$ & $\sqrt{ }$ & $\sqrt{ }$ & & $\sqrt{ }$ & $\sqrt{ }$ & $\sqrt{ }$ & $\sqrt{ }$ \\
\hline Load growth & $\sqrt{ }$ & $\sqrt{ }$ & $\sqrt{ }$ & & $\sqrt{ }$ & $\sqrt{ }$ & $\sqrt{ }$ & \\
\hline $\begin{array}{l}\text { +/-Gas or } \\
\text { Renewable \$ }\end{array}$ & $\sqrt{ }$ & $\sqrt{ }$ & $\sqrt{ }$ & & $\sqrt{ }$ & $\sqrt{ }$ & & $\sqrt{ }$ \\
\hline $\begin{array}{l}\text { Delay } \\
\text { Regulations }\end{array}$ & $\sqrt{ }$ & & & & & & & \\
\hline $\begin{array}{l}\text { CO2 Cost } \\
\text { Adjust }\end{array}$ & & $\sqrt{ }$ & $\sqrt{ }$ & & & & $\sqrt{ }$ & $\sqrt{ }$ \\
\hline $\begin{array}{l}\text { PHEV } \\
\text { variations }\end{array}$ & & & & $\sqrt{ }$ & & & & \\
\hline $\begin{array}{l}\text { Extra EE } \\
\text { savings }\end{array}$ & & & & $\sqrt{ }$ & & & & \\
\hline $\begin{array}{l}\text { Clean Energy } \\
\text { Standard }\end{array}$ & & & & & $\sqrt{ }$ & $\sqrt{ }$ & & \\
\hline $\begin{array}{l}\text { Small Modular } \\
\text { Reactors }\end{array}$ & & & & & & & $\sqrt{ }$ & \\
\hline $\begin{array}{l}\text { Higher RPS } \\
\text { limits }\end{array}$ & & & & & & & & $\sqrt{ }$ \\
\hline
\end{tabular}

Future 1 was the business as usual (BAU) scenario. It had 17 sensitivities run that were used to establish the transmission build-out and explore the effects of gas prices, renewable costs, delayed environmental policies, and other factors. The final scenario, Future 1, Scenario 17 or F1S17, was used as the basis for the BAU scenario in Phase 2. Futures 2 and 3 examined the impact of raising the cost of $\mathrm{CO}_{2}$ to lower the level of $\mathrm{CO}_{2}$ emissions to $20 \%$ of 2005 levels by 2050. The distinction between them was the amount of interregional cooperation and transfer capacity within the EI. Future 4 examined the effect of more aggressive energy efficiency (EE), demand response (DR), and distributed generation (DG). Because it reduced demand, there was no need to expand the transmission grid.

Futures 5 and 6 examined a national renewable portfolio standard (RPS) with different levels of interregional cooperation. The second, Future 6, had only regional implementation, meaning each territory (roughly) was responsible for meeting their RPS requirements, and transmission capacity was not expanded between territories to assist. There were 10 sensitivities in this future and the final one, F6S10, was used for Phase 2. Future 7 examined the potential for a nuclear resurgence based on lower costs for nuclear and other factors; a base and four sensitivities were examined. Future 8 was the final future of Phase 1 and combined both the $\mathrm{CO}_{2}$ costs from Future 2 with the aggressive EE-DR-DG expansion from Future 4 and the RPS from Future 5. There were seven sensitivities run, so it is referred to in this report as the F8S7 scenario.

Three scenarios, representing transmission needs under a broad array of hypothetical futures were selected for more extensive transmission-focused evaluation in Phase 2. The EI was modeled at a very 
detailed level (70,000 buses, 9,900 generators) using the Power System Simulator for Engineering (PSS/E) model for a peak hour and off-peak hour in each case (only the peak hour in the BAU case). Transmission lines and other upgrades were added to ensure reliability criteria were met in those hours. The resulting build-outs of the transmission system in these scenarios were then used to model the EI in the General Electric Multi-Area Production Simulation software (GE MAPS) model run by CRA. GE MAPS is a detailed economic dispatch and production cost model that simulates electric power system operation, taking into account transmission topology, to predict energy production costs, constraints limiting dispatch and interregional transactions, anticipated emissions, renewable energy production, and other pertinent factors. Results from the GE MAPS cases (hourly and annual results for the year 2030) were released to stakeholders. In addition, separate cost calculations were done by the EIPC and others for transmission and generation capital costs and other costs not calculated in GE MAPS. Following are some of the key characteristics of the Phase 2 modeling phase.

- The transmission build-out with PSS/E used an hour from Block 1 (peak summer) and an hour from Block 13 (mid-shoulder), using the average expected wind generation for each block.

- Transmission lines and substations were added during the build-out primarily to meet reliability concerns; cost optimization was not a factor except indirectly through engineering judgment on line placement.

- GE MAPS modeled the system chronologically for the 8,760 hours of 2030, incorporating CRA estimates of wind patterns for the different regions.

- Operating reserves rather than planning reserves were modeled; technologies to meet reserve requirements were more restrictive than in Phase 1, limiting them to coal, combined cycle (CC), and hydro units.

In Phase 2, the nomenclature for cases changed. The EIPC focused first on building out the transmission for the combined $\mathrm{CO}_{2}+$ RPS + EE-DR-DG scenario. Consequently, it was called Scenario 1. Four sensitivities were run on the scenario to examine questions surrounding the amount of wind curtailment that occurred in the base case. The RPS with regional implementation scenario was chosen as the second future to examine in Phase 2 and so was called Scenario 2, with no sensitivities run for it. The BAU scenario was the last to be examined and so was called Scenario 3. Two sensitivities were run for it: higher gas prices and higher demands.

The mixture of futures, sensitivities, and scenarios, with different nomenclature, has caused some confusion during the process. While many cases and scenarios were analyzed, the final results discussed in this report were derived based on three main scenarios. Brief descriptions of the three follow, including the names of the cases from the two different phases and the labels used in this report.

\section{- Business as Usual}

- Labeled BAU

- Future 1, Sensitivity 17 (F1S17) in Phase 1

- Scenario 3 (S3) in Phase 2

- A continuation of current trends, policies, laws, and regulations

- National Renewable Portfolio Standard Implemented Regionally

- Labeled RPS/R

- Future 6, Sensitivity 10 (F6S10) in Phase 1

- Scenario 2 (S2) in Phase 2

- A national RPS of 30\% by 2030, with regional implementation

- Combined $\mathrm{CO}_{2}+\mathrm{RPS}+$ EE-DR-DG

- Labeled $\mathrm{CO}_{2}+$

- Future 8, Sensitivity 7 (F8S7) in Phase 1

- Scenario 1 (S1) in Phase 2 
— Also called “Combined Policies" in some reporting

- A combination of a high $\mathrm{CO}_{2}$ cost $\sim \$ 150 /$ metric Ton $\mathrm{CO}_{2}$; national RPS of $30 \%$; and aggressive energy efficiency, demand response, and distributed generation expansion

The results from Phase 1 and 2 provided a wealth of data that could be examined further to address energy-related questions. In January 2013, a small group of members of the EIPC, EISPC, and SSC were contacted about possible additional analyses and what topics would be of most interest. Based on feedback from this group, a list of 13 potential study topics was developed, which the group categorized as high, medium, or low priority and then ranked within these categories (Table 3). Order in the ranking was determined in such a way that earlier, lower numbered, items contribute to later items within the same category.

Table 3. Topics to Be Studied as Part of Analysis of EIPC Cases

\begin{tabular}{|ll|}
\hline & High Priority Topics \\
\hline $\mathbf{1}$ & How do Phase 2 results compare to Phase 1 \\
\hline $\mathbf{2}$ & Were there significant changes in earlier years within various regions? \\
\hline $\mathbf{3}$ & When all costs are integrated, how do results compare between scenarios? \\
\hline $\mathbf{4}$ & Do some regions face over-reliance on certain fuels or technologies? \\
\hline $\mathbf{5}$ & What are the gas sector Interrelationships in the different regions? \\
\hline & Medium Priority Topics \\
\hline $\mathbf{6}$ & How did regional operating and planning reserves definitions affect the results? \\
\hline $\mathbf{7}$ & Why was there so much wind curtailment in the RPS/R and $\mathrm{CO}_{2}+$ scenarios? \\
\hline $\mathbf{8}$ & How much did demand response as defined in the models affect results? \\
\hline $\mathbf{9}$ & What transmission lines were of value in all scenarios? \\
\hline & Low Priority Topics \\
\hline $\mathbf{1 0}$ & Regional vs. national implementation of policies \\
\hline $\mathbf{1 1}$ & Load growth sensitivities on resource mix and cost \\
\hline $\mathbf{1 2}$ & Environmental policy sensitivity impacts \\
\hline $\mathbf{1 3}$ & Technology sensitivity impacts \\
\hline
\end{tabular}

The first five topics were discussed in the report Additional EIPC Study Analysis: Interim Report on High Priority Topics (Hadley 2013). The second set of topics is covered in this report.

Section 2 (Topic 6) begins with a discussion of the different definitions for reserve margins used in the study and how their application varied between regions. Reserves represent an amount of capacity above demand available to continue to provide adequate electricity at the correct voltage and frequency to maintain the grid during abnormal occurrences. There are two main types of reserves that were used in the EIPC study: planning reserves and operating reserves. They each have different purposes and definitions, but the distinctions are often lost in discussions.

The regional planning reserve requirement, given the demand forecast and the amount of existing resources, determines the need for new resources. In the RPS/R and $\mathrm{CO}_{2}+$ scenarios, a significant amount of wind resources was added. Because of the way the model is structured, wind resources contribute only a fraction of their nameplate capacity (related to the coincidence of wind production at the time of peak system loads) toward meeting the regional planning reserve requirement. Thus, the potential for a large amount of wind energy exists, which leads to curtailments that are explored in Section 3 (Topic 7).

The rules determining how operating reserves are provided, both the amounts by region and the requirements for the units that provide them, also contribute to the wind energy curtailments examined in 
Section 3 because they require commitment of units that must be running at least at a minimum operating point. The output from these committed units means that there is less demand that would be supplied by wind energy. In some cases, wind is curtailed as a result.

Demand response (DR) is a complex collection of programs and technologies that let demand respond to supply, mainly through reduction of demand in the face of supply shortages. While DR was modeled as a viable option to supply planning reserves in Phase 1, it could not supply operating reserves in Phase 2. Additionally, the costs associated with calling on DR were modeled differently in the two models. Section 4 (Topic 8) looks at the different ways in which DR was modeled in Phase 1 and Phase 2 and how the modeling affected the results.

In Phase 2 a number of transmission components were included in the build outs of each of the three scenarios to meet reliability concerns. Because the scenarios capture significantly different outlooks for the future, there may be value in examining the components that show up in all three scenarios as they potentially represent elements that will be needed under a wide variety of future circumstances. If they were to be constructed, it would not be at the expense of other opportunities or more advantageous outcomes as it appears they will be needed regardless of what happens in the future. Section 5 (Topic 9) identifies and discusses these transmission components.

\section{TOPIC 6: OPERATING AND PLANNING RESERVES}

\subsection{RESERVES DEFINITIONS}

Reserves represent an amount of capacity above demand available to provide adequate electricity at the correct voltage and frequency to maintain the grid under unusual or abnormal circumstances. Two main types of reserves were used in the EIPC study: planning reserves and operating reserves. They each have different purposes and definitions, but the distinctions are often lost in discussions.

Planning reserves are used for long-term resource planning and defining regional planning reserve margins. These were discussed at length in the EISPC-sponsored white paper The Economic Ramifications of Resource Adequacy White Paper (Astrape 2013). The North American Electric Corporation (NERC) publishes the standards for all regions on its website (NERC 2013). Most regions begin with a reliability criterion such as 1 day of outages in 10 years, but there are a number of variations on how this is calculated. The regions then determine the reserve margin required to meet that criterion. For example, the ReliabilityFirst Corporation region includes the following requirements (among others), as listed in Standard BAL-502-RFC-02 of the NERC reliability standards.

R1 The Planning Coordinator shall perform and document a Resource Adequacy analysis annually. The Resource Adequacy analysis shall [Violation Risk Factor: Medium]:

R1.1 Calculate a planning reserve margin that will result in the sum of the probabilities for loss of Load for the integrated peak hour for all days of each planning year analyzed (per R1.2) being equal to 0.1. (This is comparable to a "one day in 10 year" criterion).

R1.1.1 The utilization of Direct Control Load Management or curtailment of Interruptible Demand shall not contribute to the loss of Load probability.

R1.1.2 The planning reserve margin developed from R1.1 shall be expressed as a percentage of the median forecast peak Net Internal Demand (planning reserve margin). (NERC 2013) 
In this example, the planning reserve margin is to meet the 1-day-in-10-year loss of load probability; load lost through utility-controlled DR (direct load control and interruptible rates) will not be counted as loss of load for the probability, and the reserve margin is applied to the median forecast peak load to determine the number of megawatts needed for the region. Planning reserve margins were included in NEEM in Phase 1.

In Phase 2, the GE MAPS model used operating reserves or its subset spinning reserves as a key variable. These reserves are needed on an ongoing basis and vary as demand and other factors come into play. The NERC "Glossary of Terms" in the NERC reliability standards (NERC 2013) defines the different reserves, shown in Table 4. Note that the terms include two definitions for spinning reserves. In one, only unloaded generation is included, but in the second, load fully removable from the system is included as well. This distinction plays a role in the results from Phase 2.

As a complement to operating reserves, the NERC standards also define "contingency reserves" (Standard BAL-002-1). These reserves "may be supplied from generation, controllable load resources, or coordinated adjustments to interchange schedules.” (R1). The contingency reserves are a mix of the operating reserves_-spinning and the operating reserves—supplemental, as defined in Table 4. Both of these must be capable of being synchronized to the grid within the "disturbance recovery period." Elsewhere in the standards the default value for the period is set at $15 \mathrm{~min}$, although individual interconnections are allowed to set alternatives with approval of the NERC Operating Committee.

Table 4. NERC Definitions of Reserves (NERC 2013)

\begin{tabular}{|c|c|}
\hline NERC Term & Definition \\
\hline Operating Reserve & $\begin{array}{l}\text { That capability above firm system demand required to provide for regulation, load } \\
\text { forecasting error, equipment forced and scheduled outages and local area protection. It } \\
\text { consists of spinning and non-spinning reserve. }\end{array}$ \\
\hline Non-Spinning Reserve & $\begin{array}{l}\text { 1. That generating reserve not connected to the system but capable of serving } \\
\text { demand within a specified time. } \\
\text { 2. Interruptible load that can be removed from the system in a specified time. }\end{array}$ \\
\hline Spinning Reserve & Unloaded generation that is synchronized and ready to serve additional demand. \\
\hline Contingency Reserve & $\begin{array}{l}\text { The provision of capacity deployed by the Balancing Authority to meet the Disturbance } \\
\text { Control Standard (DCS) and other NERC and Regional Reliability Organization } \\
\text { contingency requirements. }\end{array}$ \\
\hline $\begin{array}{l}\text { Operating Reserve- } \\
\text { Spinning }\end{array}$ & $\begin{array}{l}\text { The portion of Operating Reserve consisting of: } \\
\text { - Generation synchronized to the system and fully available to serve load within the } \\
\text { Disturbance Recovery Period following the contingency event; or } \\
\text { - Load fully removable from the system within the Disturbance Recovery Period } \\
\text { following the contingency event. }\end{array}$ \\
\hline $\begin{array}{l}\text { Operating Reserve- } \\
\text { Supplemental }\end{array}$ & $\begin{array}{l}\text { The portion of Operating Reserve consisting of: } \\
\text { - Generation (synchronized or capable of being synchronized to the system) that is } \\
\text { fully available to serve load within the Disturbance Recovery Period following the } \\
\text { contingency event; or } \\
\text { - Load fully removable from the system within the Disturbance Recovery Period } \\
\text { following the contingency event. }\end{array}$ \\
\hline
\end{tabular}

\subsection{PLANNING RESERVES IN PHASE 1}

Phase 1 of the EIPC study used planning reserve margins, with each region supplying its requirement (Table 5). MRN-NEEM took into account reserve margins for individual regions and for collections of 
regions into larger regions, such as MISO* and NYISO. MRN-NEEM covers all of the United States and Canada, so reserve margins were defined for regions inside and outside of the EI.

Table 5. Reserve Margin Regions, Reserve Requirements, and NEEM Regions (CRA 2010)

\begin{tabular}{|c|c|c|}
\hline Reserve Margin Area & Reserve Requirement & NEEM Regions \\
\hline ALB & $18.0 \%$ & ALB \\
\hline AZ-NM-SNV & $15.7 \%$ & AZ-NM-SNV \\
\hline BC & $18.0 \%$ & $\mathrm{BC}$ \\
\hline \multirow[t]{2}{*}{ CA } & $16.6 \%$ & NP15 \\
\hline & & SP15 \\
\hline ENT & $14.0 \%$ & ENT \\
\hline ERCOT & NA & ERCOT \\
\hline FRCC & $16.0 \%$ & FRCC \\
\hline MAPP US & $14.0 \%$ & MAPP US \\
\hline MAPP CA & $12.0 \%$ & MAPP CA \\
\hline \multirow[t]{5}{*}{ MISO } & $17.4 \% *$ & MISO IN \\
\hline & & MISO MI \\
\hline & & MISO MO-IL \\
\hline & & MISO W \\
\hline & & MISO WUMS \\
\hline NEISO & $16.0 \%$ & NEISO \\
\hline Non-RTO Midwest & $14.0 \%$ & Non-RTO Midwest \\
\hline NWPP & $18.0 \%$ & NWPP \\
\hline \multirow[t]{3}{*}{ NYISO } & $16.5 \%$ * & NYISO A-F \\
\hline & & NYISO GHI \\
\hline & & NYISO JK \\
\hline \multirow[t]{2}{*}{ NYISO GHI JK } & $-5.0 \%$ & NYISO GHI \\
\hline & & NYISO JK \\
\hline NYISO JK & $-8.0 \%$ & NYISO JK \\
\hline OH (IESO) & $17.0 \%$ & $\mathrm{OH}$ \\
\hline \multirow[t]{3}{*}{ PJM } & $15.3 \% *$ & PJM E \\
\hline & & PJM ROM \\
\hline & & PJM ROR \\
\hline PJM E & $-2.2 \%$ & PJM E** \\
\hline RMPA & $14.0 \%$ & RMPA \\
\hline SOCo & $14.0 \%$ & SOCO \\
\hline \multirow[t]{3}{*}{ SPP } & $13.6 \%$ & $\mathrm{NE}$ \\
\hline & & SPP N \\
\hline & & SPP S \\
\hline TVA & $15.0 \%$ & TVA \\
\hline VACAR & $14.0 \%$ & VACAR \\
\hline \multicolumn{3}{|c|}{$\begin{array}{l}\text { * Based on coincident peak in reserve margin area. For PJM, CRA } \\
\text { applied a diversity factor to the noncoincident peaks. }\end{array}$} \\
\hline${ }^{* *}$ For purposes of th & Idy, set equal to actc & 10 Reserve Margin \\
\hline
\end{tabular}

For planning reserve margin calculations, all generating capacity qualified to meet the reserve margin, including DR. However, the EIPC applied a fractional resource contribution credit to intermittent generation (wind and solar). The installed capacity of the technology is multiplied by this fraction to

*Note: Refer to Table 1 or the Eastern Interconnection regions list at the front for complete definitions of region identifiers used in the figures, tables, and text. 
represent the amount of capacity that will be available during the peak period. The amount can vary depending on the type of technology and quality of resources in the region. Solar generation is set at 30\% to reflect that the peak time is likely on a hot, sunny day, but often later in the day when the sun is not at full strength. Offshore wind is set similarly based on expectations for future installations. Onshore wind generation is set lower to reflect that its generation during the peak can be lower than its average generation because winds are often calmer on the hottest, highest demand days. Table 6 lists the credit factors for each region as used in Phase 1 of the study.

Table 6. Intermittent Resource Contributions (CRA 2010)

\begin{tabular}{|lcc|}
\multicolumn{1}{|c}{ NEEM Region } & Technology & $\begin{array}{c}\text { Reserve } \\
\text { Contribution }\end{array}$ \\
\hline All Regions & Photovoltaic & $30 \%$ \\
\hline All Regions & Solar Thermal & $30 \%$ \\
\hline All Regions & Offshore Wind & $30 \%$ \\
\hline California & Wind & $25 \%$ \\
\hline Canada & Wind & $20 \%$ \\
\hline ERCOT & Wind & $9 \%$ \\
\hline New York & Wind & $15 \%$ \\
\hline PJM (-E, -ROM, -ROR) & Wind & $13 \%$ \\
\hline SPP & Wind & $15 \%$ \\
\hline TVA & Wind & $12 \%$ \\
\hline IESO & Wind & $11 \%$ \\
\hline MAPP CA & Wind & $11 \%$ \\
\hline All Other Regions & Wind & $15 \%$ \\
\hline
\end{tabular}

An important consequence of the capacity credit is that wind generation on average is higher than its credit, yet a region will build its combined total capacity to meet the reserve margin using the lower value. This means that there will be significant generation capacity above what is needed, and even with the low capacity factors of intermittent renewables (25\%-40\%) there should be a number of hours in which there is substantial low or zero variable cost renewable power being generated. If this power cannot be absorbed within its own region, it will be exported if tie line capacity is available. In Fig. 2 the $\mathrm{CO}_{2}+$ scenario generating capacities for each major region are shown as a fraction of the region's peak demand. In it, the intermittent generation (solar, wind) have been split into two categories; the amount credited toward the reserve margin is shown immediately above the hydro capacity, while the remaining wind and solar capacity are shown on the top of each column. MAPP US, MISO, and SPP have significant amounts of capacity above the required amounts. This power is available for internal use or export if it is being produced and transmission capacity is available. If the production cannot be used then the plants must be curtailed, with loss of revenues to plant owners and loss of low-cost power to users. This was a significant issue in the $\mathrm{CO}_{2}+$ scenario, as described in Sect. 3.

Another note of interest is that, at least for the $\mathrm{CO}_{2}+$ scenario (Fig. 2), the line representing $100 \%$ of peak demand passes through the capacity from DR. While many regions will import from the wind-rich areas to avoid use of DR, those regions far from wind sources (e.g., VACAR, FRCC) need to use DR for some of their peak hours. This does not occur in the BAU or RPS/R scenarios as DR is not as significant a fraction of the capacity contribution to the reserve margin for these two scenarios.

The RPS/R and BAU scenarios also do not have the large surpluses of wind that were in the $\mathrm{CO}_{2}+$ scenario (Fig. 3 and Fig. 4). In the RPS/R scenario, MAPP US continues a high proportion of wind to demand to supply the rest of the Northwest. MISO and SPP have much lower surplus wind capacity because they do not have the transmission capability to export to the east. PJM and VACAR increase their surplus wind capacity to help meet RPS requirements for their regions. The BAU scenario has relatively little excess capacity because RPS requirements are not expanded beyond current state regulations. 


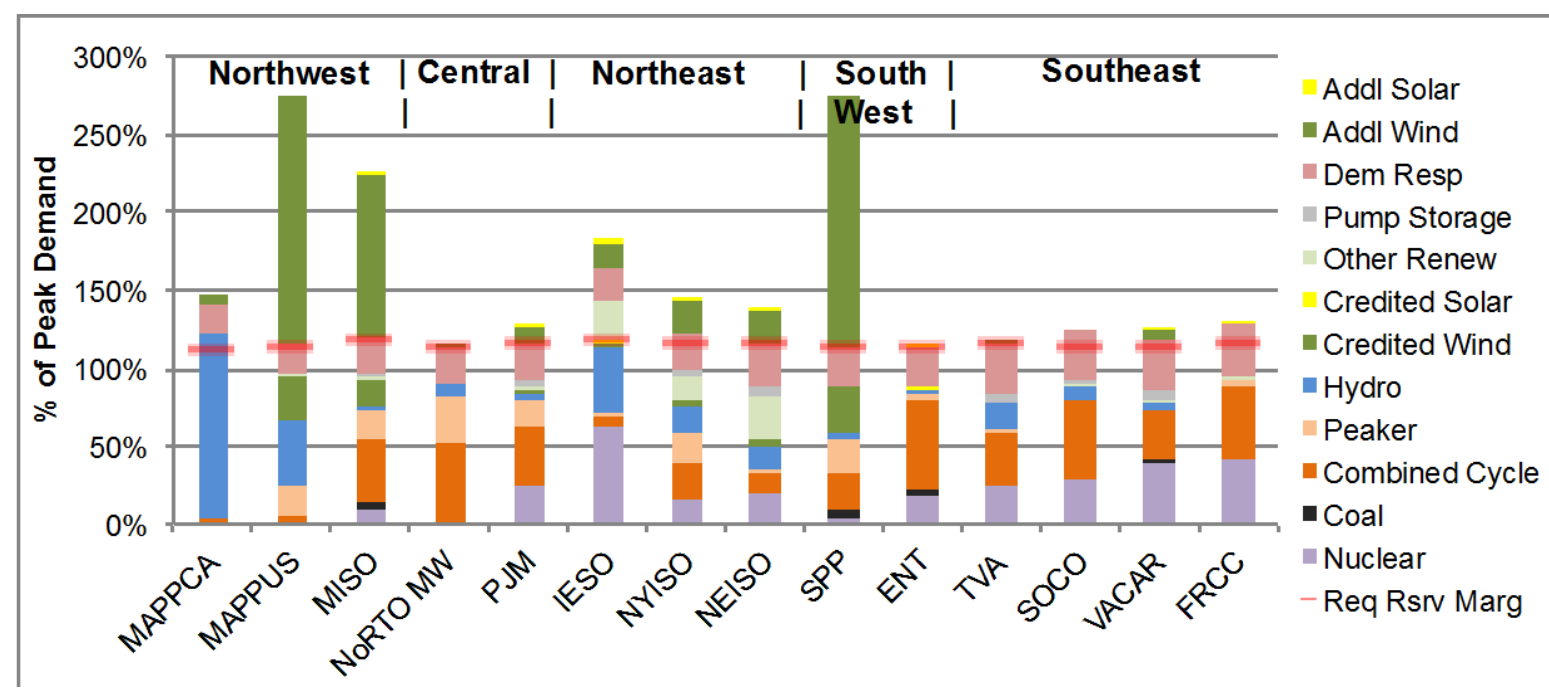

Fig. 2. Phase 1 ratio of capacities to peak demand in the $\mathrm{CO}_{2}+$ scenario.

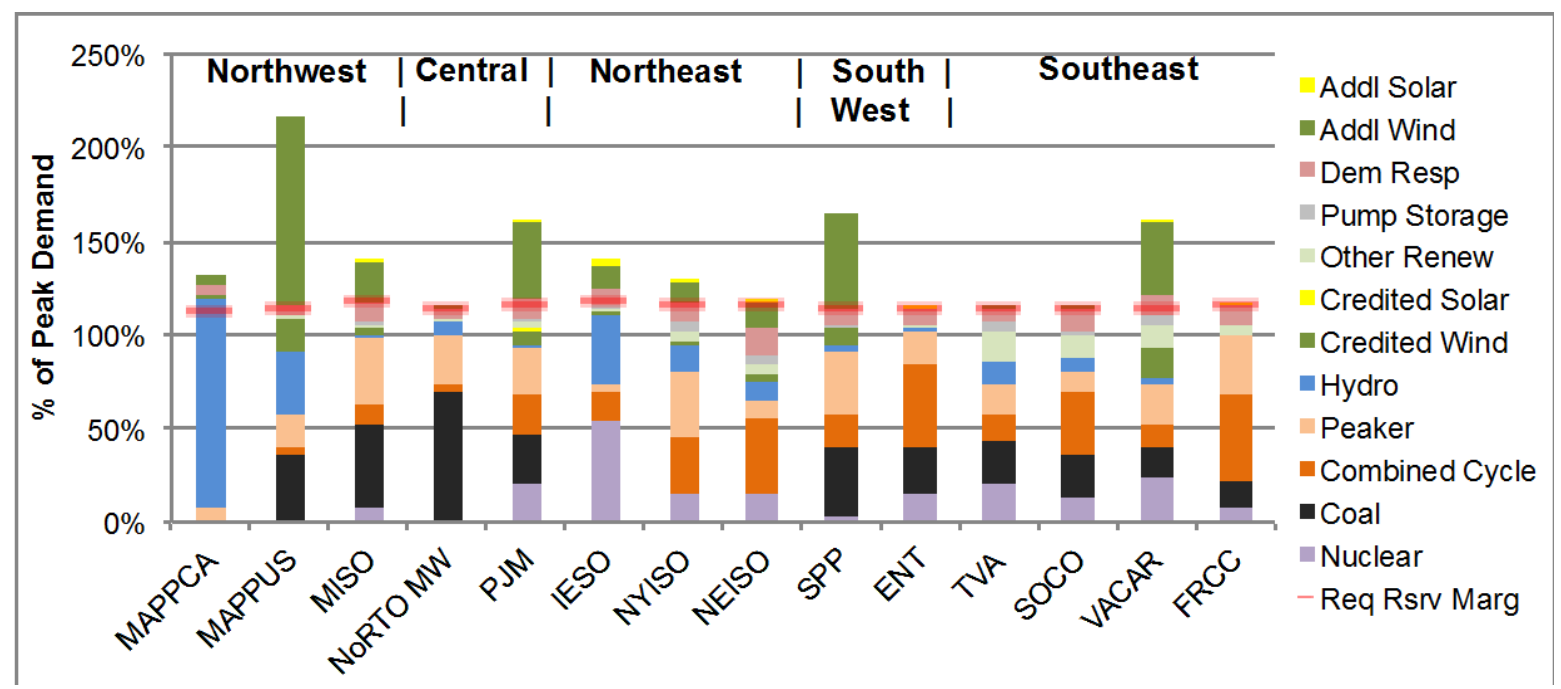

Fig. 3. Phase 1 ratio of capacities to peak demand in the RPS/R scenario.

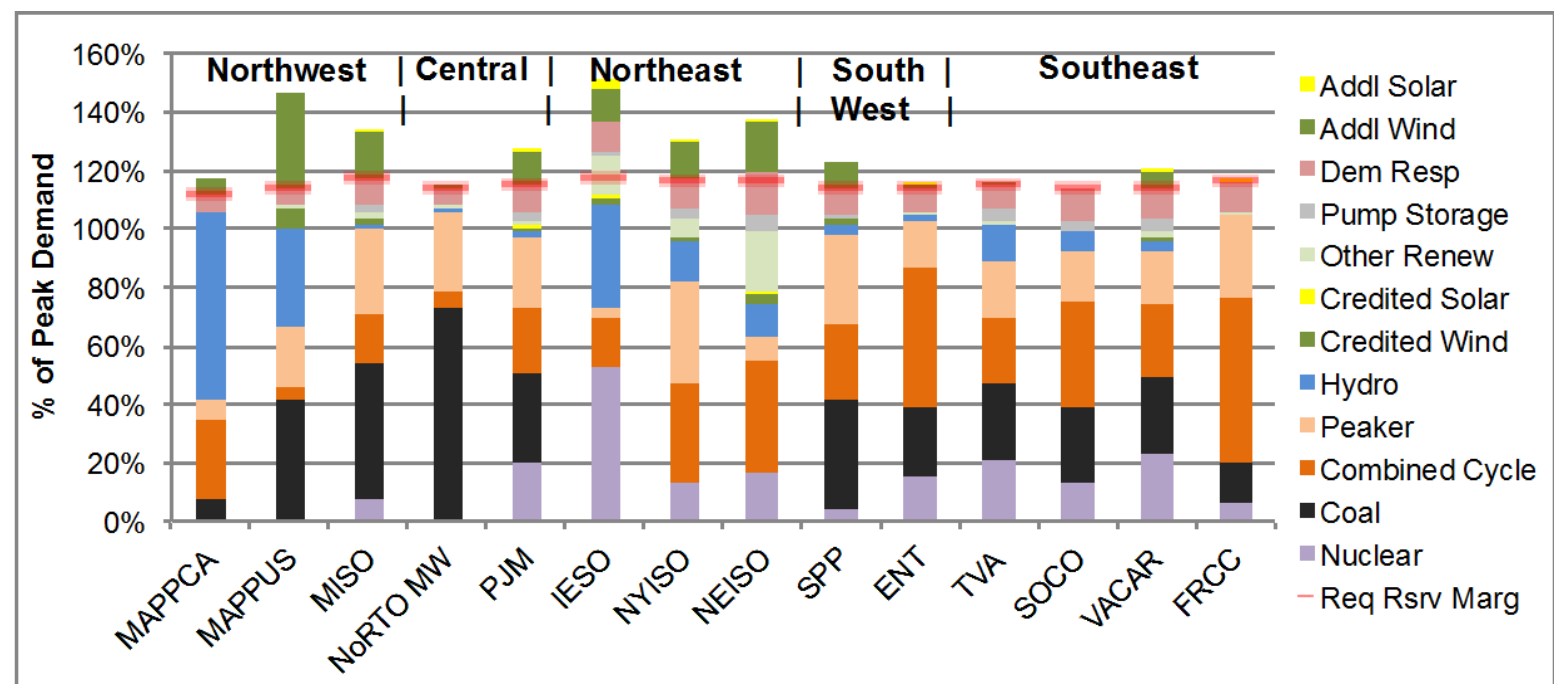

Fig. 4. Phase 1 ratio of capacities to peak demand in the BAU scenario. 
Figures 2, 3 and 4 include lines on each column showing the planning reserve margin for each region. One question raised early in the EIPC study was whether NEEM would force capacity down to the reserve margin in each year or would leave capacity higher than the minimum if it was cost-effective overall. This could happen if one region had a lower cost resource that it could use for export to other regions. At the same time, the importing regions still must have sufficient capacity to meet their internal reserve margins unless they have formal reserve sharing agreements. The $\mathrm{CO}_{2}+$ scenario allowed reserve sharing between the southwest and southeast territories and between the northwest and central territories. In the RPS/R scenario a more regional condition was set, with each territory required to meet its requirements internally. (Hydro Quebec power could be counted for NYISO and NEISO in all cases.)

Examining the results, it is clear that NEEM did allow capacity to be higher. Table 7 shows the reserve requirement in 2030 for each consolidated region and the actual reserve margin for each of the three final cases studied. In the BAU scenario, almost all regions were at their minimum requirement, but in the subsequent scenarios some regions had higher margins as needed for minimizing costs.

Table 7. Phase 1 Reserve Requirement and 2030 Reserve Margins by Region

\begin{tabular}{|lcccc|}
\hline Reserve Margin Area & $\begin{array}{c}\text { Reserve } \\
\text { Requirement }\end{array}$ & BAU & $\begin{array}{c}\text { 2030 Reserve Margin } \\
\text { RPSIR }\end{array}$ & $\mathbf{C O}_{2+}{ }^{+}$ \\
\hline MAPP CA & $12.0 \%$ & $12.0 \%$ & $26.2 \%$ & $40.8 \%$ \\
\hline MAPP US & $14.0 \%$ & $14.0 \%$ & $15.9 \%$ & $15.5 \%$ \\
\hline MISO & $17.4 \%$ & $17.4 \%$ & $17.4 \%$ & $20.1 \%$ \\
\hline Non-RTO Midwest & $14.0 \%$ & $14.0 \%$ & $14.0 \%$ & $14.0 \%$ \\
\hline PJM & $15.3 \%$ & $15.3 \%$ & $19.9 \%$ & $15.3 \%$ \\
\hline IESO & $17.0 \%$ & $23.7 \%$ & $25.5 \%$ & $43.3 \%$ \\
\hline NYISO & $16.5 \%$ & $16.5 \%$ & $16.5 \%$ & $18.9 \%$ \\
\hline NEISO & $16.0 \%$ & $19.3 \%$ & $20.4 \%$ & $16.0 \%$ \\
\hline SPP & $13.6 \%$ & $13.6 \%$ & $13.6 \%$ & $13.6 \%$ \\
\hline ENT & $14.0 \%$ & $14.0 \%$ & $14.0 \%$ & $14.0 \%$ \\
\hline TVA & $15.0 \%$ & $15.0 \%$ & $15.0 \%$ & $15.0 \%$ \\
\hline SOCO & $14.0 \%$ & $14.0 \%$ & $14.9 \%$ & $23.5 \%$ \\
\hline VACAR & $14.0 \%$ & $14.0 \%$ & $21.0 \%$ & $17.3 \%$ \\
\hline FRCC & $16.0 \%$ & $16.0 \%$ & $16.0 \%$ & $28.1 \%$ \\
\hline
\end{tabular}

\subsection{OPERATING RESERVES IN PHASE 2}

In Phase 2, the focus in the GE MAPS modeling was on spinning reserves rather than planning reserves. The amounts for each region were based on the EIPC members' stated requirements for each, taking into account loss of the single largest generator, largest generator plus half of the second largest, or percentage of demand. Table 8 is from the Phase 2 final report (EIPC 2012). NYISO includes requirements both for the region as a whole (600 MW) and for subregions (300 MW for zone J-K, 0 MW for zone K). PJM similarly has requirements both for the mid-Atlantic region and the full region. Note that the PJM region has the largest reserve requirement. With a peak demand of $137 \mathrm{GW}$, its spinning reserve at peak is 11.8 GW, 7.6 times that of SOCO, the next largest, at its peak.

Table 8. Phase 2 Spinning Reserve Requirements

\begin{tabular}{|c|c|c|c|}
\hline $\begin{array}{c}\text { GE MAPS } \\
\text { Commitment Pool }\end{array}$ & $\begin{array}{l}\text { GE MAPS Operating } \\
\text { Reserve Group }\end{array}$ & Spinning Reserve Requirement & $\begin{array}{c}\text { Spinning Reserve Amount at } \\
\text { Peak }\end{array}$ \\
\hline NEISO & NEISO & $530 \mathrm{MW}$ & $530 \mathrm{MW}$ \\
\hline NYISO & Long Island & 0 MW for NYISO-K (Long Island) & $0 \mathrm{MW}$ \\
\hline NYISO & East NY & 300 MW for NYISO-G NYISO-K & $300 \mathrm{MW}$ \\
\hline NYISO & NYISO & 600 MW for NYISO-A NYISO-K & $600 \mathrm{MW}$ \\
\hline PJM & PJM Mid Atlantic & $1150 \mathrm{MW}+7.5 \%$ of load & 4,844 MW \\
\hline PJM & PJM RTO & $1509 \mathrm{MW}+7.5 \%$ of load & $11,785 \mathrm{MW}$ \\
\hline
\end{tabular}


Table 8 (continued)

\begin{tabular}{|c|c|c|c|}
\hline $\begin{array}{l}\text { GE MAPS } \\
\text { Commitment Pool }\end{array}$ & $\begin{array}{l}\text { GE MAPS Operating } \\
\text { Reserve Group }\end{array}$ & Spinning Reserve Requirement & $\begin{array}{c}\text { Spinning Reserve Amount at } \\
\text { Peak }\end{array}$ \\
\hline Midwest & MISO & $800 \mathrm{MW}$ & $800 \mathrm{MW}$ \\
\hline TVA & TVA & $625 \mathrm{MW}$ & $625 \mathrm{MW}$ \\
\hline SPP & SPP & $983 \mathrm{MW}$ & $983 \mathrm{MW}$ \\
\hline VACAR & VACAR & $2 \%$ of hourly load & $958 \mathrm{MW}$ \\
\hline soco & SOCO & $3 \%$ of hourly load & $1,542 \mathrm{MW}$ \\
\hline FRCC & FRCC & $350 \mathrm{MW}$ & $350 \mathrm{MW}$ \\
\hline IESO & IESO & $225 \mathrm{MW}$ & $225 \mathrm{MW}$ \\
\hline
\end{tabular}

Another factor was the technologies that qualified as spinning reserve and the quantity available from them. According to the Phase 2 documentation (EIPC 2012), only coal, gas/oil steam, CC, and hydro units were available to provide spin. The amount of spin available was calculated on a unit-by-unit basis. The maximum spin from thermal plants was limited to the lesser of the amount of capacity above their minimum amount and 10 times their per minute ramp rate (to reflect a $10 \mathrm{~min}$ response.) Because the ramp rates used were $3 \mathrm{MW} / \mathrm{min}$ for coal, $6 \mathrm{MW} / \mathrm{min}$ for oil/gas steam, and $10 \mathrm{MW} / \mathrm{min}$ for CC, the maximum spin was $30 \mathrm{MW}$ from coal units, $60 \mathrm{MW}$ from oil/gas steam, and $100 \mathrm{MW}$ from CC. Also, the reserves were limited to $50 \%$ of the unit's capacity.

As an example, a $600 \mathrm{MW}$ CC plant has a minimum capacity of $300 \mathrm{MW}$. So to provide the maximum $100 \mathrm{MW}$ of spin it must operate at a minimum of $300 \mathrm{MW}$. To provide 10,000 MW of spin for PJM, assuming $600 \mathrm{MW}$ CC plants, there would need to be $30 \mathrm{GW}$ of CC plants operating. Using this formula, smaller units of $200 \mathrm{MW}$ could run at their minimum of just $100 \mathrm{MW}$ and still provide $100 \mathrm{MW}$ of spinning reserve. (Note: The capacity and operations of specific plants are not available from the results reported, so it is not possible to determine which plants provided spinning reserves.)

Besides thermal plants, hydro plants could provide spinning reserves equal to $50 \%$ of the difference between the plant's capacity and the month's average generation. So for example, a $300 \mathrm{MW}$ hydro plant operating at $100 \mathrm{MW}$ on average for a given month could provide $100 \mathrm{MW}$ of spin. For many of the regions, hydro capacity could provide a large portion of the spin requirement. Table 9 shows the amount of spin required and available by month for the $\mathrm{CO}_{2}+$ scenario. Six of the regions have sufficient hydro to provide all of their spinning reserve; two others have more than half provided by hydro. Only PJM and FRCC require significant spinning reserve from thermal resources.

Table 9. Regional Average Spin Requirements and Contributions from Hydro

\begin{tabular}{|lcccccccccc|}
\hline $\begin{array}{l}\text { Average Spin } \\
\text { Required }\end{array}$ & NEISO & NYISO & PJM & MISO & TVA & SPP & VACA & SOCO & FRCC & IESO \\
\hline $\begin{array}{l}\text { Average Spin } \\
\text { from Hydro }\end{array}$ & 1,303 & 600 & 7,665 & 800 & 625 & 983 & 520 & 889 & 350 & 225 \\
\hline Ratio & $246 \%$ & $109 \%$ & $21 \%$ & $79 \%$ & $241 \%$ & $54 \%$ & $115 \%$ & $151 \%$ & $7 \%$ & $1031 \%$ \\
\hline
\end{tabular}

One sensitivity was run on the $\mathrm{CO}_{2}+$ scenario that relaxed several variables relative to reserve requirements. The "Hi-Spin” sensitivity implementation included the following.

- $\quad$ Reduce spinning reserve requirements in MISO, SPP, PJM and Ontario by 50\%.

- $\quad$ All CC units were modeled with a $100 \mathrm{MW} / \mathrm{min}$ ramp rate, turndown $14 \%$ of base load, minimum runtime, and downtime of $2 \mathrm{~h}$.

Ontario already met all spin requirements from hydro, so the changes had no effect on it. MISO, SPP, and PJM received some of their spin requirements from thermal plants, so a change in their generation was 
expected because of these modifications. The second step in the sensitivity greatly increased the flexibility and amount of spin from CC plants. Plants could provide up to 1,000 MW of spin based on the new ramp rate, which effectively eliminated that restriction. The earlier example of a $600 \mathrm{MW}$ CC plant could operate as low as $84 \mathrm{MW}$ while providing $300 \mathrm{MW}$ of spin (half of its capacity), so 10,000 MW of spin would only need 2,800 MW of CC operating at minimum power. This is less than 1/10 of the amount needed under the original specification. Furthermore, the minimum runtime and downtime of $2 \mathrm{~h}$ are much less than the base case values of $6 \mathrm{~h}$ and $8 \mathrm{~h}$ for minimum runtime and downtime. These combined changes reduced the need for CC plants and also allowed for their shut down when not needed much more frequently. This resulted in less forced curtailment of wind generation, as discussed in the next section.

\subsection{CONCLUSIONS}

In Phase 1, the regional planning reserve requirement, given a demand forecast and schedule of plant retirements, determines the need for new resource builds. Planning reserves include all generation technologies in the calculation but reduce the capacities of wind and solar to reflect their limited availability during peak demands. Some scenarios (the $\mathrm{CO}_{2}+$ scenario especially) included large amounts of wind, which contributed only a small fraction toward meeting the planning reserve requirement. Because generation from these sources was often much larger than the reduced amount included in the reserves requirement, there was extra generation for export to other regions if transmission was available but curtailments were necessary (as noted in Phase 2) if not. This is discussed further in Sect. 3.

The Phase 2 calculations used operating reserves in their calculations. The required reserve quantities varied greatly by region, with PJM having the greatest requirements, both in megawatts and as a percentage of demand. In the modeling, only thermal fossil plants (coal, gas steam, and CC) and hydroelectric plants could provide reserves; these plants had to be running at least at their minimum dispatch points and could only provide limited quantities based on their ramp rates. While many regions had sufficient hydro to cover most of their reserves requirement, other regions were forced by their reserves requirements to increase output from the committed thermal units while other lower cost units (most notably wind) were curtailed. A sensitivity was run that reduced the reserves requirement by $50 \%$ (to represent DR supply of reserves in some of the regions) and enhanced CC flexibility (minimum power levels, minimum up/down times, and ramp rates). This led to a reduction in the amount of low cost power curtailed, more fully discussed in Sect. 3. During peak times, some regions had to back down their more efficient CC plants to provide reserves and call on more expensive combustion turbine (CT) units and DR to provide energy, as discussed in Sect. 4.

\section{TOPIC 7: WIND CURTAILMENT}

\subsection{BACKGROUND OF TOPIC}

Wind power is a resource that can provide large amounts of electrical power at very low marginal cost. The variable operating cost is near zero, and with production tax credits the final cost to producers is actually negative. Generally, it is most economic for the sector to take all generation provided from wind. However, there are various reasons why at times the system cannot accept all the wind power available and some wind farms have to reduce power levels. There can be multiple contributing factors to curtailment: there is simply more production than consumers demand at the time; there is insufficient transmission to carry the power to other regions where there is demand; and/or there are other factors such as local reserve requirements, transmission impedance, ramping limitations, environmental regulations, or other low cost resources available. These factors become more of an issue as the fraction of power from wind increases. 
In Phase 1 of the EIPC study, there was a brief question about whether any curtailment would occur. An analysis showed that even in the $\mathrm{CO}_{2}+$ scenario, the level of curtailment was less than $2 \%$ in all of the regions. However, in Phase 2 there was a significant amount of wind curtailment in the $\mathrm{CO}_{2}+$ scenario from the GE MAPS runs, along with some in the RP/R scenario as well. CRA released data that showed the amount curtailed over the course of the year for each region (Table 10).

Table 10. Phase 2 Wind Curtailment Amounts and Percent of Potential Generation

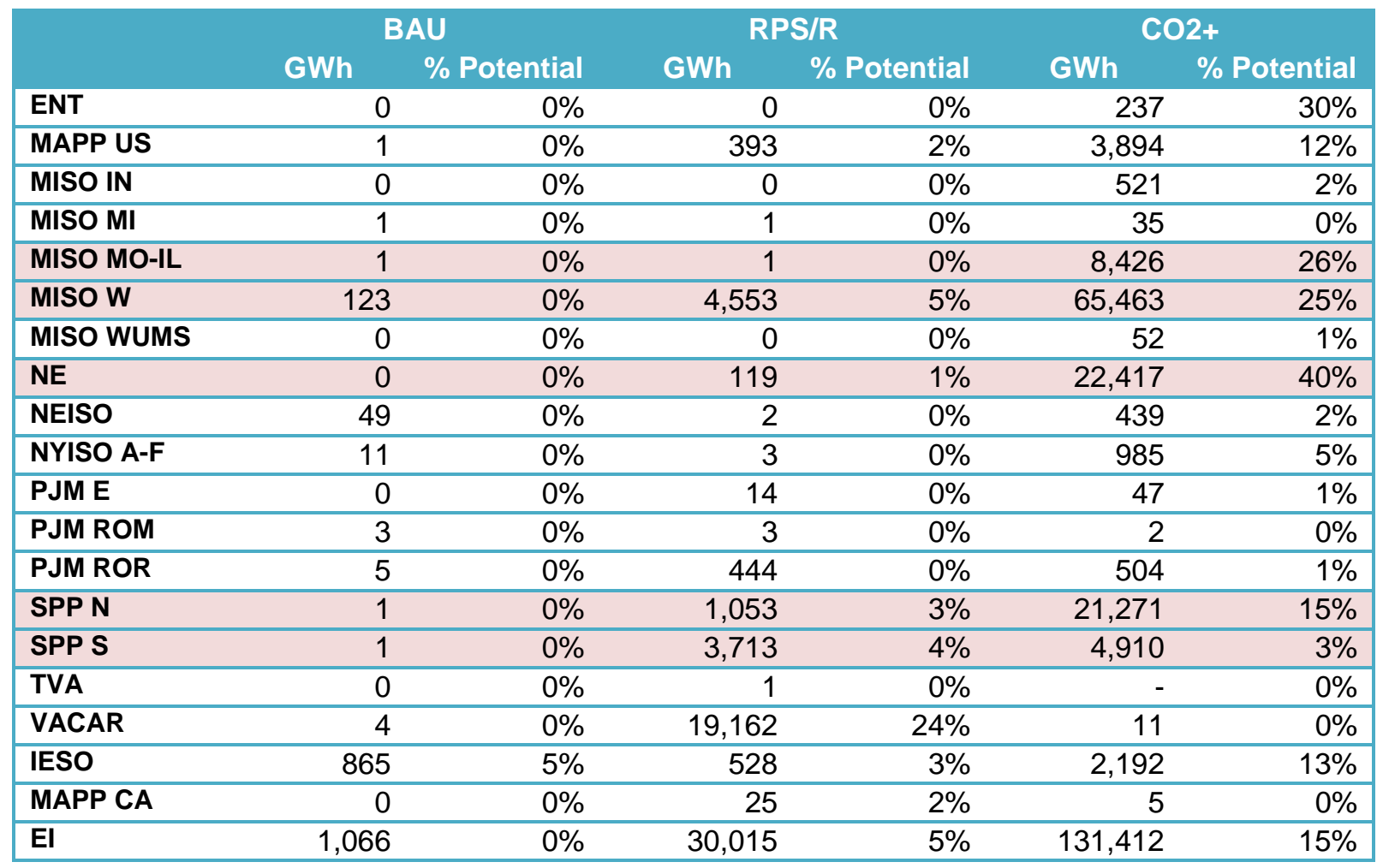

The $\mathrm{CO}_{2}+$ scenario had the most widespread curtailments and so was the subject of the most scrutiny. The western plains regions had the largest amount of curtailment, although there were pockets of curtailments in other regions as well. In the RPS/R scenario, the largest curtailments occurred in VACAR. These were likely offshore wind curtailments and possibly due to inadequate transmission build-out.

\subsection{ESTIMATION OF HOURLY WIND SCHEDULE AND CURTAILMENTS}

To explore the various reasons for the curtailments it was necessary to determine when the curtailments happened and what the demands and production requirements were across the EI. The Phase 2 reports included hourly output for all types of generation, including wind, for each NEEM region. The reports also included the amount of wind energy curtailed for the year by NEEM region (Table 10). Neither wind curtailments nor wind energy available (also referred to here as potential wind generation) were provided on an hourly basis. Thus, we had to estimate the amount of wind energy available in each hour based on the data available. We created a heuristic and applied it to five specific regions that had high levels of curtailment (MISO MO-IL, MISO W, NE, SPP N, and SPP S). These regions are highlighted in Table 10. MISO MO-IL, MISO W, NE, and SPP N all experienced high levels of wind curtailments in the $\mathrm{CO}_{2}+$ scenario. SPP S experienced high levels of wind curtailments in the RPS/R scenario. While VACAR also experienced high levels of wind curtailments in RPS/R, an estimated hourly wind availability schedule could not be produced for that region due to inconsistencies in the reported data for wind output and 
capacity. A comparison of the estimated wind availability to the wind output from the model provided an estimate of hourly curtailments.

Hourly wind availability was estimated using the hourly wind generation information from the $\mathrm{CO}_{2}+$ and RPS/R scenarios and their sensitivities. Because the $\mathrm{CO}_{2}+$ and RPS/R scenarios and the $\mathrm{CO}_{2}+$ sensitivity that had reduced wind capacity have different amounts of wind capacity installed, the hourly wind generation was normalized based on the amount of capacity for each scenario or sensitivity. Thus, the hourly wind generation data were converted from a megawatt basis to a fraction of wind capacity basis. This placed the various scenarios and sensitivities on an equal footing for a direct comparison. The estimated wind availability for a particular hour was determined by taking the maximum of the normalized wind generation levels across the scenarios/sensitivities for that hour. This operation was performed for all hours of the year to find the estimated wind availability schedule.

The estimated hourly wind availability schedule was then converted back to a megawatt basis for the various scenarios and sensitivities. The hourly curtailments were then estimated by subtracting the hourly wind generation from the hourly wind availability.

The estimation method does not capture all of the curtailments but does significantly reduce the amount of unaccounted for energy for all of the regions except MISO MO-IL. (MISO MO-IL experienced significant local congestion in the production costing model that likely caused curtailments across all the sensitivities.) While the estimation method does not exactly recreate the hourly wind availability, it is sufficient to identify specific hours of the year with large curtailment levels. The transmission interchange levels and generation levels of other generation sources can then be examined for these hours to provide insight into the causes of the wind curtailments.

\subsection{TIMING OF CURTAILMENTS}

A first analysis compares the potential wind generation, wind curtailments, and wind generation by hour of day (Fig. 5). These curves show the average values for all 365 days of the year. Curtailments were highest in the early morning hours, peaking around 5:00 a.m. Because demands are lowest at these times, there is clearly a connection between level of curtailments and demand. While it is also true that potential wind generation is also highest before noon, a clear suppression of demand in the early hours can be seen for most regions examined. SPP-S has a relatively flat and low level of curtailment, so its actual generation stays about the same shape as the potential generation.

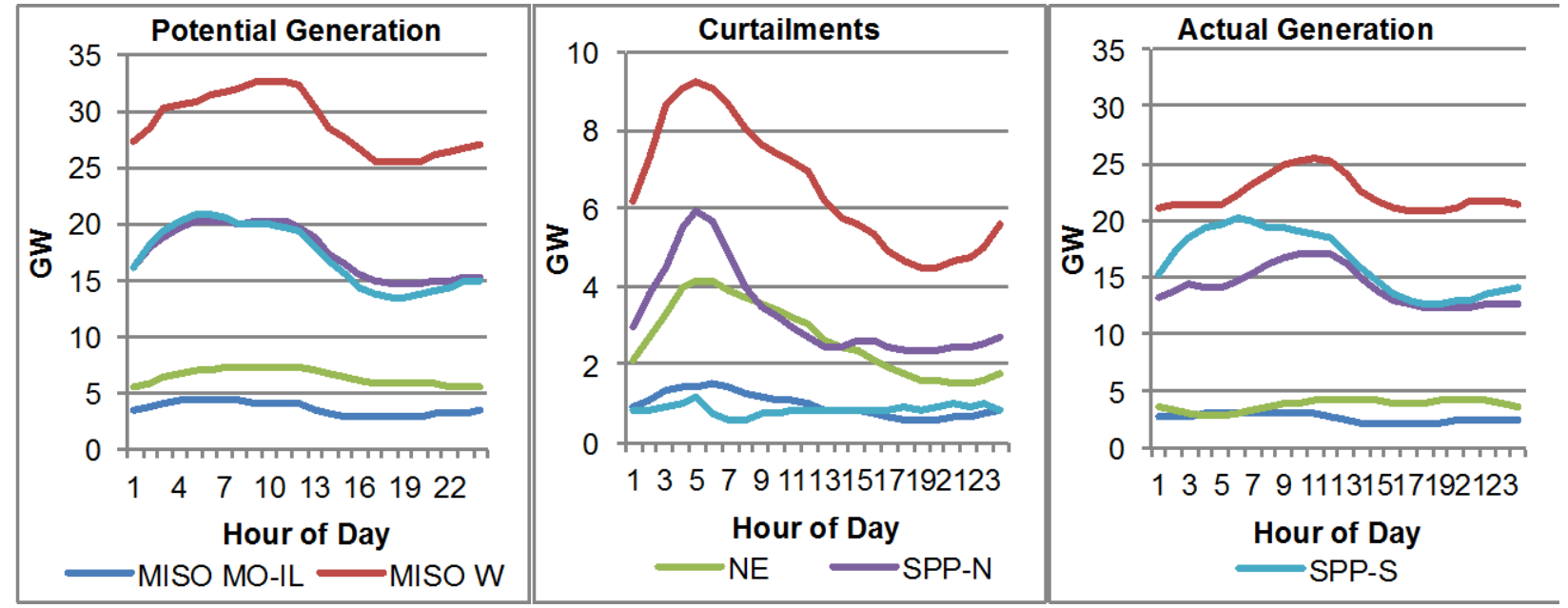

Fig. 5. Potential wind generation, curtailments, and actual wind generation in the $\mathrm{CO}_{2}+$ scenario. 


\subsection{EXPLORATION OF PEAK CURTAILMENT DAY}

Another avenue of exploration is to examine the transmission flows during an hour of high curtailment to see whether regional transfer capacities are being strained. As an example, April 1 had the highest level of curtailment for the year for those regions in which we calculated hourly curtailments (Fig. 6). There was major curtailment in the early hours and supply was only slightly above the region's demands, so little was exported.

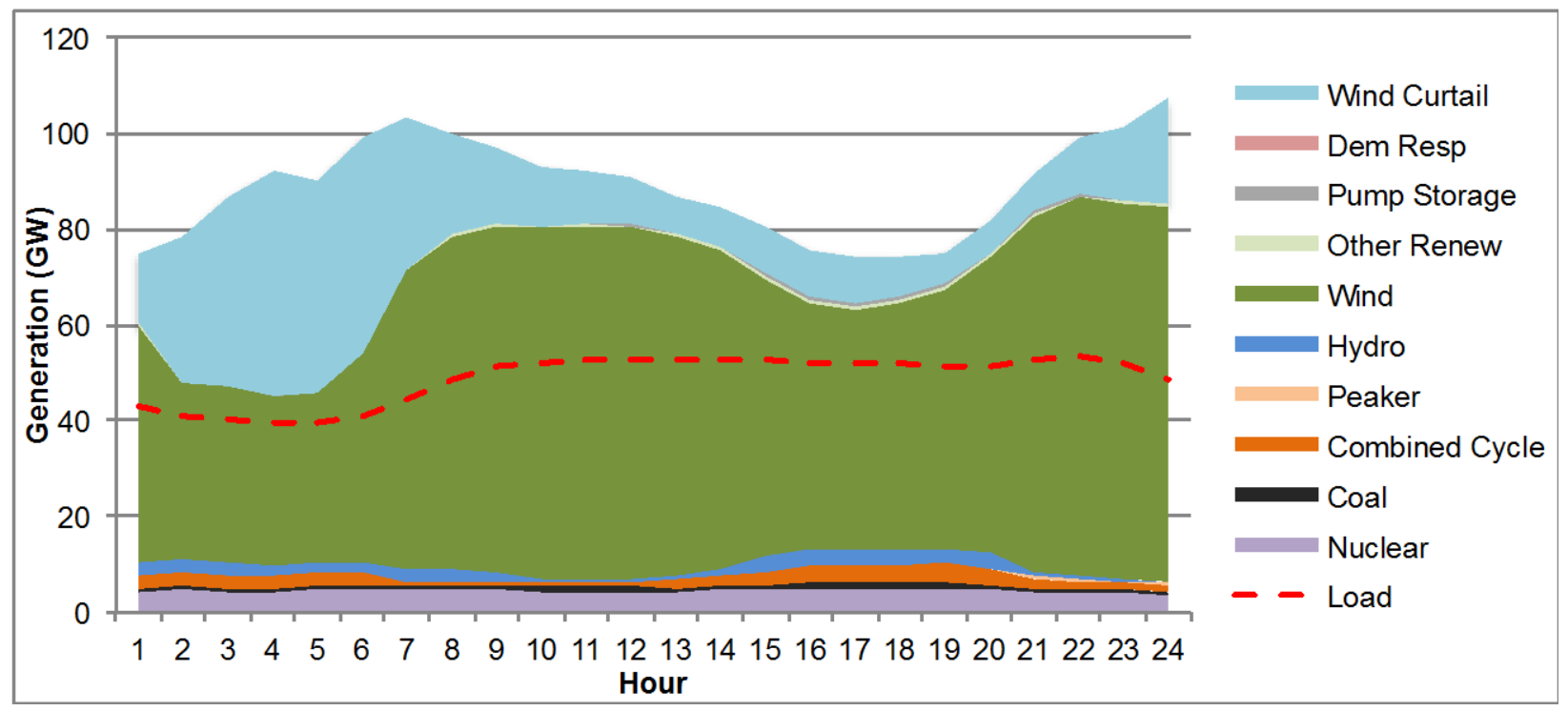

Fig. 6. Supply and demand for major curtailed regions on April 1 in the $\mathrm{CO}_{2}+$ scenario.

The lack of export is verified by looking at the tie line flows at 4:00 a.m. for the scenario (Fig. 7). Even the high voltage direct current (HVDC) lines from SPP N and MISO W to PJM were only lightly loaded. (In the detailed reports, one of the four HVDC lines between MISO W and PJM ROR was actually flowing back into MISO W.) PJM and other regions were not able to absorb the extra wind power in this hour.

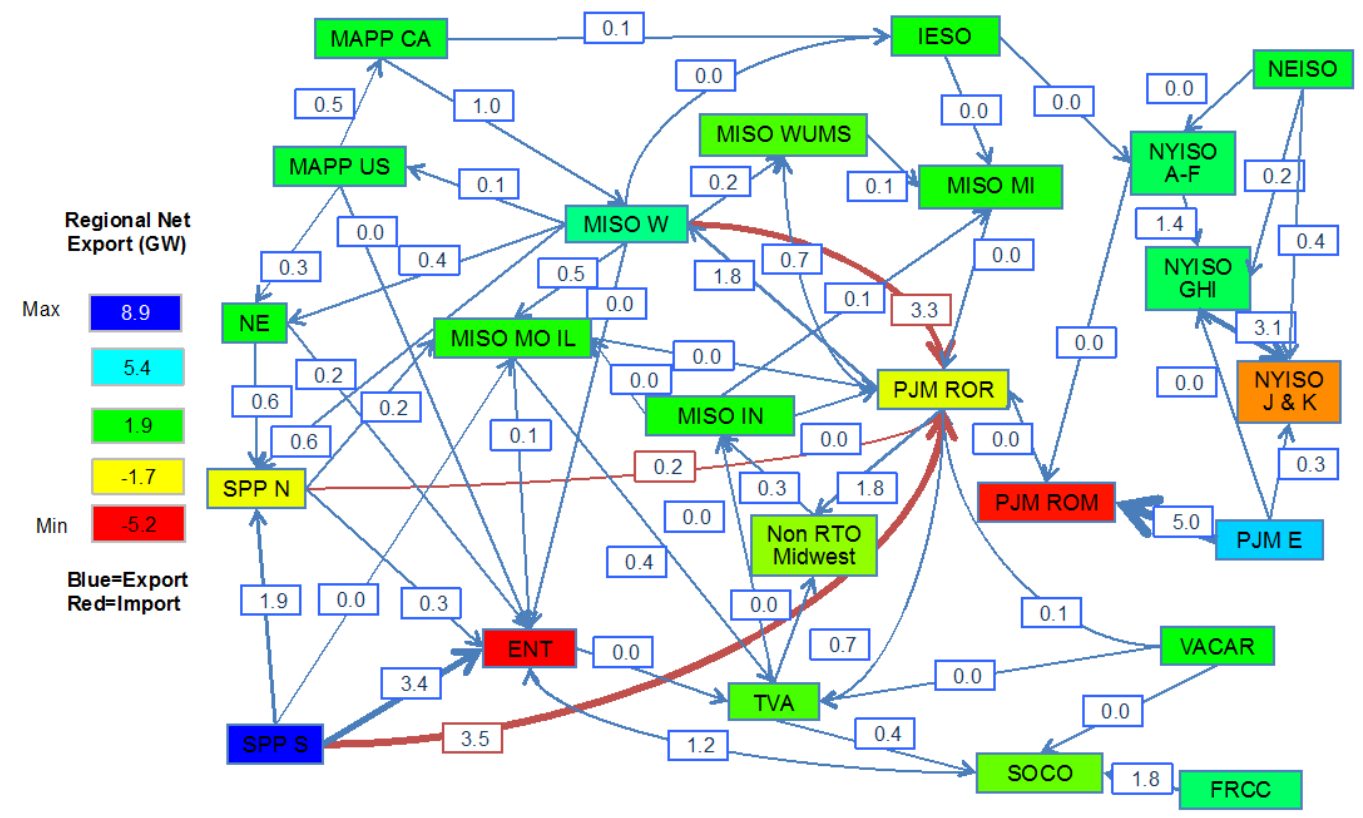

Fig. 7. Tie line flows on April 1 at 4:00 a.m. for the $\mathrm{CO}_{2}+$ scenario. 
The PJM region could not take additional power because its plants were running at the minimum levels or had to be running to be available in later hours. In Fig. 8, the generation levels by technology are shown for the three PJM regions combined. Note that the CC plants are running at 17,300 MW constantly through the morning. If these were all $750 \mathrm{MW}$ plants running at their minimum of 50\% of capacity, then there would be 50 plants running, and they would provide 5,000 MW of reserves. Based on the equation for required reserves, PJM needs 6,200 MW of reserves in that hour. Subtracting 1,400 MW supplied by hydro leaves 4,800 MW of reserves needed, about the same amount as provided by the CCs. So for this hour, it appears that the main cause of the curtailed wind was the reserves requirements and other operating constraints, not lack of transmission.

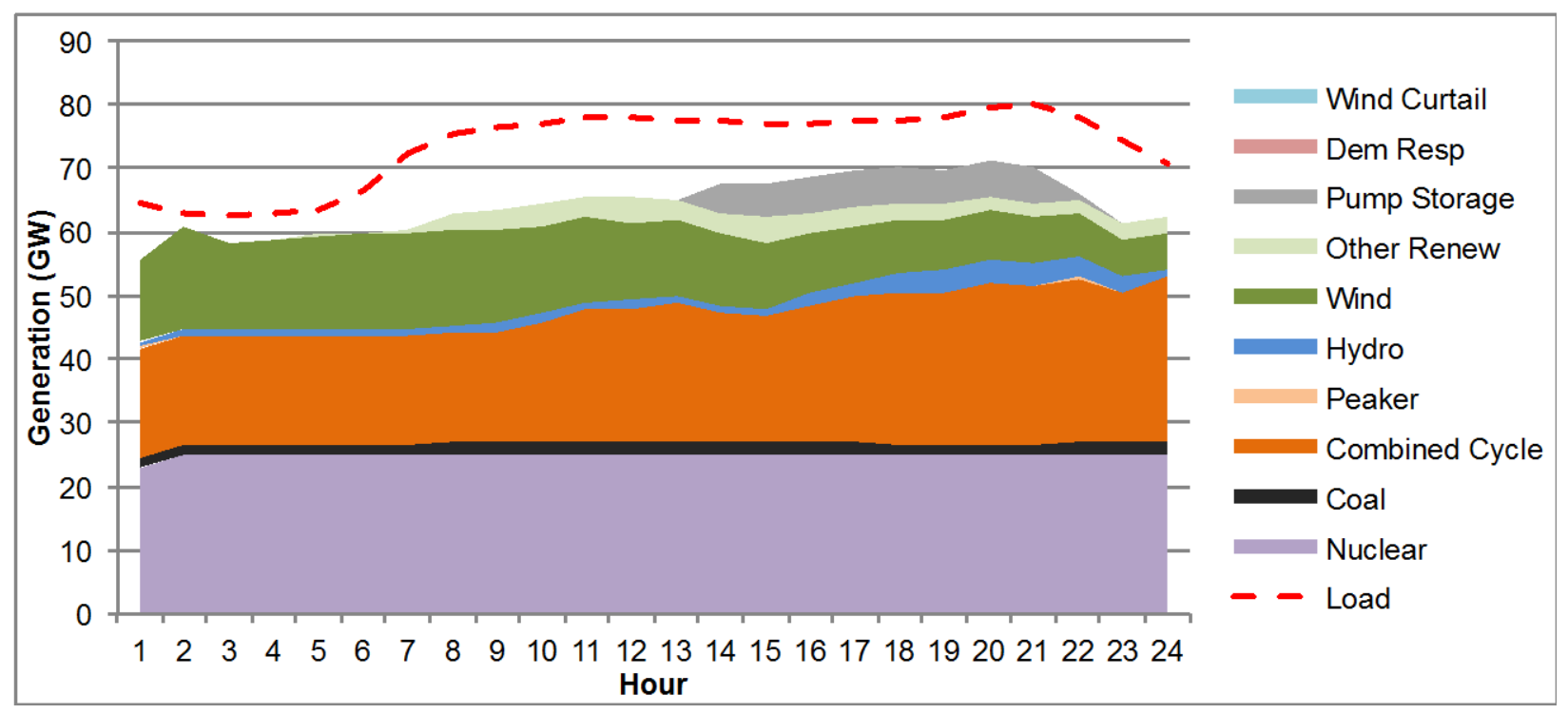

Fig. 8. Generation and loads for PJM regions on April 1 in the $\mathrm{CO}_{2}+$ scenario.

A further bit of information about the state of the grid at any point in time is the locational marginal prices for the different balancing areas (BAs). CRA reports the hourly prices for 154 different BAs across the EI. These have been mapped to the general location of the areas, although some BAs cover overlapping regions and have their headquarters near each other. Plotting the points and color-coding based on the price shows the span of prices across the EI for the April 1 case (Fig. 9). Most areas have prices at or below $\$ 10 / \mathrm{MWh}$, with some areas even below zero. As all coal and CC plants have variable costs higher than this price, they must be operating at a loss on energy sales and operating because either they are needed for operating reserves or because they will be needed later in the day. (The location in North Dakota with a high spot price appears to be the result of a localized transmission issue resulting in a load pocket.) Sure enough, by 10 a.m. prices have risen across most of the EI to around \$60/MWh. 


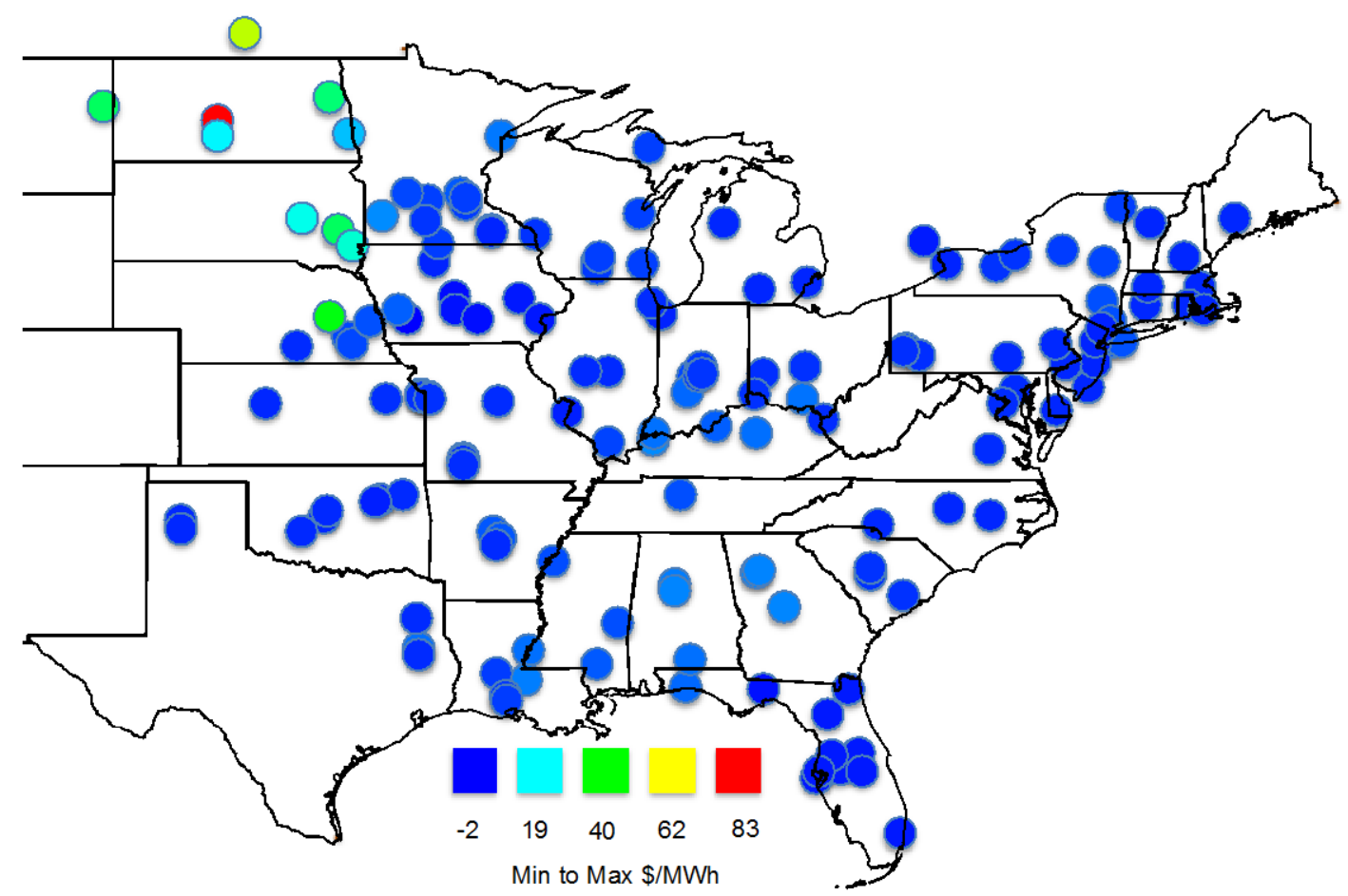

Fig. 9. Locational marginal prices for balancing areas across the EI on April 1 at 4:00 a.m. for the $\mathrm{CO}_{2}+$ scenario.

\subsection{EFFECT OF REDUCED SPIN REQUIREMENTS AND FLEXIBLE COMBINED CYCLE}

Another means to examine the question is to evaluate the results from the Hi Spin sensitivity. As mentioned previously, spin requirements were lowered for several regions, while ramp rates (and consequent reserves supply) were increased for several technologies, and the minimum up and down times for these technologies were also reduced. These changes all combined to significantly reduce the curtailments in many of the hours of study. Production levels on April 1 are significantly different for both the curtailed regions and PJM, as shown in Fig. 10 and Fig. 11. Comparing these to Fig. 6 and Fig. 8 reveals a much lower level of curtailment in the curtailed regions and a greatly reduced level of CC production in PJM in the early hours of the day. Clearly the spin requirements and/or minimum up/down times in the base case played a role in the level of curtailments. This is further revealed in the tie line flows for 4 a.m. across the EI (Fig. 12). The HVDC lines become almost fully loaded and large amounts of power are transferred from MISO W, NE, and SPP N through SPP S to ENT, TVA, and SOCO (as compared to the $\mathrm{CO}_{2}+$ case in Fig. 7.) 


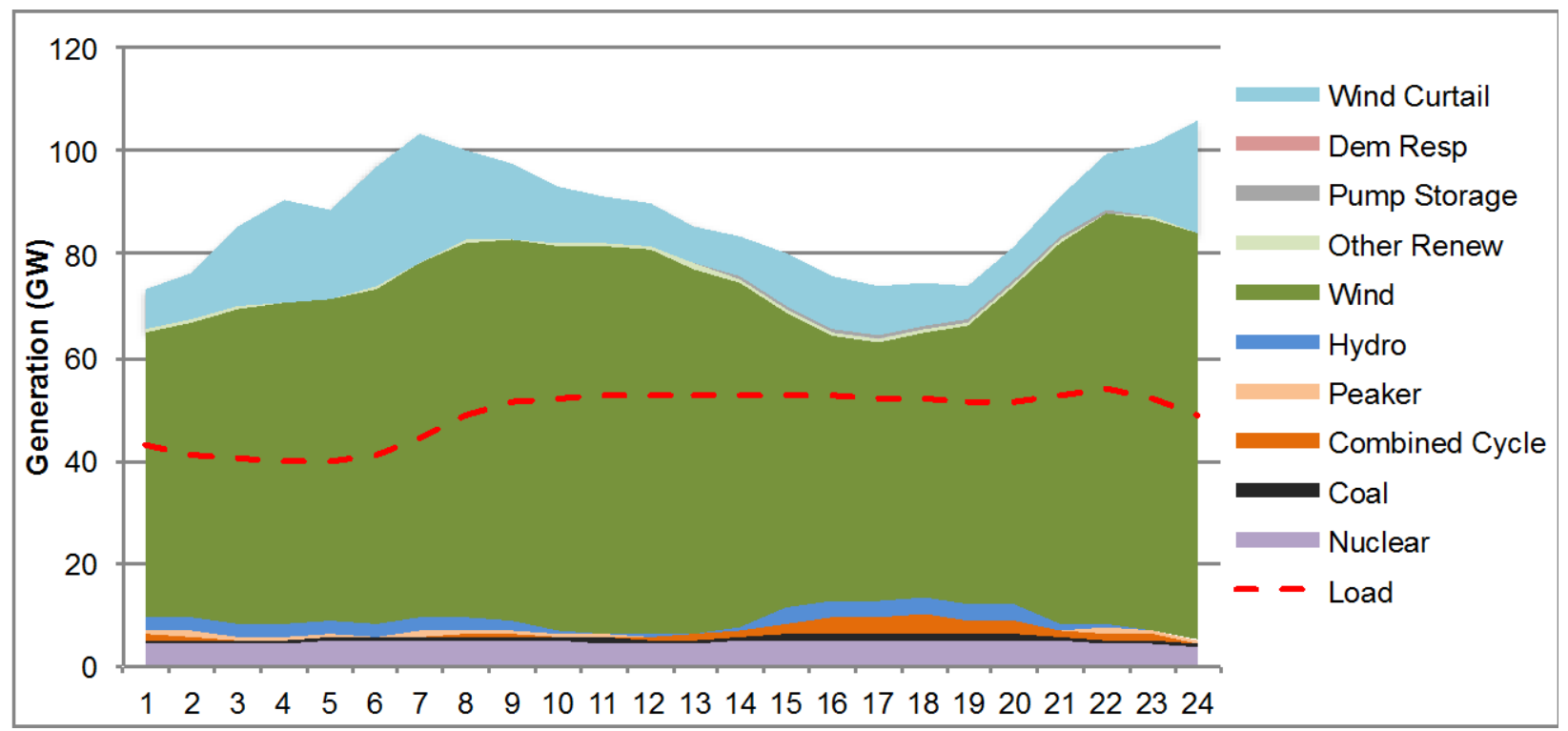

Fig. 10. Generation on April 1 in the curtailed regions in the Hi Spin sensitivity.

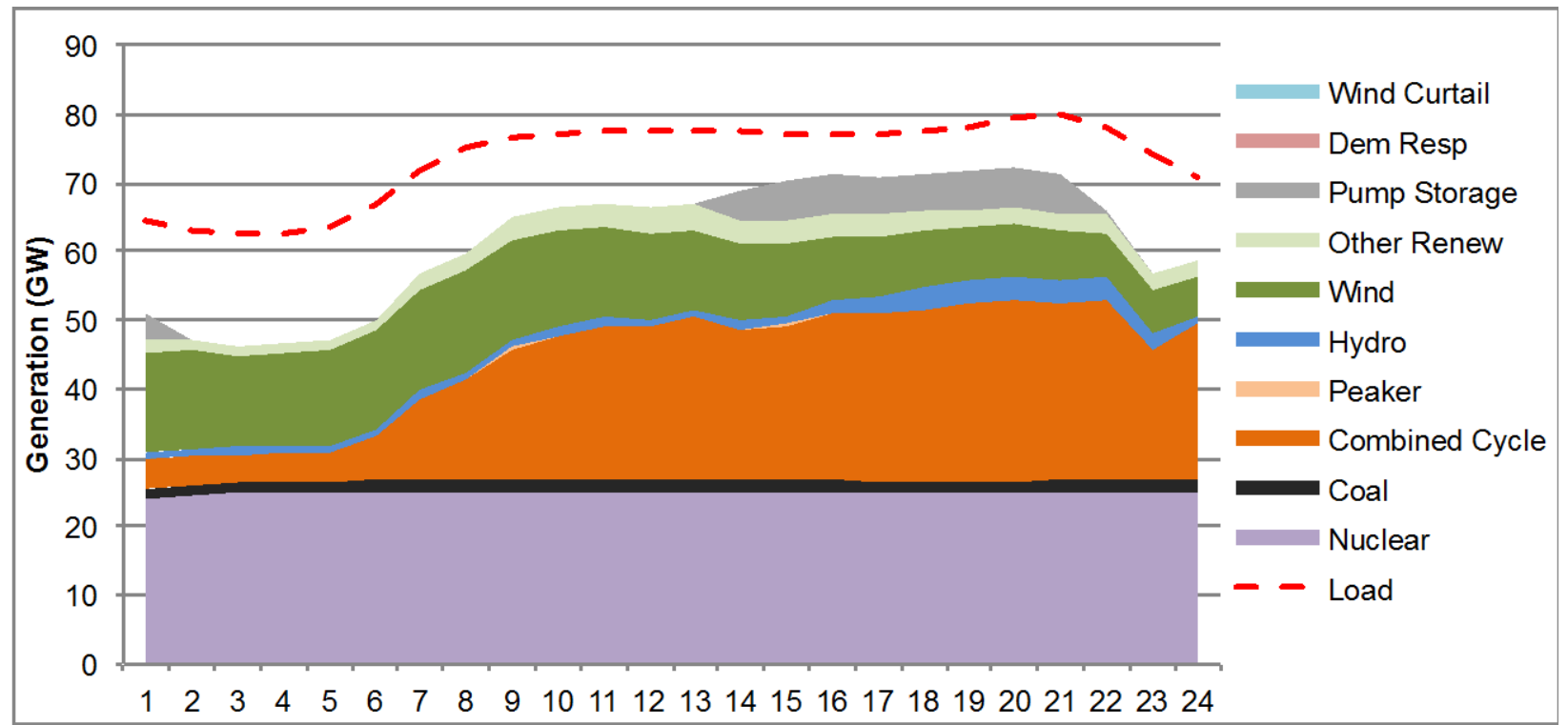

Fig. 11. Generation on April 1 in PJM in the Hi Spin sensitivity. 


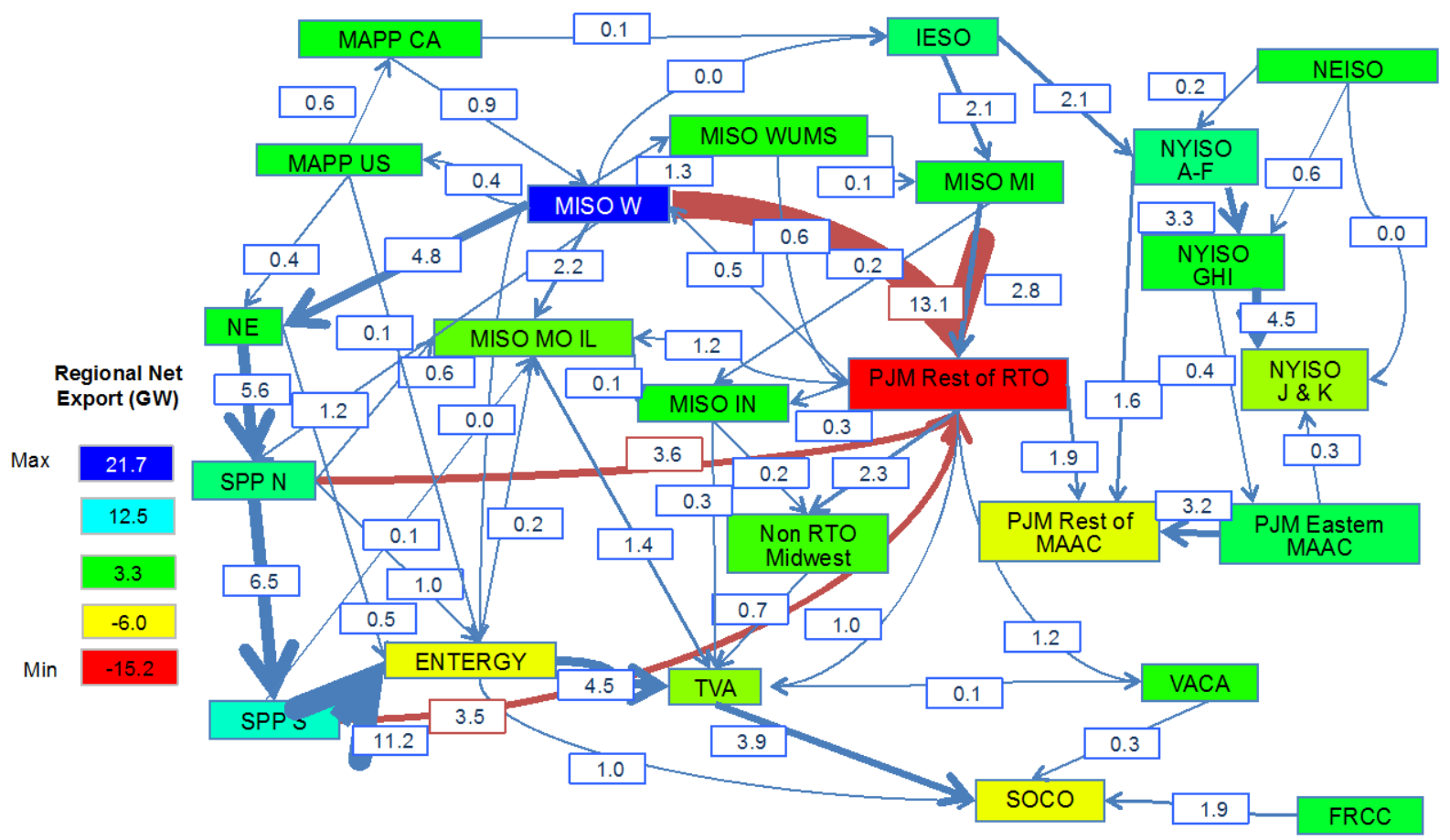

Fig. 12. Tie line flows on April 1 at 4:00 a.m. in the Hi Spin sensitivity.

While spinning reserve requirements and generating plant parameters had some effect on the amount of curtailment, relaxing those requirements still left most of the curtailments. The total curtailments dropped just 9\% from 131 TWh in $\mathrm{CO}_{2}+$ to 120 TWh in the Hi Spin sensitivity. MISO W curtailments for the whole year dropped just 5\%, from 65 TWh to 62 TWh. Spinning reserve requirements do not seem to account for all wind curtailments. We next examined tie line loading to determine whether those constraints may have resulted in additional curtailment.

\subsection{CURTAILMENTS VERSUS TIE LINE CAPACITY}

It is possible that wind is curtailed because there is not enough transmission capacity to transport it to where it is needed. If the curtailments occurred due to tie lines being fully loaded, then most curtailment should occur during high tie line activity. We summed the hourly net tie line flows out of the five curtailed regions for which we calculated the curtailments by hour. We then compared that to the amount of curtailment in these five regions combined. In the $\mathrm{CO}_{2}+$ scenario there is a general peak tie line flow out of the curtailed regions of around $40 \mathrm{GW}$ (Fig. 13). The highest curtailments typically occurred when the tie lines were at this power level, which indicates that curtailments could probably have been reduced with increasing tie line capacity. 


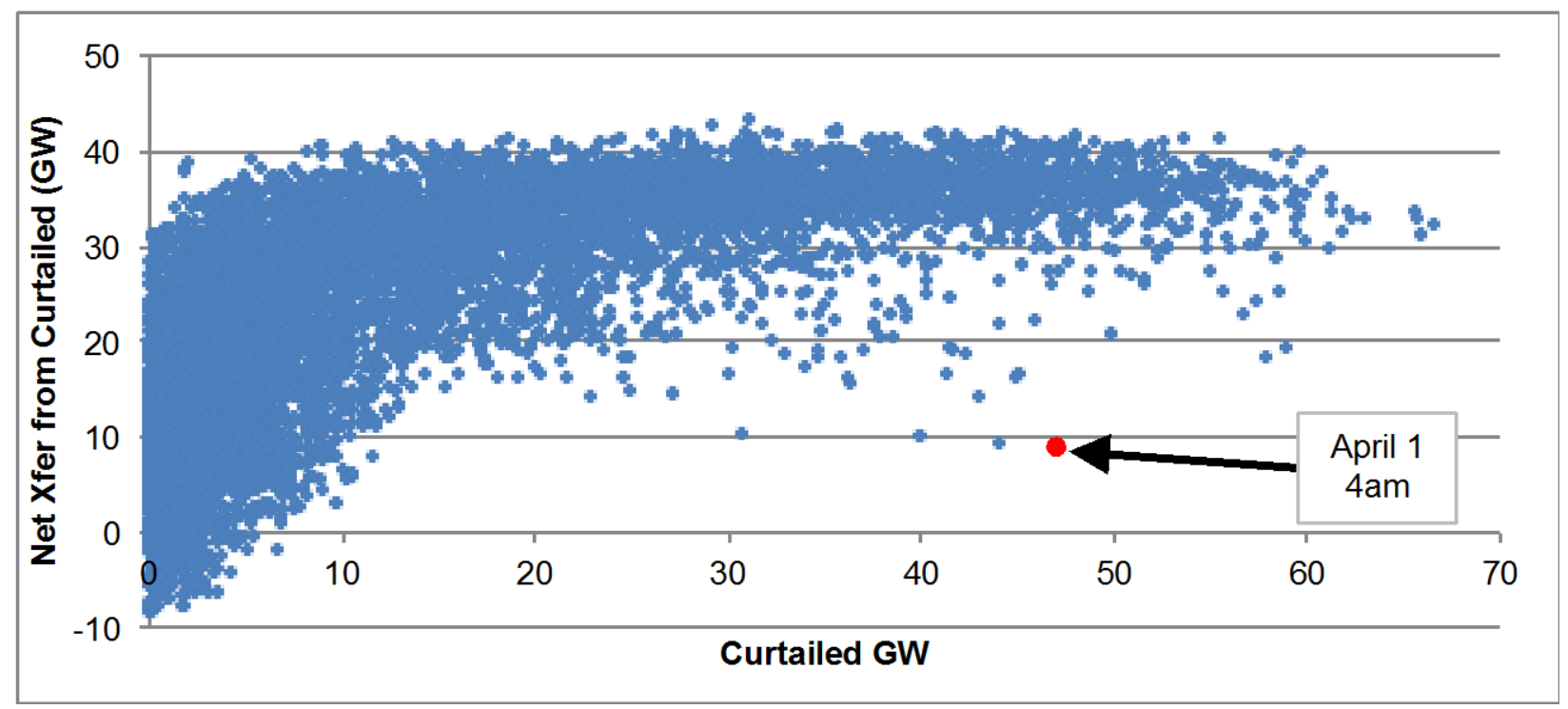

Fig. 13. Net transfer vs. curtailment in the curtailed regions for the $\mathrm{CO}_{2}+$ scenario.

This is even more apparent when comparing the Hi-Spin sensitivity (Fig. 14). Many of the points with high curtailments but low tie line flows either increase their flow, reduce their curtailment, or both. Examples include the April 1 4:00 a.m. example, with curtailments and transfers for the two cases shown in Table 11. In those hours affected by the changes in reserve requirements and plant capabilities, the tie lines were more heavily used and the curtailment amounts went down because the power was used in the other regions.

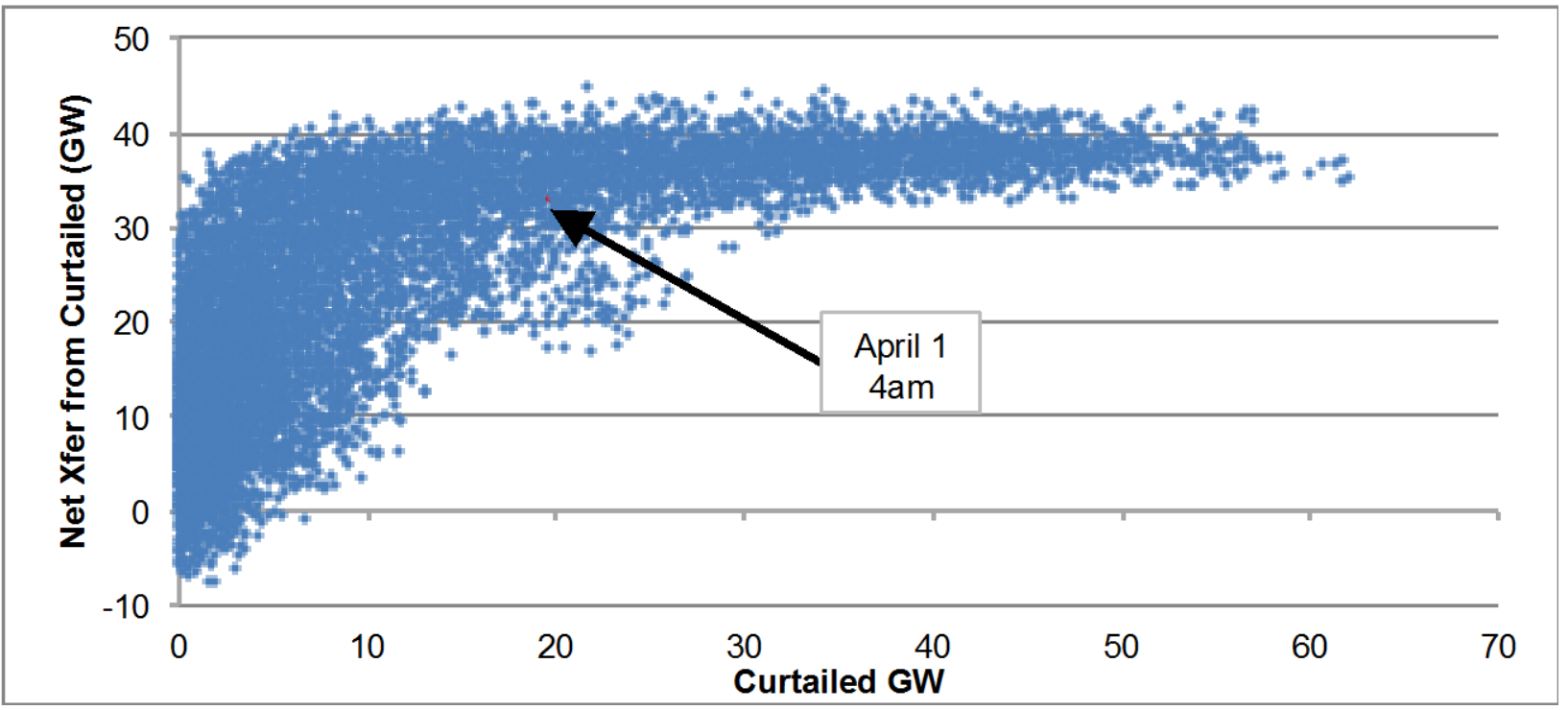

Fig. 14. Net transfer vs. curtailment in the curtailed regions for the Hi Spin sensitivity.

Table 11. Curtailments and Net Transfers April 1 at 4:00 a.m. for curtailed regions

\begin{tabular}{|lcc|}
\hline $\mathrm{CO}_{2}+$ Scenario & Curtailments & Transfers \\
\hline $\mathrm{Hi}$ Spin Scenario & $47.0 \mathrm{GW}$ & $8.9 \mathrm{GW}$ \\
\hline
\end{tabular}


More than half the hours have curtailments below $10 \mathrm{GW}$ in the five regions studied and over $70 \%$ of the time curtailments are below $20 \mathrm{GW}$. Fig. 15 is a histogram showing the fraction of the year for different ranges of curtailment levels. There is a slight difference between the $\mathrm{CO}_{2}+$ scenario and the $\mathrm{HI}$ Spin sensitivity, reflecting the shift to lower curtailment amounts with the Hi Spin changes in reserves requirements and plant capabilities.

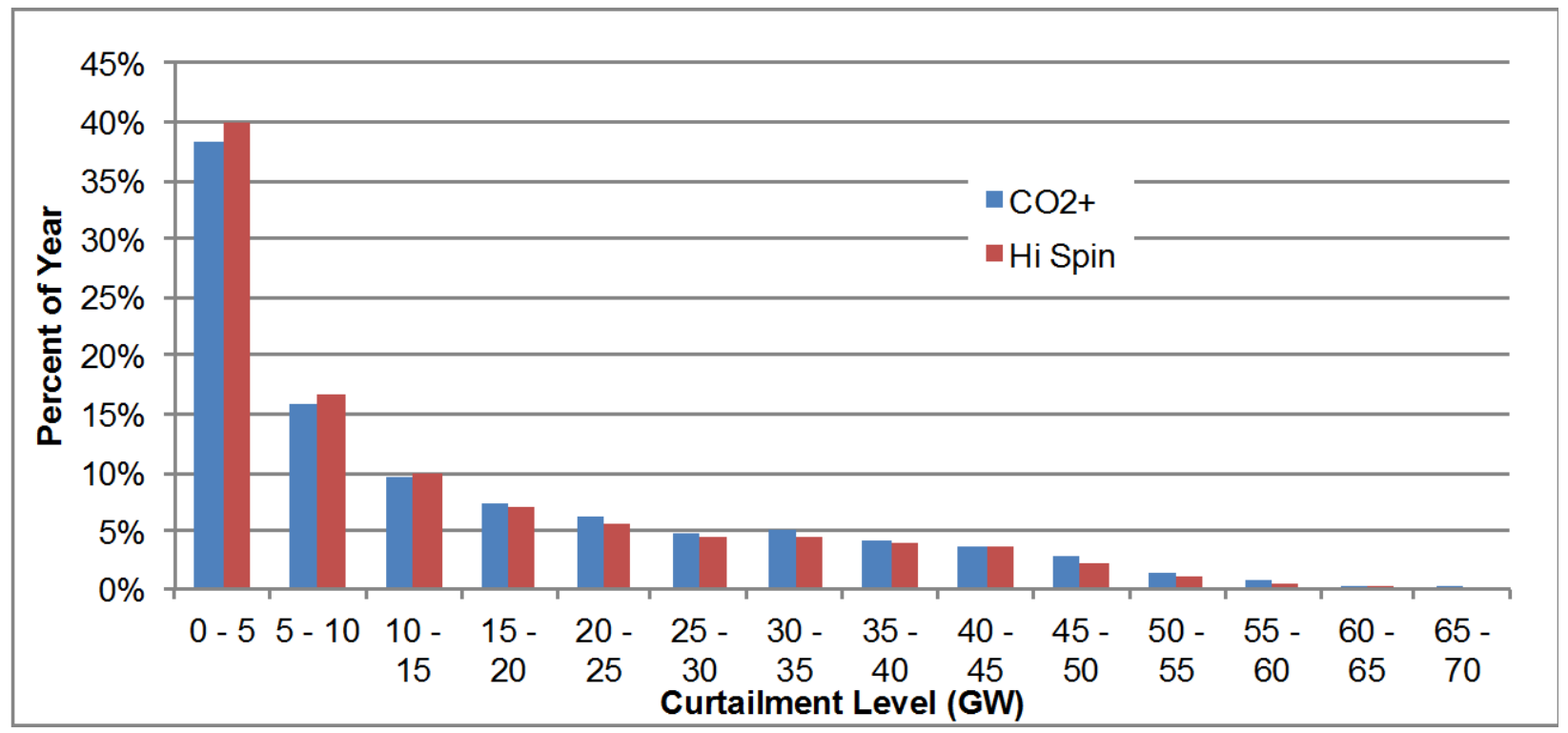

Fig. 15. Percent of year that curtailments in curtailed regions were at different levels.

The amount of curtailments that could be resolved through tie line improvements is unknown. The $\mathrm{CO}_{2}+$ scenario included $21 \mathrm{GW}$ of additional HVDC lines (plus a large amount of conventional transmission). As there were still some hours with more than $60 \mathrm{GW}$ of curtailment, adding 4 times as much HVDC capacity as in that scenario might eliminate most but still not all curtailments. Also, their construction would be quite difficult and placement would likely require significant upgrades in supporting infrastructure. The economic rationale for expansion of the grid, which must balance a large number of factors, is thus more complicated than just meeting reliability criteria during peak times (the method used in the EIPC study) or eliminating all wind curtailments.

An examination of the hourly curtailments in the Hi Spin sensitivity reveals that the periods with high levels of curtailments also have high levels of tie line transfers out of the curtailed regions. Fig. 16 shows the curtailments in the curtailed region (MISO W, MISO MO-IL, SPP N, SPP S, and NE) and the net transfer from the curtailed regions to other areas for each hour, the same as Fig. 14. The vertical red line represents the median hourly wind curtailment (7,712 MW). Thus, half of the hourly curtailments lie to the left of the line (lower than the median) and the other half lie to the right of the line (greater than the median). The horizontal red line represents the median hourly net transfer (27,174 MW) from the curtailed region. These lines divide the graph into four quadrants, described in Table 12.

If the two sets of data are independent, roughly the same number of points will lie in each quadrant. If quadrants I and III are overrepresented, the sets of data tend to be correlated. In this case, there are $3,690 \mathrm{~h}$ in each of quadrants I and III and $690 \mathrm{~h}$ in each of II and IV. This means that $42 \%$ of the time both transfers and curtailments are higher than the median, $42 \%$ of the time they are both lower than the median, and $8 \%$ for each of the other two possibilities. In general, this indicates that high levels of wind curtailments occur when net transfers are high and low levels of curtailments happen when net transfers are low. 


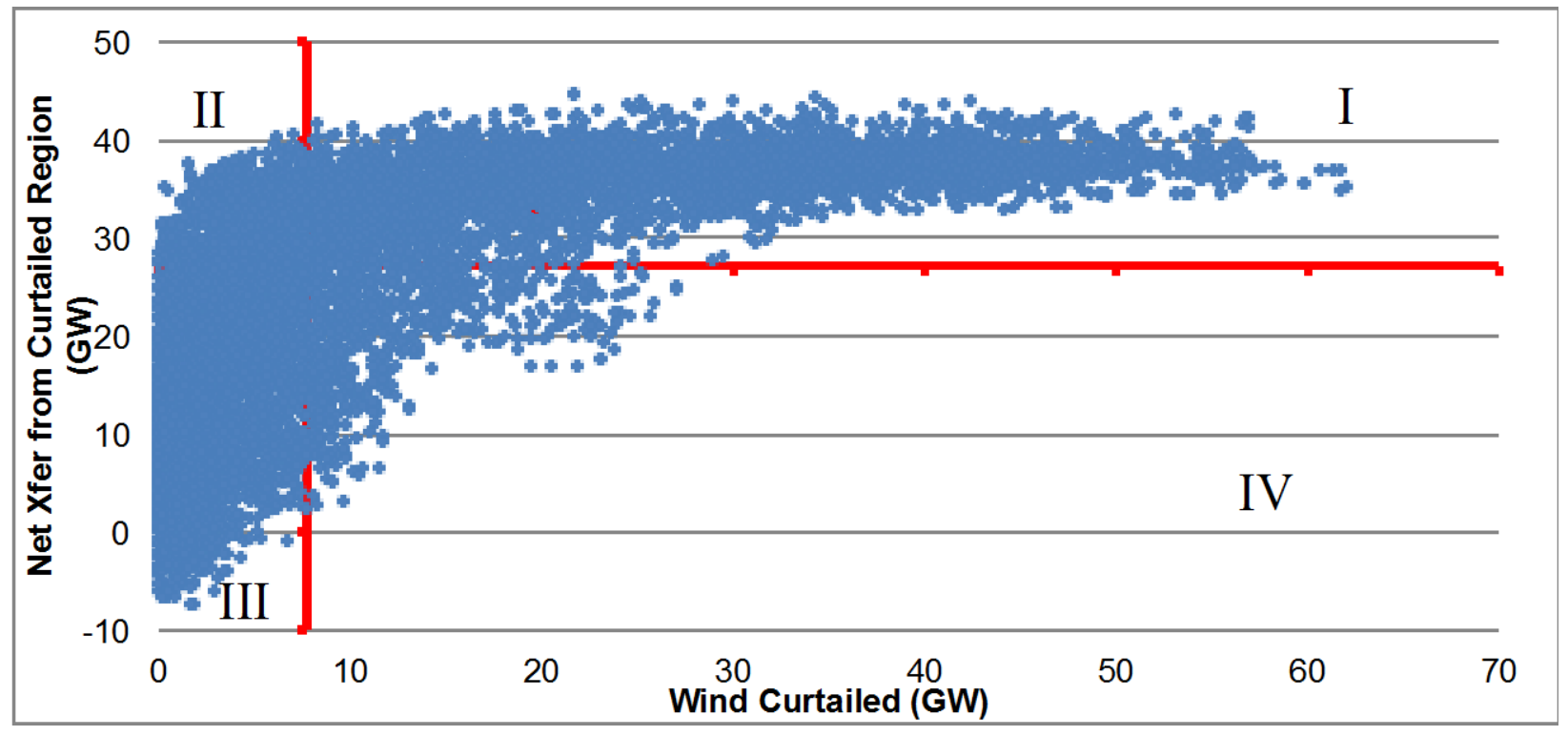

Fig. 16. Net transfer vs. wind curtailment in the curtailed regions in the Hi Spin sensitivity.

Table 12. Curtailment and Transfer Quadrants for the Hi Spin Sensitivity

\begin{tabular}{|ccccc|}
\hline Region & Transfers & Curtailments & Hours & \multicolumn{2}{c|}{ Curtail TWh } \\
\hline I & $>$ Median & $>$ Median & 3,690 & 96.5 \\
\hline II & $>$ Median & $<$ Median & 690 & 3.1 \\
\hline III & $<$ Median & $<$ Median & 3,690 & 9.4 \\
\hline IV & $<$ Median & $>$ Median & 690 & 8.5 \\
\hline
\end{tabular}

Looking further out toward the extremes, there are 1,390 hours where curtailments exceed $30 \mathrm{GW}$. Of those, only two occur in hours with less than $30 \mathrm{GW}$ of transfers, and neither of those occurs when transfers are lower than the median. Thus, once we account for the hours where large amounts of curtailments result from spinning reserve requirements by adjusting the spinning reserve requirements and generator characteristics in the Hi Spin sensitivity, the high curtailments occur during hours with high transfers. This indicates that transfer limitations are a major factor.

A final point is that the vast majority of curtailed energy occurs in Quadrant I (last column in Table 12), when both curtailments and transfers are above the median. More than 96 TWh of curtailment from these five regions occurred in Quadrant I in the Hi Spin sensitivity. In the $\mathrm{CO}_{2}+$ scenario, Quadrant I contained more than 101 TWh. The Hi Spin sensitivity only reduced curtailment by 9 TWh overall, so compared to spinning reserve requirements, the dominant reason for the curtailments was the transfer limitations.

\subsection{MISO MO-IL SUPPLY POCKET}

There still remain a number of hours in the Hi Spin sensitivity when net transfers are well below the peak amount but curtailments arise. These can occur when there are local pockets of congestion within a region. Wind power is available but blocked behind a bus with inadequate capacity, even though there is capacity available on one of the outbound tie lines. This occurred in the MISO MO-IL region (as well as the VACAR and MAPP US regions) a significant percent of the time.

Fig. 17 is a map of the locational marginal prices at the different BAs on April 1 at 10:00 a.m. in the $\mathrm{CO}_{2}+$ scenario. The price in the Ameren Corporation control area, located in southwestern Illinois, is 
\$125/MWh (the highest in the EI), while in the neighboring Columbia Water and Light area (Columbia, Missouri), the price is only $\$ 1 / \mathrm{MWh}$ (the lowest in the EI) in that hour.

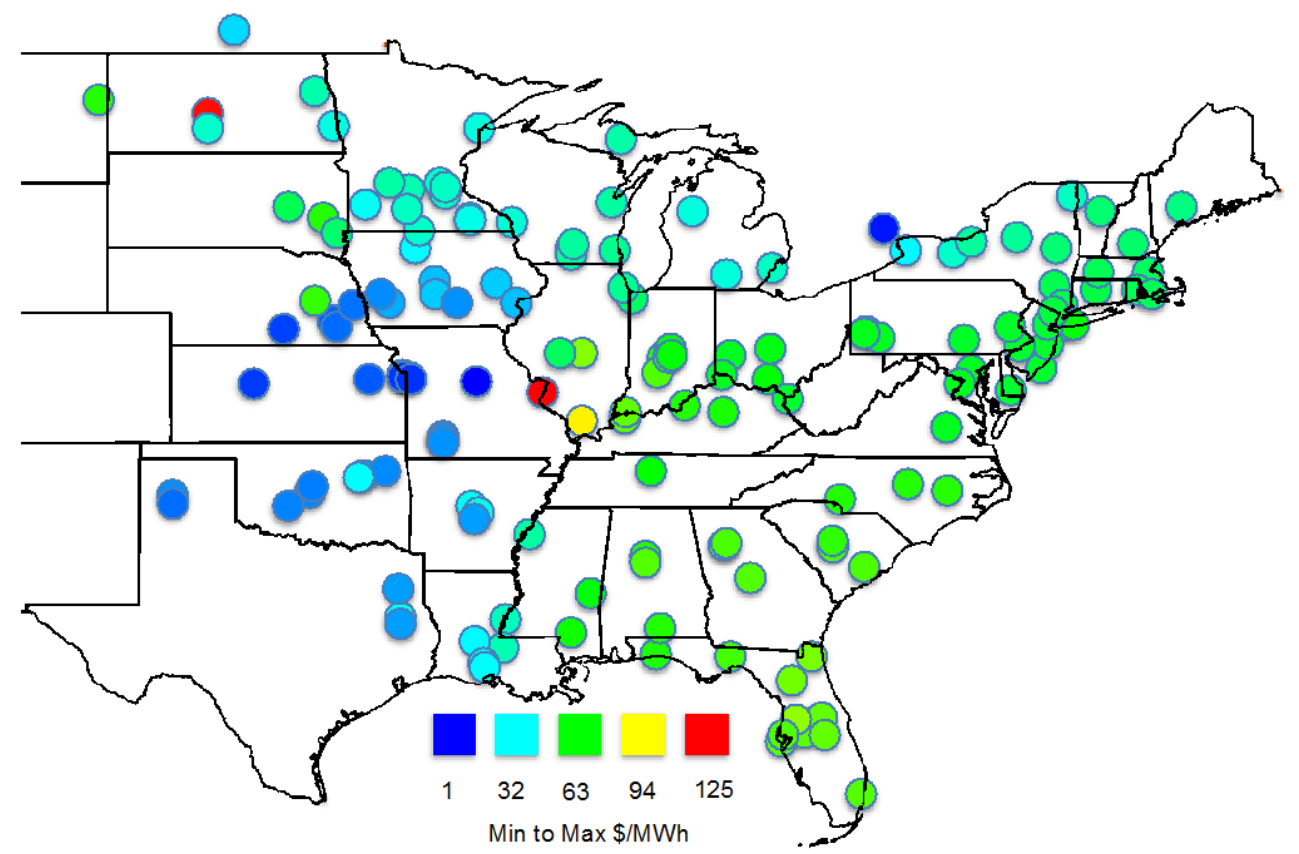

Fig. 17. Locational marginal prices on April 1 at 10:00 a.m. in the $\mathrm{CO}_{2}+$ scenario.

Wind was curtailed in MISO MO-IL throughout the morning in this scenario, even though MISO MO-IL had to import significant amounts of power after 7:00 a.m. (Fig. 18). Meanwhile, some "peaker" capacity had to be run, especially in the late evening. This indicates that some regions within MISO MO-IL could not access the available power in other parts of the region.

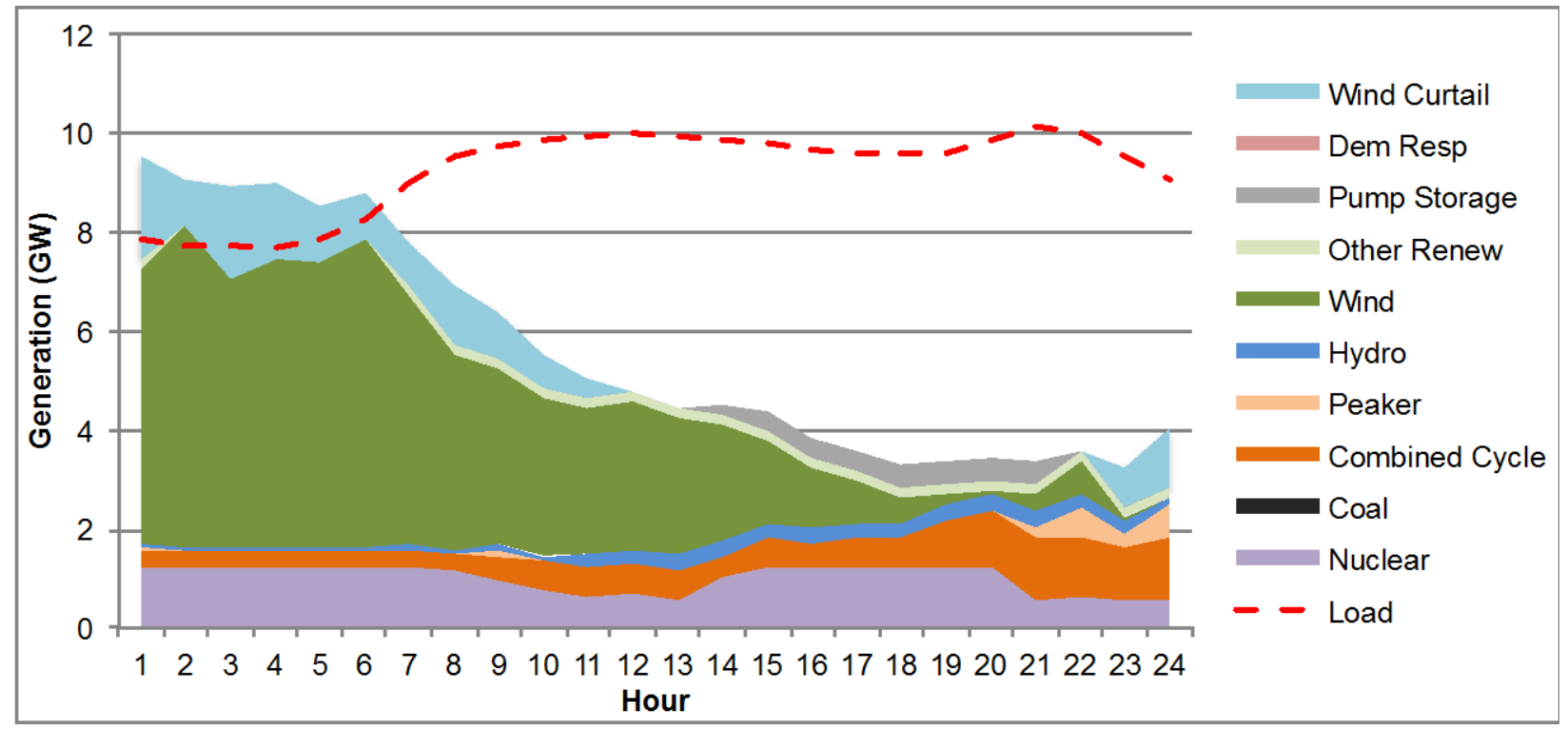

Fig. 18. MISO MO-IL generation and load on April 1 in the $\mathrm{CO}_{2}+$ scenario.

Discussions with EIPC and examination of the transmission build-out revealed that a significant wind farm (4,000 MW) had been added to the grid in northeast Missouri. Shadow prices between flowgates 
from GE MAPS show a frequent difference in price between certain buses west of St. Louis. Likely, this bus or tie line should have been upgraded to open up the curtailed wind to the Ameren control area but was not caught during the first part of Phase 2. It would require further analysis in the PSS/E model to determine appropriate changes and possible consequent changes to other infrastructure.

\subsection{CONCLUSIONS}

The high levels of wind curtailments in Phase 2 occurred because the GE MAPS model was unable to use all of the available wind during a number of hours of the year. The factors driving this inability differed depending on the hour and region being examined. During certain hours, such as the morning of April 1, operating reserve requirements outside of the curtailed region limited the ability to export power even though tie line capacity was not being fully used. During other periods, tie line capacity was not sufficient to move the available power to other regions. Finally, local transmission congestion such as within the MISO MO-IL region created a generation pocket from which wind generation could not get out to the rest of the system.

\section{TOPIC 8: DEMAND RESPONSE}

\subsection{DEMAND RESPONSE IN PHASE 1}

DR is a complex collection of programs and technologies that let demand respond to supply, mainly through reduction of demand in the face of supply shortages. The Federal Energy Regulatory Commission (FERC) defines DR as "the changes in electric usage by demand-side resources from their normal consumption patterns in response to changes in the price of electricity over time, or to incentive payments designed to induce lower electricity use at times of high wholesale market prices or when system reliability is jeopardized” (FERC 2009). Different DR programs can be automated or not, controlled by the utility or customer, involve direct price incentives or appeals, and apply to different demand sectors. Several studies on DR in the EI were commissioned during the EIPC process. ${ }^{*}$ The following are two notable ones.

- Baek, Young Sun, et al. Eastern Interconnection Demand Response Potential. ORNL/TM2012/303. Oak Ridge, TN: Oak Ridge National Laboratory, November 2012.

- Navigant, Assessment of Demand-Side Resources within the Eastern Interconnection, prepared for the Eastern Interconnection States’ Planning Council, March 2013.

In June 2009, FERC released a study on DR, A National Assessment of Demand Response Potential, or NADR (FERC 2009). For the EIPC study, the amount of DR for each region was calculated using the state-by-state projections of DR from the FERC NADR model. The model projects both future DR and future peak demand through 2019 for four different scenarios: BAU, expanded BAU, achievable amounts, and full participation. The state-weighted average ratio of DR to peak demand was found for each NEEM region in the study.

For most of the futures in Phase 1, the SSC decided that the percentage of demand that DR could supply would transition from the percentages of demand in the FERC BAU scenario in 2015 to that of the FERC Expanded BAU by 2025 and then continue with those percentages to the end of the period. For the aggressive DR Future 4, the SSC transitioned from the BAU percentages in 2015 to the full participation

\footnotetext{
${ }^{*}$ A similar study (Satchwell et al., 2013) was conducted for the Western Interconnection.
} 
percentages by 2025 and then continued those percentages to the end. Some utilities treat DR as an alternative supply (where $1 \mathrm{MW}$ of DR equals $1 \mathrm{MW}$ of supply) and some as a reduction in demand (where $1 \mathrm{MW}$ of DR reduces demand by $1 \mathrm{MW}$, and so for calculation of the reserve requirement the DR is equal to its capacity times 1 plus the reserve margin). To approximate the variations between regions, the SSC multiplied the DR capacity by one plus half of the required reserve margin for each region.

The calculations fixed the amount of DR capacity that would be added within each region rather than allowing NEEM to select how much DR capacity to build. However, the model could choose to call upon, or dispatch, this power. Within NEEM, CRA modeled DR as a forced-in pseudo-generator with no fixed cost but a high energy cost (and consequent price for dispatch decisions) so that it would only be used when most or all other supplies were deployed. In Phase I of the modeling, the original amount of potential DR from NADR was calculated based on NADR's default ratio of critical peak price (CPP) to average price of 8 . With the default ratio of CPP to average price and a rough estimate of average retail electricity price, the average price of dispatching DR was set at \$750/MWh. This estimated DR price was applied to all DR supplies in the dispatch process of NEEM. However, in Phase 1 very little DR was dispatched, just $39 \mathrm{GWh}$ in the VACAR and $24 \mathrm{GWh}$ in the FRCC in the $\mathrm{CO}_{2}+$ scenario and none in the other regions or scenarios. Even so, DR served to reduce the capacity requirements from other resources for all regions because it could be applied in the reserve margin calculations.

\subsection{DEMAND RESPONSE SUPPLY CURVE FOR PHASE 2}

The modeling in Phase 2 allowed a more detailed approach but still treated DR as pseudo-generators within each region. Instead of a single price, there could be up to six supply amounts, each at a different price point. Still, as with NEEM, the GE MAPS model did not limit DR to a maximum number of hours per year or total amount of generation over the year, so the modeling had to use price as a lever to get DR to be dispatched semi-realistically. A more realistic DR supply curve was needed than the single tier at \$750/MWh. Therefore, a tiered pricing arrangement or supply curve for DR was calculated, with six different DR price tiers, but still with an average price for DR of \$ 750/MWh to match the Phase 1 assumption.

ORNL researchers who conducted the DR study created a national stepwise DR supply curve for 2030 based on the ORNL version of the FERC NADR model (ORNL NADR). Under the full deployment scenario of the ORNL NADR, 30 different cases with a variation of CPP ranging from \$50/MWh to $\$ 1,500 /$ MWh were run to see how system peak load would respond to changes in CPP (Fig. 19).

Fig. 20 shows three supply curves for comparison: a supply curve for pricing-related full DR deployment, the five-tier step function of the same supply curve, and the supply curve used in NEEM for Phase 1 . The NEEM curve from Phase 1 was driven based on the FERC 2009 NADR results and shows the maximum DR available in 2030 would be 209 GW.

Actual DR would have a mixture of programs that dispatchers could call upon. Some programs have no specific price but have time or frequency limits. Some allow customers to vary their response at different price points. In addition, the variation in CPP addresses only the impact from pricing programs (Fig. 19 and Fig. 20). To reflect such DR supply from nonpricing programs, ORNL researchers chose to allocate the nonpricing DR amount into each tier proportionally (Fig. 21). Seventy percent of the peak load reductions (PLR) that came from nonpricing DR was distributed into the first five price tiers, and the remaining $30 \%$ of PLR was allocated to a new sixth price tier. The price for this last tier was set so that the weighted average of DR price stayed at \$750/MWh to maintain consistency with Phase 1. 


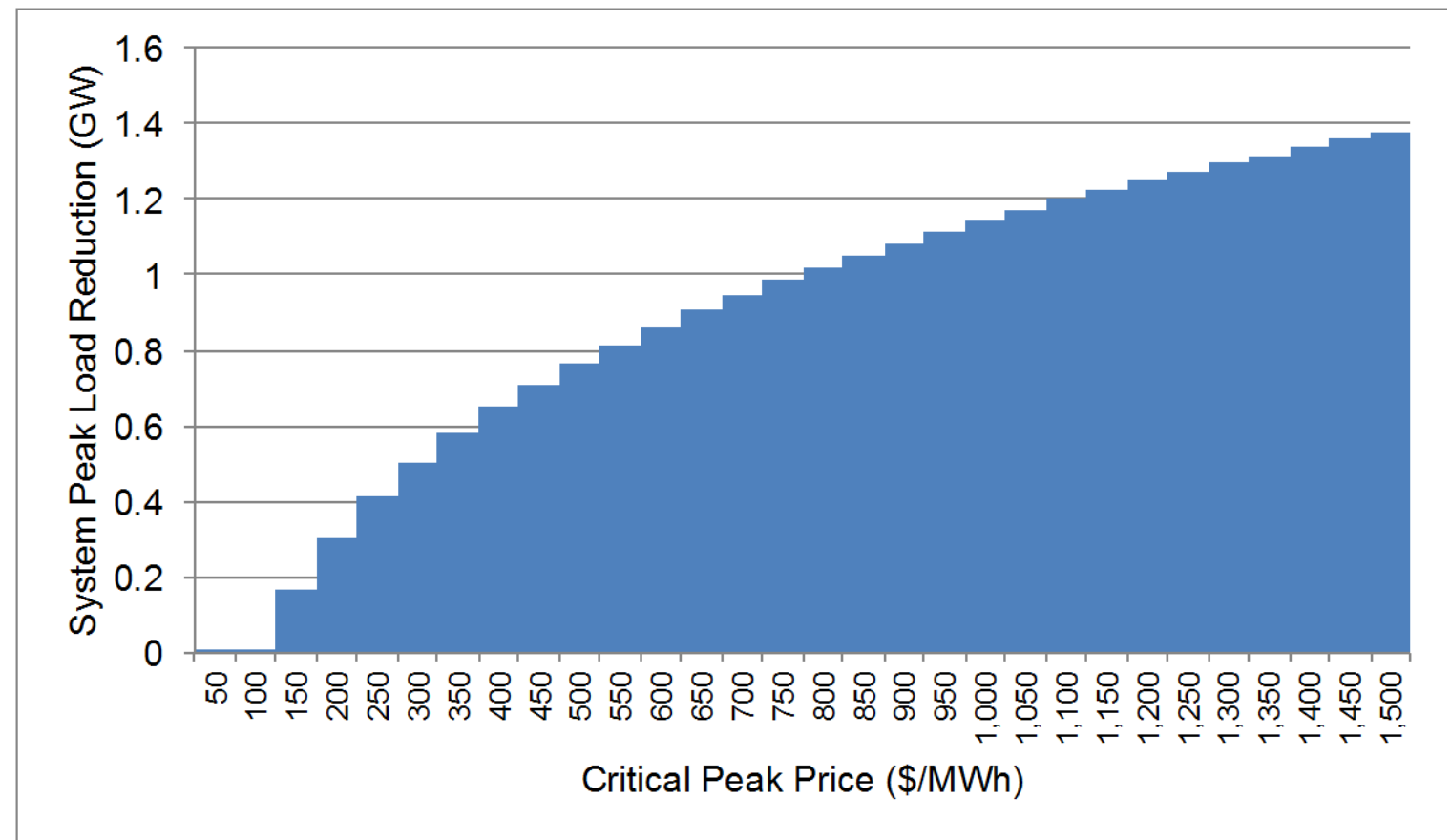

Fig. 19. ORNL NADR runs with variation in critical peak price.

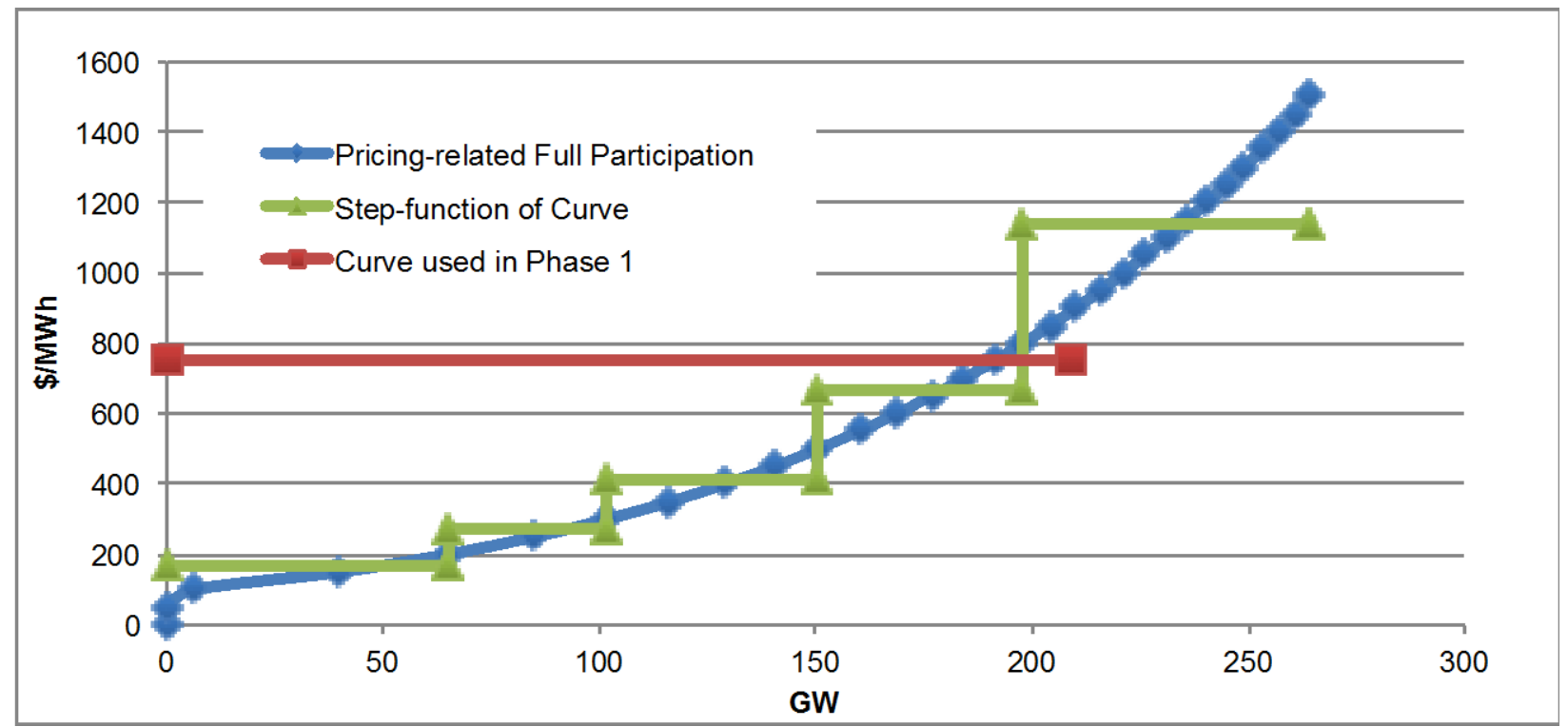

Fig. 20. Supply curve for pricing-related DR programs in 2030. Five-tier approximation and Phase 1 single tier curve also shown.

The lowest tier size was picked so that its average price would be in the neighborhood of the cost of a CT. The lowest cost tier of 22\% of maximum DR available in any region could be supplied at the first price tier of \$165/MWh, roughly between the efficient and inefficient CT costs, as shown in Fig. 21. This amount of DR could possibly replace CTs in the dispatch process. The last price tier represents exceptionally expensive DR options such as rotational blackouts that involve high societal costs but are not included in the typical DR program categories. 


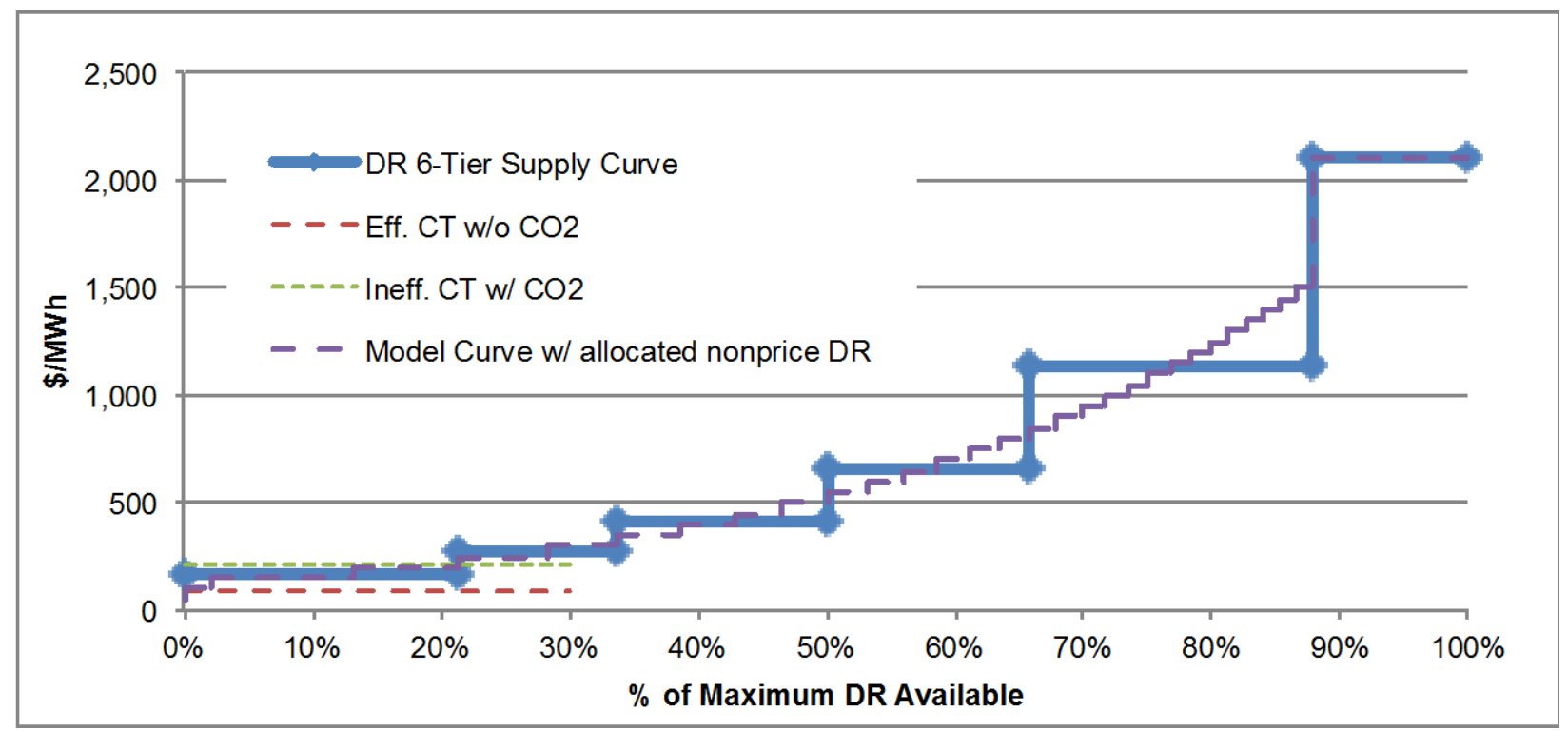

Fig. 21. Six-tier supply curve and model curve with allocated nonprice DR in 2030 for Phase 2.

The resulting six tiers with both their price and the fraction of total DR within each region, as used in the EIPC Phase 2 study, are shown in Table 13. Each region's total DR potential for the scenario in question was multiplied by the fractions from the table and priced at the amount shown. This simplified the supply curve for modeling each region's DR amounts for the purpose of the analysis.

Table 13. Demand Response Supply Curve as Proportion of Total DR Available in Regions for EIPC Study

\begin{tabular}{|cccc|}
\hline Tier & $\begin{array}{c}\text { Price } \\
\text { \$MWh }\end{array}$ & \multicolumn{2}{c|}{ Percent of Total Capacity } \\
& Incremental & 22 \\
\hline $\mathbf{1}$ & 165 & 22 & 34 \\
\hline $\mathbf{2}$ & 273 & 12 & 50 \\
\hline $\mathbf{3}$ & 418 & 16 & 66 \\
\hline $\mathbf{4}$ & 665 & 16 & 88 \\
\hline $\mathbf{5}$ & 1,142 & 22 & 100 \\
\hline $\mathbf{6}$ & 2,100 & 12 & \\
\hline
\end{tabular}

\subsection{DEMAND RESPONSE DISPATCHED IN PHASE 2}

As shown in Fig. 2, many of the regions rely on DR to supply some amount of capacity to meet $100 \%$ of their peak demand. This is also shown for the $\mathrm{CO}_{2}+$ scenario in Fig. 22 for all of the NEEM regions individually. The wind and solar capacities are split between the fraction that counts toward the reserve margin and the uncredited capacities that do not contribute to the reserve margin. The red lines show the peak demand for the year in specific regions for the $\mathrm{CO}_{2}+$ scenario. DR equals a significant fraction of the supply as shown in Table 14 (between $20 \%$ and $30 \%$ in most regions).

In the BAU and RPS/R scenarios, DR generation is concentrated in the three most southeastern regions (Table 14). Overall DR capacity and generation was highest in the $\mathrm{CO}_{2}+$ scenario. All regions had at least some small amount of DR use. The most significant use is in two regions with wind power (MISO MOIL, and MAPP US) where, based on BA prices, there appeared to be some internal load pockets or generation constraints as described in the previous section. The other major area was the Southeast, with FRCC, SOCO, and especially VACAR showing high levels of DR use. These regions do not have easy 
access to significant amounts of wind power and so must rely on DR to provide power during peaking periods.

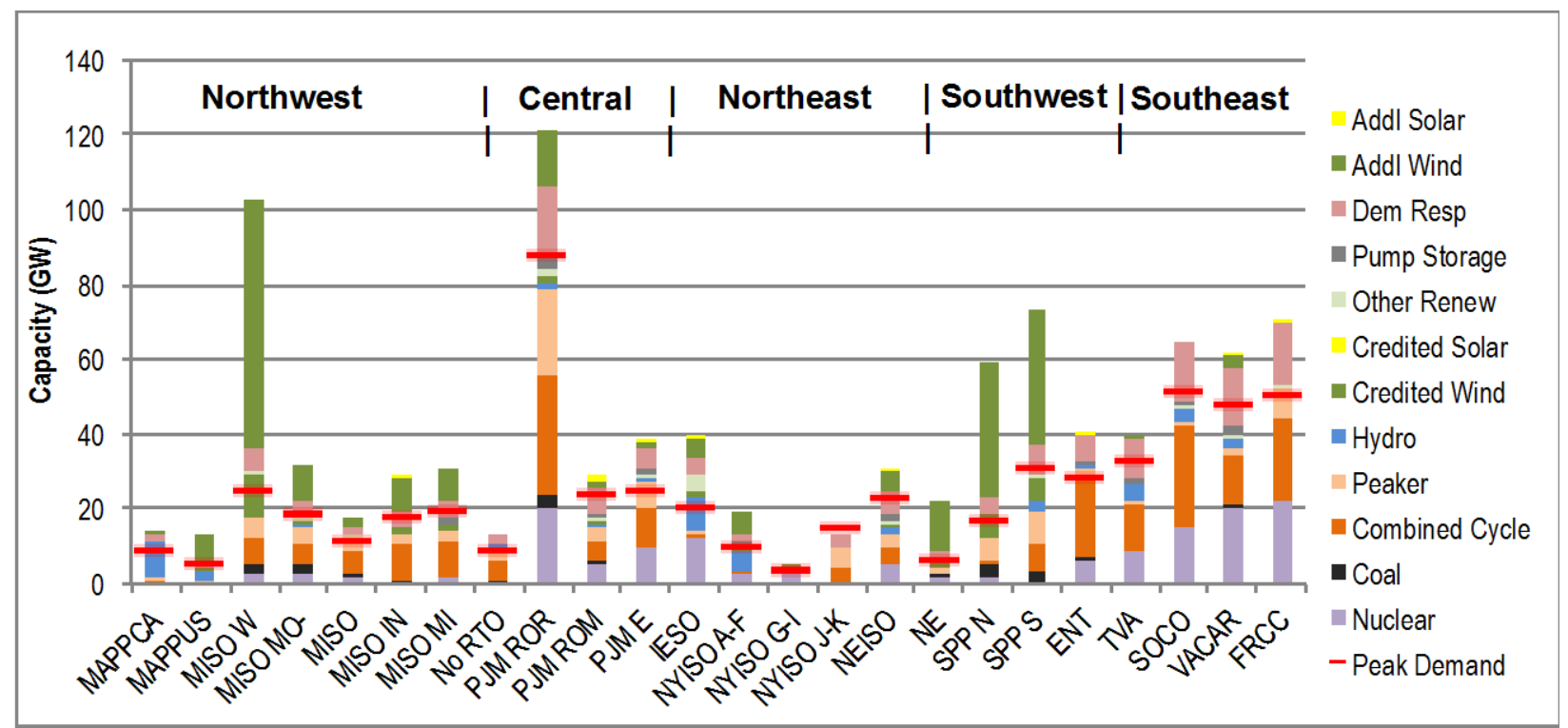

Fig. 22. Capacities and peak demand for each region for the $\mathrm{CO}_{2}+$ scenario.

Table 14. Phase 2 Demand Response Capacity (in gigawatts and percent of demand) and Generation in NEEM Regions

\begin{tabular}{|c|c|c|c|c|c|c|c|c|c|}
\hline & BAU & BAU & $\mathrm{BAU}$ & RPS/R & RPS/R & RPS/R & $\mathrm{CO}_{2}+$ & $\mathrm{CO}_{2}+$ & $\mathrm{CO}_{2}+$ \\
\hline Region & $\begin{array}{c}\text { Capac- } \\
\text { ity } \\
\text { (GW) }\end{array}$ & $\begin{array}{l}\text { Capac- } \\
\text { ity ( } \% \\
\text { Peak) }\end{array}$ & $\begin{array}{c}\text { Gener- } \\
\text { ation } \\
(\mathrm{GWh})\end{array}$ & $\begin{array}{c}\text { Capac- } \\
\text { ity } \\
\text { (GW) }\end{array}$ & $\begin{array}{l}\text { Capac- } \\
\text { ity ( } \% \\
\text { Peak) }\end{array}$ & $\begin{array}{l}\text { Gener- } \\
\text { ation } \\
\text { (GWh) }\end{array}$ & $\begin{array}{c}\text { Capac- } \\
\text { ity } \\
\text { (GW) }\end{array}$ & $\begin{array}{c}\text { Capac- } \\
\text { ity (\% } \\
\text { Peak) }\end{array}$ & $\begin{array}{c}\text { Gener- } \\
\text { ation } \\
(\mathrm{GWh})\end{array}$ \\
\hline MAPP CA & 0.6 & $6 \%$ & 1 & 0.56 & $6 \%$ & 0 & 1.49 & $18 \%$ & 26 \\
\hline MAPP US & 0.4 & $6 \%$ & - & 0.39 & $6 \%$ & - & 0.99 & $19 \%$ & 119 \\
\hline MISO W & 3.4 & $11 \%$ & - & 3.26 & $11 \%$ & - & 5.99 & $24 \%$ & 3 \\
\hline MISO MO-IL & 2.2 & $10 \%$ & - & 2.17 & $10 \%$ & 0 & 4.60 & $25 \%$ & 139 \\
\hline MISO WUMS & 0.8 & $5 \%$ & - & 0.67 & $5 \%$ & - & 1.80 & $16 \%$ & 1 \\
\hline MISO IN & 1.5 & $7 \%$ & 0 & 1.83 & $7 \%$ & 0 & 3.93 & $22 \%$ & 14 \\
\hline MISO MI & 3.1 & $13 \%$ & 1 & 3.06 & $13 \%$ & 0 & 4.04 & $21 \%$ & 16 \\
\hline Non-RTO Midwest & 0.7 & $7 \%$ & - & 0.72 & $7 \%$ & - & 2.46 & $27 \%$ & 7 \\
\hline PJM ROR & 10.2 & $9 \%$ & 5 & 9.54 & $9 \%$ & 7 & 18.79 & $21 \%$ & 147 \\
\hline PJM ROM & 3.5 & $12 \%$ & 5 & 3.41 & $12 \%$ & 4 & 7.32 & $30 \%$ & 69 \\
\hline PJM E & 2.5 & $8 \%$ & 2 & 2.44 & $8 \%$ & 3 & 5.85 & $23 \%$ & 25 \\
\hline IESO & 2.4 & $10 \%$ & - & 2.39 & $10 \%$ & - & 4.41 & $22 \%$ & 0 \\
\hline NYISO A-F & 1.2 & $10 \%$ & 1 & 1.11 & $10 \%$ & 1 & 2.14 & $22 \%$ & 19 \\
\hline NYISO G-I & 0.5 & $10 \%$ & 1 & 0.42 & $10 \%$ & 1 & 0.83 & $22 \%$ & 6 \\
\hline NYISO J-K & 1.8 & $10 \%$ & 2 & 1.68 & $10 \%$ & 2 & 3.27 & $22 \%$ & 26 \\
\hline NEISO & 4.3 & $15 \%$ & 5 & 4.35 & $15 \%$ & 4 & 6.28 & $27 \%$ & 42 \\
\hline NE & 1.0 & $14 \%$ & - & 0.97 & $13 \%$ & 1 & 1.75 & $30 \%$ & 66 \\
\hline SPP N & 1.5 & $7 \%$ & - & 1.78 & $7 \%$ & 2 & 3.81 & $23 \%$ & 2 \\
\hline SPP S & 3.7 & $10 \%$ & 81 & 3.53 & $10 \%$ & 5 & 7.68 & $25 \%$ & 2 \\
\hline ENT & 2.9 & $8 \%$ & 0 & 2.83 & $8 \%$ & 1 & 7.09 & $25 \%$ & 5 \\
\hline TVA & 3.4 & $9 \%$ & - & 3.45 & $9 \%$ & - & 10.49 & $32 \%$ & 2 \\
\hline SOCO & 7.5 & $12 \%$ & 573 & 7.09 & $12 \%$ & 135 & 15.60 & $30 \%$ & 677 \\
\hline VACAR & 5.9 & $10 \%$ & 212 & 5.84 & $10 \%$ & 64 & 15.12 & $32 \%$ & 1,929 \\
\hline FRCC & 5.9 & $10 \%$ & 48 & 5.36 & $10 \%$ & 24 & 16.72 & $33 \%$ & 151 \\
\hline
\end{tabular}




\subsection{SOUTHEAST DEMAND RESPONSE USE AND PRICE IMPACTS}

The lack of local surplus wind and solar in the Southeast is further compounded in that DR cannot be used as reserves, so the regions must run their CC plants at partial load to supply required operating reserves while using DR to supply energy. This is shown for the $\mathrm{CO}_{2}+$ scenario in Fig. 23 and Fig. 24 for the VACAR and SOCO regions on August 1. Demands increase throughout the day, and various technologies are added (at increasing cost) to respond. However, as demand continues to rise, CC generation declines slightly to provide a compensating supply of reserves. "Peakers" are added and pumped storage is used, and DR is called upon for a number of hours over the day. The gap between generation and load is supplied by imports. If DR or peakers could be used for reserves, then additional CC capacity could be used for generation. The figures also include the locational marginal price for each region (a weighted average based on the prices and loads in the different BAs within the region.) The rise in prices as DR was called upon is readily apparent. If DR had been allowed to qualify for reserves, then less would have been dispatched and prices would have been lower.

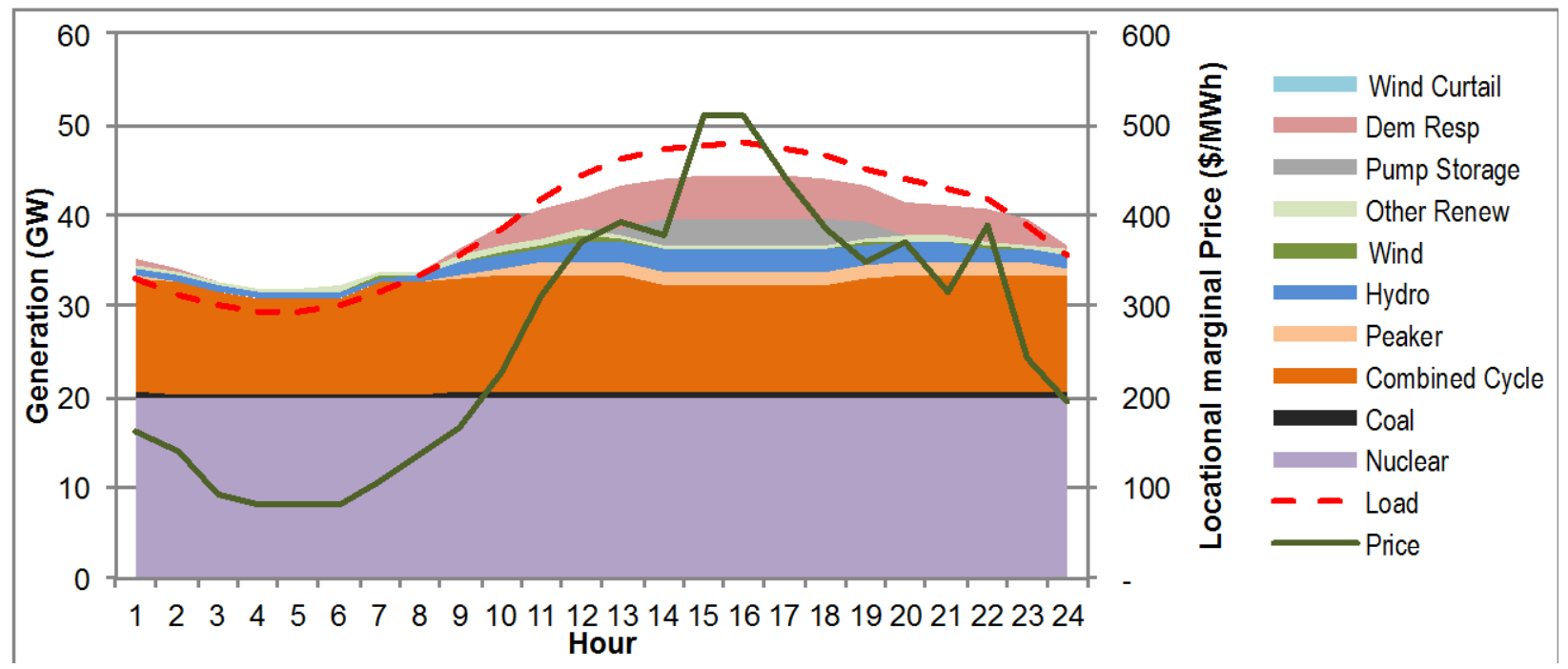

Fig. 23. VACAR generation, load and marginal prices on August 1 under the $\mathrm{CO}_{2}+$ scenario.

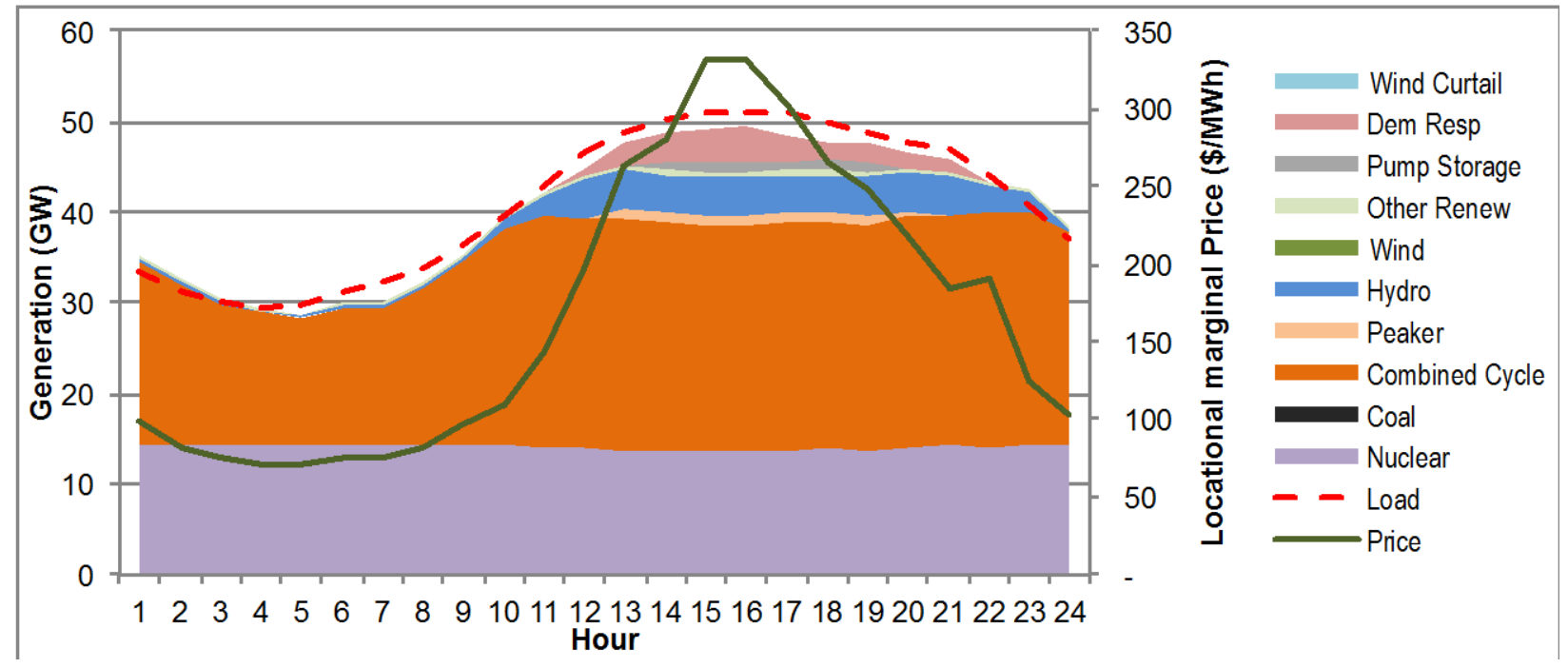

Fig. 24. SOCO generation, load, and marginal prices on August 1 under the $\mathrm{CO}_{2}+$ scenario. 
A key question that arose during the EIPC study was the lack of new lines in the Southeast despite high prices for the region, especially VACAR. The August 1 data are a case in point. VACAR can send and receive power from PJM ROR, SOCO, and TVA. In the scenario represented in Fig. 25, at 4:00 p.m. VACAR is receiving 4.5 GW of power from PJM ROR, which is near the maximum. It also receives a small amount from TVA and actually ships power to SOCO to supply its shortfall. SOCO is also using DR to meet demands while getting power from ENT, TVA, and VACAR and sending power to FRCC.

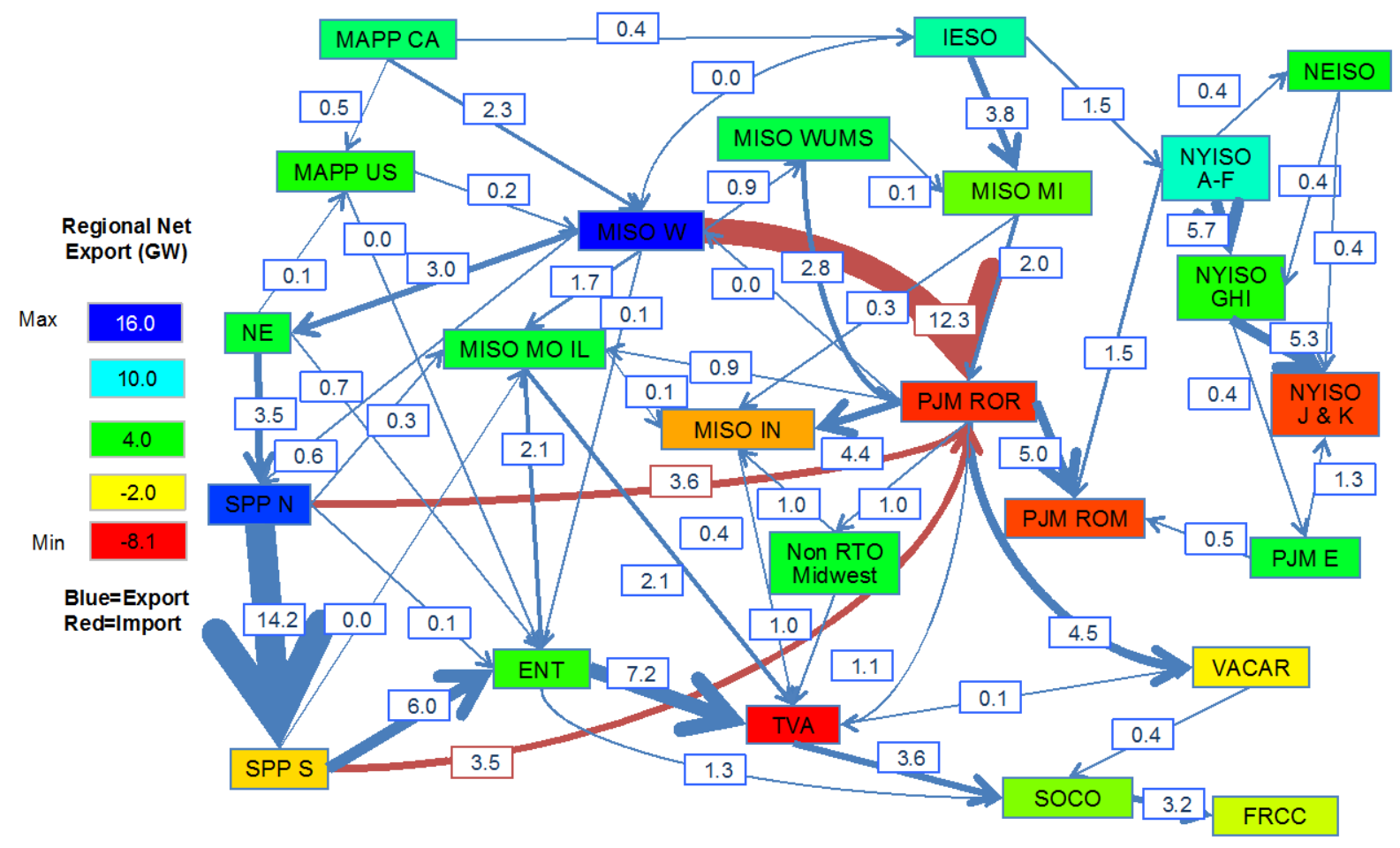

Fig. 25. Eastern Interconnection tie line loads on August 1 at 4:00 p.m. for the $\mathrm{CO}_{2}+$ scenario.

An examination of the flows and shadow prices on the individual flowgates to, from, and within VACAR show where some of the congestion occurs. There are three main flowgates from PJM ROR to VACAR; in this hour much of the power is flowing from central Virginia down toward central South Carolina, with a shadow price of $\$ 100 / \mathrm{MWh}$. This represents the cost difference for power at either end of the line and indicates a congested line. (Other flowgates from PJM ROR do not appear to have shadow prices and so are not immediate congestion points.) Larger congestion occurs on the lines between SOCO and VACAR. There are three main flowgates between the two. Around 2.7 GW is flowing from VACAR to SOCO on the western link, but power is flowing in the other direction on the eastern two. Shadow prices are high on the line from Plant Vogtle into South Carolina, reflecting this line being highly constrained. A review of the PSS/E results indicates that this line is heavily loaded. There are also a few lines within the state that are congested in this hour, as shown by flowgate shadow prices.

Similar analyses show a mixture of congested lines within SOCO. While there were no shadow prices between it and ENT, within SOCO there were several lines indicating congestion, with marginal prices between \$100/MWh and \$500/MWh. These would indicate load pockets within the state that caused the dispatch of DR shown in Fig. 24.

As shown in Fig. 21, the DR capacity has a rising price as more is required. The DR was modeled by CRA as being spread across a region in proportion to its peak load, so DR can be called upon in load pockets even if the region as a whole has lower cost capacity available. Because DR generation was only 
reported at the NEEM region level and marginal prices at the BA level, while potential load pockets were at the bus level, it is difficult to show the relationship between prices and supply. However, by plotting the marginal prices within VACAR vs. the DR amounts a distinct supply curve appears.

Fig. 26 plots the marginal prices for each of the six BAs in VACAR versus the total VACAR DR generation in the BAU scenario in the 412 hours where DR was dispatched. Three of the regions [Santee Cooper, Central Electric Power Cooperative, and South Carolina Electric and Gas (SCE\&G)] have prices that stair step at DR levels of $300 \mathrm{MW}, 600 \mathrm{MW}$, and 1,200 MW. The last one, SCE\&G, is located in the southern part of the state next to Georgia, while the other two are cooperatives that purchase much of their power from the other utilities. As mentioned previously, there appears to be a transmission constraint between SOCO and VACAR, and so these areas are the first to reach constraints and need to dispatch DR.

The last three entries in the legend for Fig. 26 (Progress Energy, Duke, and Greenville Utilities) are located in North Carolina or the northern part of South Carolina. Their prices are lower and smoother than the first three utilities and are likely less constrained by having transmission access to PJM and TVA. The Progress and Greenville prices don’t rise above \$200/MWh until the total DR generation increases above 1,200 MW. DR for these two utilities starts being dispatched at this time, starting with the lowest cost supply for each. Duke prices are lowest, likely because it has the easiest access to the supplies of other regions. It likely does not start dispatching DR until the others have already begun using theirs. As DR continues to be dispatched, all utilities start to see increasing marginal prices, with some fluctuations at the highest levels where all utility prices become more highly correlated.

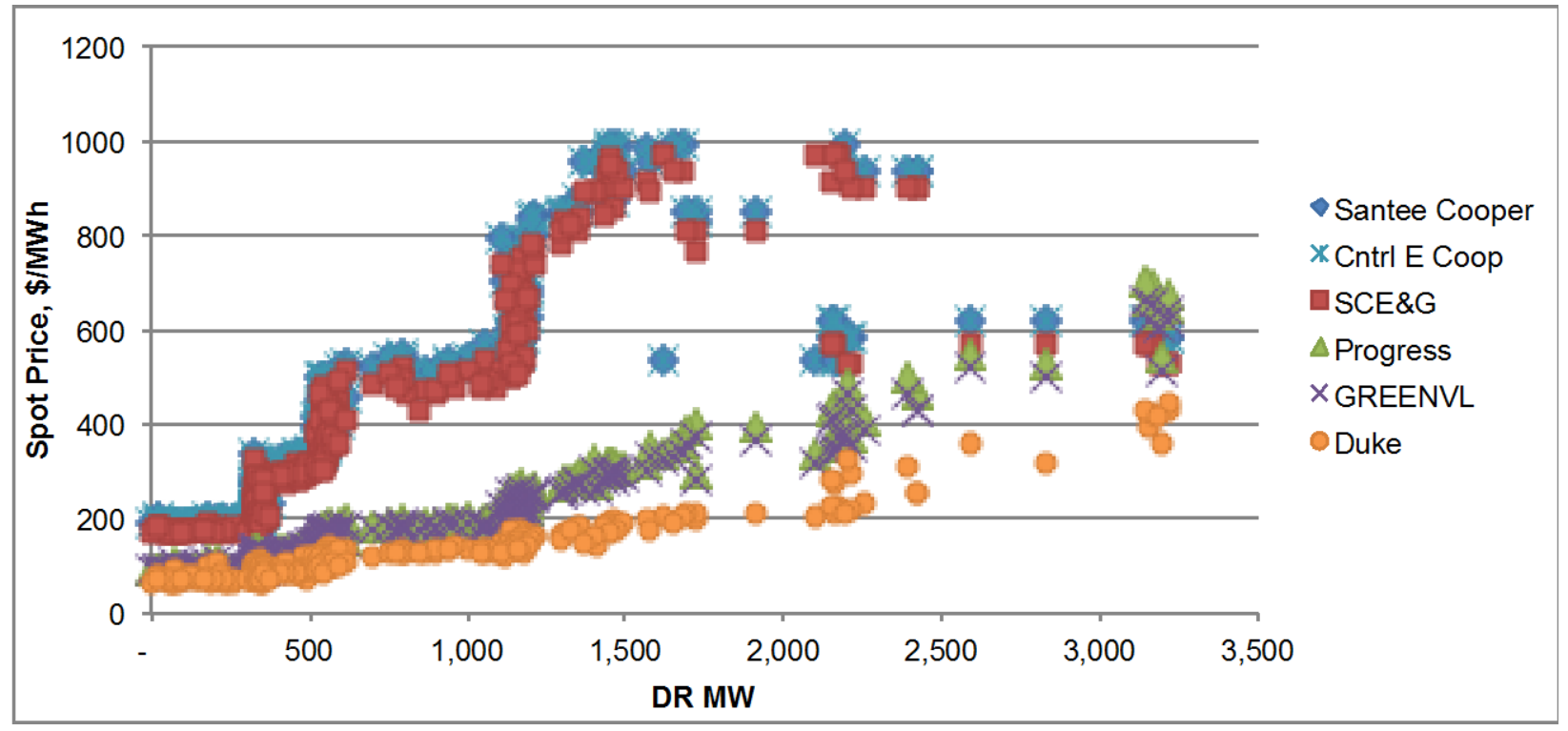

Fig. 26. Marginal prices at six balancing areas versus the corresponding DR demand for all of VACAR in the BAU scenario.

\subsection{SOUTHEAST TRANSMISSION BUILD-OUTS}

If DR was needed for a number of hours in these scenarios, why were lines not built during Phase 1 ? In Phase 1, the initial NEEM run for each future established the marginal prices between regions and the second run calculated "soft" lines between each region based on those prices and the relative power needs. NEEM added soft lines that varied in capacity for each block of each year studied. Because a "real" line had to be set at a constant size for all blocks and years, the SSC had to calculate a representative size to "harden" the lines between regions. 
In the case of the southeastern regions, the soft lines added by NEEM were used for roughly $20 \%$ of the year, during the peak periods. As an example, Fig. 27 shows the flow duration curves for the PJM ROR to VACAR tie line in Phase 1 for several different study years. In Phase 1, members of the modeling working group of the SSC developed several complex methods that considered the capacity factors over multiple years to harden the lines. The results of the different methods are the data points on the baseline that represent existing capacity. The soft expansions in the Southeast were not used for a large enough fraction of the year to justify their construction as hardened lines in the Phase 1 modeling. Instead, it was more cost-effective to use DR or peaking plants for the time they would be needed. There could be additional factors such as hurdle rates between the regions or it could simply be due to the "peakiness" of loads in the south with higher summer demand.

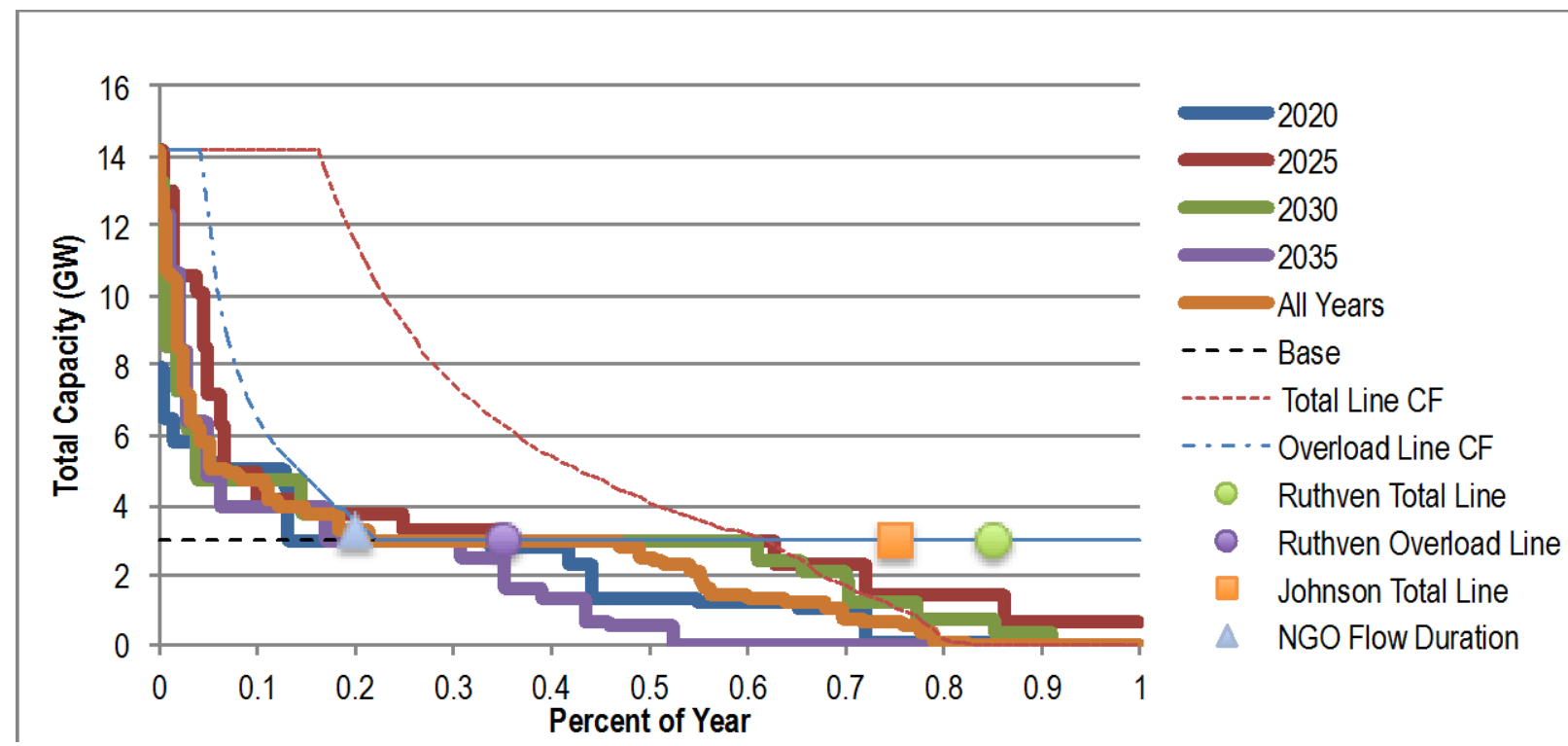

Fig. 27. Phase $1 \mathrm{CO}_{2}+$ flow duration curves for the "soft" tie line between PJM ROR and VACAR.

In Phase 2, the build-out of lines was based on the results from Phase 1 plus the addition of lines solely for reliability purposes during the hour studied. Also, in Phase 2 the interregional flows were based on actual transmission lines and flowgates, so tie line capacities could be different from Phase 1. Loop flows could also have limited the amount of net power transfer. As an example, Fig. 27 shows the Phase 1 flows with the existing capacity set at 3,000 MW, but in Phase 2 the maximum flow between PJM ROR and VACAR was 5,000 MW. Economics did not play a role in the build-out portion of the study. It was only in the last part when using GE MAPS that the full cost impact over the period was identified. In addition, there were one or two lines between SOCO and VACAR that should have been strengthened during the first part of Phase 2 but were missed by the planners.

\subsection{CONCLUSIONS}

The modeling efforts in this study provide only a rough approximation of the vital role DR can play in balancing supply and demand. The resource had to be modeled as a pseudo-generator with a price set high to model its limited availability. In Phase 1, because only a single price for all DR could be applied, it was set at roughly what the available models represented for the total potential supply. In Phase 2 a more complex supply curve with six price steps provided a more nuanced approach. Because DR was used in meeting the minimum planning reserve margin, some regions relied on it to meet their peak demand. In the $\mathrm{CO}_{2}+$ scenario DR capacity was highest cost and those regions without access to surplus wind (most notably VACAR) used high levels of DR at consequent high prices. Some of this was due to the 
differences in the geographic, transmission, and time step detail in Phase 1 and Phase 2 modeling. At times, DR was called on because of transmission constraints that limited the ability to import power from other regions or elsewhere within a region.

\section{TOPIC 9: “NO REGRETS” LINES}

\subsection{TRANSMISSION ELEMENTS COMMON TO MULTIPLE SCENARIOS}

In Phase 2 a number of transmission components were included in the build-outs of each of the three scenarios to address reliability concerns. Because the scenarios capture significantly different outlooks for the future, there may be value in examining the components that show up in all three scenarios as they potentially represent elements that will be needed under a wide variety of future circumstances. If they were to be constructed, it would not be at the expense of other opportunities or more advantageous outcomes as it appears they will be needed regardless of what happens in the future.

An important consideration when examining the transmission elements that are common to all three scenarios is the development of the Stakeholder-Specified Infrastructure (SSI) in Phase 1. Before the MRN-NEEM runs, stakeholders identified new transmission and generation facilities that were to be included in the models. The SSI would eventually impact the transmission build-outs for all three scenarios as some of the elements common to all scenarios were added to fully integrate the SSI additions rather than strictly for reliability reasons.

Table 15 lists the number of transmission build-out elements that are common to all three scenarios by region and stated reason for inclusion. A large number of the NEISO elements resulted from the inclusion of a number of wind farms in the SSI. A number of lines and transformers were included to interconnect those facilities to the network.

Table 15. Elements in Common Across All Scenarios by Region

\begin{tabular}{|c|c|c|c|c|}
\hline Region & $\begin{array}{c}\text { Interconnect } \\
\text { New Generation }\end{array}$ & $\begin{array}{l}\text { Prevent } \\
\text { Overloads }\end{array}$ & $\begin{array}{c}\text { Prevent } \\
\text { Low Voltage }\end{array}$ & Total \\
\hline ENT & & 11 & & 11 \\
\hline FRCC & & 3 & & 3 \\
\hline MAPP CA & & 3 & & 3 \\
\hline MISO IN & & 1 & & 1 \\
\hline MISO MI & & 2 & & 2 \\
\hline MISO W & 1 & & & 1 \\
\hline MISO WUMS & & 1 & & 1 \\
\hline NEISO & 41 & 4 & 1 & 46 \\
\hline Non-RTO Midwest & & 1 & & 1 \\
\hline NYISO & & 1 & & 1 \\
\hline PJM ROM & 2 & 2 & & 4 \\
\hline PJM ROR & & 5 & & 5 \\
\hline SOCO & & 3 & & 3 \\
\hline VACAR & 5 & 2 & & 7 \\
\hline TOTAL & 49 & 39 & 1 & 89 \\
\hline
\end{tabular}

Of the 89 elements, 49 are new transmission lines, 14 are new transformers or autotransformers, 8 are new reactive support devices (reactors or static var controllers), and 18 are upgrades to existing facilities. A number of the new devices also require modifications to existing facilities (like adding bays to a substation), but they are classified as new here. In some instances, there were two separate circuits added between a pair of buses. Those are treated as separate lines for this purpose. (The appendix to this report is a list of the elements, including a description of the project and reason for its need.) 
Most of the costs associated with the common elements are for connecting new generation, much of which is associated with the SSI. Table shows the midrange estimate of the overnight capital costs of the common elements by reason of inclusion and the total costs from the three scenarios [from Table ES-3 of the EIPC Phase 2 Report (EIPC 2012)].

Table 16. Overnight Capital Costs (billions of 2010 dollars)

\begin{tabular}{|lcccc|}
\multicolumn{1}{c}{ Costs } & Common & $\mathrm{CO}_{2}+$ & RPS/R & BAU \\
\hline Interconnect New Generation & 5.7 & 49.6 & 54.3 & 7.3 \\
\hline Prevent Overloads & 2.8 & 48.4 & 13.0 & 7.9 \\
\hline Prevent Low Voltage & 0.04 & 0.5 & 0.1 & 0.2 \\
\hline
\end{tabular}

Fig. 28 shows the locations of buses where the common transmission lines have a termination point or where common transformers or reactive support devices are located.

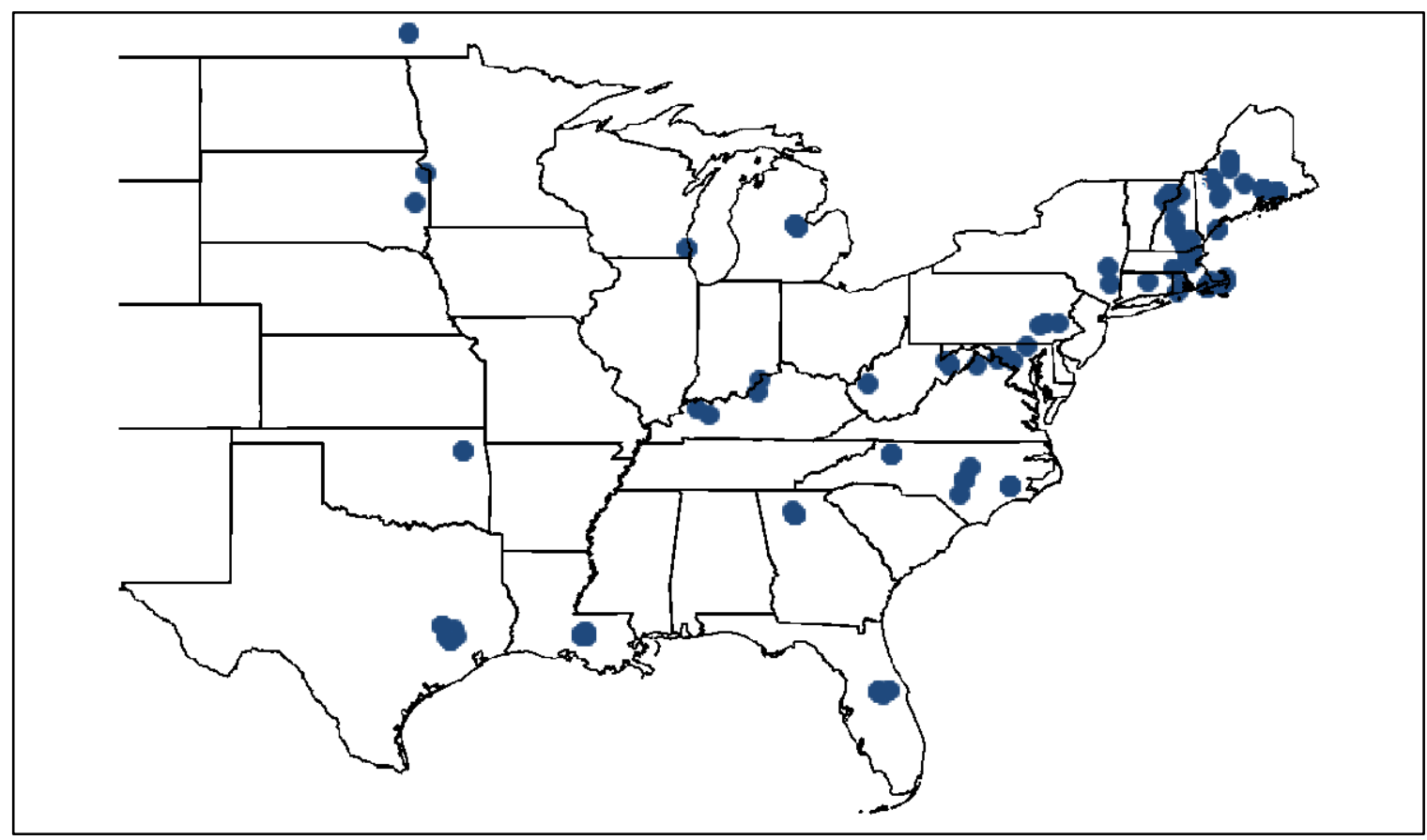

Fig. 28. Locations of buses with upgrades common to all three scenarios.

In some cases, elements were added or upgraded in each of the three scenarios, but the same thing is not done in each one. For instance, while one scenario may add an additional circuit to a transmission line, the others re-conductor the existing circuit. Alternatively, one scenario may include an element with a higher rating. While the stated reason is generally the same across all scenarios, this is not always the case. The scenario that used the least cost method is used for the reason in Table 17. 
Table 17. Elements in Common with Different Methods by Region

\begin{tabular}{|c|c|c|c|c|}
\hline Region & $\begin{array}{c}\text { Interconnect } \\
\text { New Generation }\end{array}$ & $\begin{array}{c}\text { Prevent } \\
\text { Overloads }\end{array}$ & $\begin{array}{c}\text { Prevent } \\
\text { Low Voltage }\end{array}$ & Tota \\
\hline ENT & & 1 & & 1 \\
\hline FRCC & & 2 & & 2 \\
\hline MAPP CA & & 5 & & 5 \\
\hline MISO MI & & 2 & & 2 \\
\hline MISO MO-IL & & & 1 & 1 \\
\hline NEISO & 1 & & & 1 \\
\hline PJM E & 1 & & & 1 \\
\hline PJM ROM & 3 & & & 3 \\
\hline PJM ROR & 1 & & & 1 \\
\hline SPP S & & 7 & & 7 \\
\hline VACAR & 1 & 1 & & 2 \\
\hline TOTAL & 7 & 18 & 1 & 26 \\
\hline
\end{tabular}

There are also a number of instances where an element shows up in two of the three scenarios. Of the total, 176 elements are common to the $\mathrm{CO}_{2}+$ and RPS/R scenarios but not the BAU scenario. Many of these are in SPP and MISO as part of the wind collector systems. There are 50 pairs of buses that have entries in common with the $\mathrm{CO}_{2}+$ and BAU scenarios but not the RPS/R scenario. There are 46 pairs of buses that have entries in common to RPS/R and BAU but not $\mathrm{CO}_{2}+$.

\subsection{CONCLUSIONS}

There are 89 transmission elements that are common to all three scenarios. In another 26 instances something was done at a bus (or between a pair of buses) under each scenario, but the same thing was not done in all three. In many cases, the elements were included to support new generation that was included by the SSC in the early stages of the Phase 1 process. Those elements would only be "no regrets" if the associated new generation is actually constructed.

\section{REFERENCES}

Astrape Consulting, 2013, The Economic Ramifications of Resource Adequacy White Paper, National Association of Regulatory Commissioners, January. http://communities.nrri.org/documents/68668/68defc1f-5405-4fa9-8f91-8fa9ca59d116.

Baek, Young Sun, et al., 2012, Eastern Interconnection Demand Response Potential. ORNL/TM2012/303. Oak Ridge, TN: Oak Ridge National Laboratory, November.

http://www.osti.gov/scitech/servlets/purl/1055536.

Charles Rivers Associates, 2010, Working Draft of MRN-NEEM Modeling Assumptions and Data Sources for EIPC Capacity Expansion Modeling, EIPC, December. http://www.eipconline.com/uploads/MRN-NEEM Assumptions Document Draft 12-22-10.pdf.

EIPC, 2011, Phase 1 Report: Formation of Stakeholder Process, Regional Plan Integration and Macroeconomic Analysis, Eastern Interconnection Planning Collaborative, December. http://www.eipconline.com/uploads/Phase_1_Report_Final_12-23-2011.pdf.

EIPC 2012, Phase 2 Report: DOE Draft-Part 1 Interregional Transmission Development and Analysis for Three Stakeholder Selected Scenarios, Eastern Interconnection Planning Collaborative, December. 
http://www.eipconline.com/uploads/20130103_Phase2Report_Part1_Final.pdf.

EIPC 2012, Phase 2 Report: DOE Draft-Part 2-7 Interregional Transmission Development and Analysis for Three Stakeholder Selected Scenarios, Eastern Interconnection Planning Collaborative, December. http://www.eipconline.com/uploads/20130103_Phase2Report_Part2_Final.pdf.

EIPC 2012, Phase 2 Report: DOE Draft-Appendices Interregional Transmission Development and Analysis for Three Stakeholder Selected Scenarios, Eastern Interconnection Planning Collaborative, December.

http://www.eipconline.com/uploads/20130103_Phase2Report_Part3_Final.pdf.

EIPC data documents available on the EIPC website:

- $\quad$ Phase 1 Modeling Results

- $\quad$ http://www.eipconline.com/Modeling_Results.html

- $\quad$ Phase II Modeling Inputs

- $\quad$ http://www.eipconline.com/Modeling Inputs.html

- $\quad$ Phase II Modeling Results

- $\quad$ http://www.eipconline.com/PhaseII_Modeling_Results.html

FERC, 2009, A National Assessment of Demand Response Potential NADR prepared by the Brattle Group, Freeman, Sullivan \& Co, Global Energy Partners, LLC.. Retrieved May 20, 2011 from http://www.ferc.goc/legal/staff-reports/06-09-demand-response.pdf.

Hadley, Stanton, 2013, Additional EIPC Study Analysis: Interim Report on Medium Priority Topics, ORNL/TM-2013/447, Oak Ridge, TN: Oak Ridge National Laboratory, November.

http://www.osti.gov/scitech/servlets/purl/1107841.

Navigant, 2013, Assessment of Demand-Side Resources within the Eastern Interconnection, prepared for Eastern Interconnection States’ Planning Council, March 2013. http://communities.nrri.org/documents/68668/76ae1be0-2218-4255-8bd4-d7b0fc9ecf8c.

NERC, 2013, Reliability Standards for the Bulk Electric Systems of North America, Updated December 5, 2013, North American Electric Reliability Corporation website, accessed 12/9/2013.

http://www.nerc.com/pa/Stand/Reliability Standards Complete Set/RSCompleteSet.pdf.

Satchwell, Andrew, Galen L. Barbose, Charles A. Goldman, Ryan Hledik, and Ahmad Faruqui, 2013, Incorporating Demand Response into Western Interconnection Transmission Planning, LBNL-6381E, Lawrence Berkeley National Laboratory, July. 

APPENDIX: LINES AND TRANSFORMERS COMMON TO ALL SCENARIOS 



\begin{tabular}{|c|c|c|c|}
\hline Region & Name & Reason/Need & Description \\
\hline NEISO & $\begin{array}{l}\text { CT LAKES - SEA } \\
\text { STRATTON115 kV TL }\end{array}$ & $\begin{array}{l}\text { Interconnect New } \\
\text { Generation }\end{array}$ & $\begin{array}{l}\text { Include new transmission line and } 1 \\
\text { new } 115 \mathrm{kV} \text { susbstation }\end{array}$ \\
\hline NEISO & $\begin{array}{l}\text { PITTSTON ME - PITTSTN CLR1 } \\
115 \text { kV TL }\end{array}$ & $\begin{array}{l}\text { Interconnect New } \\
\text { Generation }\end{array}$ & $\begin{array}{l}\text { Include new transmission line and } 2 \\
\text { new } 115 \mathrm{kV} \text { susbstation }\end{array}$ \\
\hline NEISO & Pittston ME 115/345 kV XFMR & $\begin{array}{l}\text { Interconnect New } \\
\text { Generation }\end{array}$ & 1 new 345/115 kV XFMR \\
\hline NEISO & $\begin{array}{l}\text { PITTSTON ME - HARRIS } \\
\text { HYDRO } 115 \mathrm{kV} \text { TL }\end{array}$ & $\begin{array}{l}\text { Interconnect New } \\
\text { Generation }\end{array}$ & Include new transmission line \\
\hline NEISO & $\begin{array}{l}\text { MARTHAS VYND - FALMOUTH } \\
\text { TAP } 115 \text { kV TL }\end{array}$ & $\begin{array}{l}\text { Interconnect New } \\
\text { Generation }\end{array}$ & $\begin{array}{l}\text { Include new transmission line and } 1 \\
\text { new } 115 \mathrm{kV} \text { susbstation }\end{array}$ \\
\hline NEISO & Ashland ME 115/345 kV XFMR & $\begin{array}{l}\text { Interconnect New } \\
\text { Generation }\end{array}$ & 1 new 345/115 kV XFMR \\
\hline NEISO & Canal 115/345 kV XFMR & $\begin{array}{l}\text { Interconnect New } \\
\text { Generation }\end{array}$ & 1 new 345/115 kV XFMR \\
\hline NEISO & $\begin{array}{l}\text { CANAL - HATCHVILLE } 115 \text { kV } \\
\text { TL }\end{array}$ & $\begin{array}{l}\text { Interconnect New } \\
\text { Generation }\end{array}$ & $\begin{array}{l}\text { Include new transmission line and } 1 \\
\text { new } 115 \mathrm{kV} \text { susbstation }\end{array}$ \\
\hline NEISO & $\begin{array}{l}\text { SEA STRATTON - PITTSTON } \\
\text { ME } 345 \mathrm{kV} \text { TL }\end{array}$ & $\begin{array}{l}\text { Interconnect New } \\
\text { Generation }\end{array}$ & $\begin{array}{l}\text { Includes new transmission line and } 2 \\
\text { new } 345 \mathrm{kV} \text { substations }\end{array}$ \\
\hline NEISO & $\begin{array}{l}\text { SEA STRATTON - ORRINGTON } \\
345 \mathrm{kV} \text { TL }\end{array}$ & $\begin{array}{l}\text { Interconnect New } \\
\text { Generation }\end{array}$ & Includes new transmission line \\
\hline NEISO & Sea Stratton 345/115 kV XFMR & $\begin{array}{l}\text { Interconnect New } \\
\text { Generation }\end{array}$ & 1 new 345/115 kV XFMR \\
\hline NEISO & $\begin{array}{l}\text { Sea Stratton } 345 \text { kV - } 50 \text { Mvar } \\
\text { Reactor }\end{array}$ & $\begin{array}{l}\text { Interconnect New } \\
\text { Generation }\end{array}$ & Includes new reactor \\
\hline NEISO & $\begin{array}{l}\text { DRACTU MA - ORRINGTON } \\
345 \mathrm{kV} \text { TL }\end{array}$ & $\begin{array}{l}\text { Interconnect New } \\
\text { Generation }\end{array}$ & Includes new transmission line \\
\hline NEISO & $\begin{array}{l}\text { DRACTU MA - MILLBURY } 345 \\
\text { kV TL }\end{array}$ & $\begin{array}{l}\text { Interconnect New } \\
\text { Generation }\end{array}$ & Includes new transmission line \\
\hline NEISO & $\begin{array}{l}\text { PITTSTON ME - ASHLAND ME } \\
345 \mathrm{kV} \text { TL }\end{array}$ & $\begin{array}{l}\text { Interconnect New } \\
\text { Generation }\end{array}$ & $\begin{array}{l}\text { Includes new transmission line and } 1 \\
\text { new } 345 \mathrm{kV} \text { substation }\end{array}$ \\
\hline NEISO & $\begin{array}{l}\text { Pittston ME } 345 \text { kV - } 30 \text { Mvar } \\
\text { Reactor }\end{array}$ & $\begin{array}{l}\text { Interconnect New } \\
\text { Generation }\end{array}$ & Includes new reactor \\
\hline NEISO & $\begin{array}{l}\text { WHITTING ME - HARRINGTON } \\
345 \text { kV TL }\end{array}$ & $\begin{array}{l}\text { Interconnect New } \\
\text { Generation }\end{array}$ & $\begin{array}{l}\text { Includes new transmission line, } 1 \text { new } \\
345 \mathrm{kV} \text { substation and } 1 \text { new 345/115 } \\
\text { kV XFMR }\end{array}$ \\
\hline NEISO & $\begin{array}{l}\text { WHITTING ME -ORRINGTON } \\
345 \text { kV TL }\end{array}$ & $\begin{array}{l}\text { Interconnect New } \\
\text { Generation }\end{array}$ & $\begin{array}{l}\text { Includes new transmission line, } 1 \text { new } \\
345 \mathrm{kV} \text { substation and } 1 \text { new 345/115 } \\
\text { kV XFMR }\end{array}$ \\
\hline NEISO & $\begin{array}{l}\text { Whiting ME } 345 \text { kV - } 60 \text { Mvar } \\
\text { Reactor }\end{array}$ & $\begin{array}{l}\text { Interconnect New } \\
\text { Generation }\end{array}$ & Includes new reactor \\
\hline NEISO & $\begin{array}{l}\text { HARRINGTON - TRENTON } 345 \\
\text { kV TL }\end{array}$ & $\begin{array}{l}\text { Interconnect New } \\
\text { Generation }\end{array}$ & $\begin{array}{l}\text { Includes new transmission line, } 1 \text { new } \\
345 \text { kV substation and } 1 \text { new 345/115 } \\
\text { kV XFMR }\end{array}$ \\
\hline NEISO & $\begin{array}{l}\text { Harrington } 345 \text { kV - } 40 \text { Mvar } \\
\text { Reactor }\end{array}$ & $\begin{array}{l}\text { Interconnect New } \\
\text { Generation }\end{array}$ & Includes new reactor \\
\hline NEISO & $\begin{array}{l}\text { TRENTON - ORRINGTON } 345 \\
\text { kV TL }\end{array}$ & $\begin{array}{l}\text { Interconnect New } \\
\text { Generation }\end{array}$ & Includes new transmission line \\
\hline NEISO & $\begin{array}{l}\text { Trenton } 345 \text { kV - } 40 \text { Mvar } \\
\text { Reactor }\end{array}$ & $\begin{array}{l}\text { Interconnect New } \\
\text { Generation }\end{array}$ & Includes new reactor \\
\hline NEISO & $\begin{array}{l}\text { BARNSTABLE - LONG TRM } \\
\text { LSM } 345 \mathrm{kV} \text { TL }\end{array}$ & $\begin{array}{l}\text { Interconnect New } \\
\text { Generation }\end{array}$ & $\begin{array}{l}\text { Includes new transmission line, } 1 \text { new } \\
345 \text { kV substation and } 1 \text { new 345/115 } \\
\text { kV XFMR }\end{array}$ \\
\hline NEISO & $\begin{array}{l}\text { Barnstable } 345 \text { kV - } 150 \text { Mvar } \\
\text { SVC }\end{array}$ & $\begin{array}{l}\text { Interconnect New } \\
\text { Generation }\end{array}$ & $\begin{array}{l}\text { Includes new static var controller } \\
\text { (SVC) }\end{array}$ \\
\hline NEISO & $\begin{array}{l}\text { ASHLAND ME - ORRINGTON } \\
345 \mathrm{kV} \text { TL }\end{array}$ & $\begin{array}{l}\text { Interconnect New } \\
\text { Generation }\end{array}$ & Includes new transmission line \\
\hline NEISO & $\begin{array}{l}\text { Ashland ME } 345 \text { kV - } 20 \text { Mvar } \\
\text { Cap Bank }\end{array}$ & $\begin{array}{l}\text { Interconnect New } \\
\text { Generation }\end{array}$ & Includes new capacitor bank \\
\hline
\end{tabular}




\begin{tabular}{|c|c|c|c|}
\hline Region & Name & Reason/Need & Description \\
\hline NEISO & Whitefield - Littleton 230 kV TL & $\begin{array}{l}\text { Interconnect New } \\
\text { Generation }\end{array}$ & Includes new transmission line \\
\hline NEISO & $\begin{array}{l}\text { Lost Nation - Whitefield } 230 \mathrm{kV} \\
\text { TL }\end{array}$ & $\begin{array}{l}\text { Interconnect New } \\
\text { Generation }\end{array}$ & $\begin{array}{l}\text { Includes new transmission line and } 1 \\
\text { new } 230 \mathrm{kV} \text { substations }\end{array}$ \\
\hline NEISO & Paris - Lost Nation 230 kV TL & $\begin{array}{l}\text { Interconnect New } \\
\text { Generation }\end{array}$ & $\begin{array}{l}\text { Includes new transmission line and } 1 \\
\text { new } 230 \mathrm{kV} \text { substations }\end{array}$ \\
\hline NEISO & Pontook - Paris 230 kV TL & $\begin{array}{l}\text { Interconnect New } \\
\text { Generation }\end{array}$ & $\begin{array}{l}\text { Includes new transmission line and } 2 \\
\text { new } 230 \mathrm{kV} \text { substations }\end{array}$ \\
\hline NEISO & $\begin{array}{l}\text { STURTEVANT - LIVERMORE } \\
\text { FL } 115 \mathrm{kV} \text { TL }\end{array}$ & $\begin{array}{l}\text { Interconnect New } \\
\text { Generation }\end{array}$ & Includes new transmission line \\
\hline NEISO & $\begin{array}{l}\text { Merrimack } 230 \text { kV - } 150 \text { Mvar } \\
\text { SVC }\end{array}$ & Low Voltage & Includes new SVC \\
\hline NEISO & Scobie - Tewksbury 345 kV TL & $\begin{array}{l}\text { Loading }>100 \% \text { of } \\
\text { System Emergency }\end{array}$ & Includes new transmission line \\
\hline NEISO & $\begin{array}{l}\text { BEEBE RIVER - WEBSTER } 115 \\
\text { kV TL }\end{array}$ & $\begin{array}{l}\text { Interconnect New } \\
\text { Generation }\end{array}$ & Includes new transmission line \\
\hline NEISO & $\begin{array}{l}\text { WEBSTER - DEERFIELD } 115 \\
\text { kV TL }\end{array}$ & $\begin{array}{l}\text { Interconnect New } \\
\text { Generation }\end{array}$ & Includes new transmission line \\
\hline NEISO & $\begin{array}{l}\text { Woburn - N. Cambridge } 345 \text { kV } \\
\text { TL }\end{array}$ & $\begin{array}{l}\text { Loading }>100 \% \text { of } \\
\text { System Emergency }\end{array}$ & Includes new transmission line \\
\hline NEISO & $\begin{array}{l}\text { BARNSTABLE - HATCHVILLE } \\
115 \mathrm{kV} \text { TL }\end{array}$ & $\begin{array}{l}\text { Interconnect New } \\
\text { Generation }\end{array}$ & Includes new transmission line \\
\hline NEISO & $\begin{array}{l}\text { BARNSTABLE - HARWICH } \\
\text { MCGR } 115 \mathrm{kV} \text { TL }\end{array}$ & $\begin{array}{l}\text { Interconnect New } \\
\text { Generation }\end{array}$ & Includes new transmission line \\
\hline NEISO & $\begin{array}{l}\text { FALMOUTH TAP - HATCHVILLE } \\
115 \mathrm{kV} \text { TL }\end{array}$ & $\begin{array}{l}\text { Interconnect New } \\
\text { Generation }\end{array}$ & Includes new transmission line \\
\hline NEISO & $\begin{array}{l}\text { WELLFLEET - ORLEANS } 115 \\
\text { kV TL }\end{array}$ & $\begin{array}{l}\text { Interconnect New } \\
\text { Generation }\end{array}$ & Includes new transmission line \\
\hline NEISO & $\begin{array}{l}\text { HARWICH MCGR - ORLEANS } \\
115 \mathrm{Kv} \text { TL }\end{array}$ & $\begin{array}{l}\text { Interconnect New } \\
\text { Generation }\end{array}$ & Includes new transmission line \\
\hline NEISO & $\begin{array}{l}\text { MILLBURY - MANCHESTER } \\
345 \text { kV TL }\end{array}$ & $\begin{array}{l}\text { Interconnect New } \\
\text { Generation }\end{array}$ & Includes new transmission line \\
\hline NEISO & Tewksbury - Woburn 345 kV TL & $\begin{array}{l}\text { Loading }>100 \% \text { of } \\
\text { System Emergency }\end{array}$ & Includes new transmission line \\
\hline NEISO & $\begin{array}{l}\text { Ward Hill - Wakefield JCT } 345 \\
\text { kV TL }\end{array}$ & $\begin{array}{l}\text { Loading }>100 \% \text { of } \\
\text { System Emergency }\end{array}$ & Includes new transmission line \\
\hline NEISO & $\begin{array}{l}\text { KENYON - KENT COUNTY } 115 \\
\text { kV TL }\end{array}$ & $\begin{array}{l}\text { Interconnect New } \\
\text { Generation }\end{array}$ & Includes new transmission line \\
\hline NYISO_A-F & Leeds - Pleasant Valley 345 kV & $\begin{array}{l}\text { Loading }>100 \% \text { of } \\
\text { System Emergency }\end{array}$ & New 345 kV line \\
\hline PJM_ROM & $\begin{array}{l}\text { Brighton - Kemptown 500kV TL } \\
\text { (PATH) }\end{array}$ & $\begin{array}{l}\text { Loading }>100 \% \text { of } \\
\text { System Emergency }\end{array}$ & $\begin{array}{l}\text { Upgrade oper temp facil/reconductor } \\
500 \mathrm{KV} \text { line }\end{array}$ \\
\hline PJM_ROM & $\begin{array}{l}\text { Conastone - Kemptown 500kV } \\
\text { TL (PATH) }\end{array}$ & $\begin{array}{l}\text { Loading }>100 \% \text { of } \\
\text { System Emergency }\end{array}$ & $\begin{array}{l}\text { Upgrade oper temp facil/reconductor } \\
500 \mathrm{KV} \text { line }\end{array}$ \\
\hline PJM_ROM & $\begin{array}{l}\text { North Temple - North Kill 230kV } \\
\text { TL (terminal equip. uprate) }\end{array}$ & $\begin{array}{l}\text { Interconnect New } \\
\text { Generation }\end{array}$ & $\begin{array}{l}\text { Upgrade } 230 \mathrm{KV} \text { sub/upgrade } 230 \mathrm{KV} \\
\text { sub }\end{array}$ \\
\hline PJM_ROM & $\begin{array}{l}\text { North Temple - Hosensack } \\
230 \mathrm{kV} \text { TL (terminal equip. } \\
\text { uprate) }\end{array}$ & $\begin{array}{l}\text { Interconnect New } \\
\text { Generation }\end{array}$ & $\begin{array}{l}\text { Upgrade } 230 \mathrm{KV} \text { sub/upgrade } 230 \mathrm{KV} \\
\text { sub }\end{array}$ \\
\hline PJM_ROR & $\begin{array}{l}\text { Doubs - Kemptown 500kV TL } \\
\text { (PATH) }\end{array}$ & $\begin{array}{l}\text { Loading }>100 \% \text { of } \\
\text { System Emergency }\end{array}$ & $\begin{array}{l}\text { Upgrade oper temp facil/reconductor } \\
500 \mathrm{KV} \text { line }\end{array}$ \\
\hline PJM_ROR & $\begin{array}{l}\text { Meadow Brook - Welton Springs } \\
500 k V \text { TL (PATH) }\end{array}$ & $\begin{array}{l}\text { Loading }>100 \% \text { of } \\
\text { System Emergency }\end{array}$ & $\begin{array}{l}\text { Upgrade oper temp facil/reconductor } \\
500 \mathrm{KV} \text { line }\end{array}$ \\
\hline PJM_ROR & $\begin{array}{l}\text { Welton Springs - Kemptown } \\
765 \mathrm{kV} \text { TL (PATH) }\end{array}$ & $\begin{array}{l}\text { Loading }>100 \% \text { of } \\
\text { System Emergency }\end{array}$ & New 765 KV line/new 765 KV line \\
\hline PJM_ROR & $\begin{array}{l}\text { Welton Springs - John Amos } \\
\text { 765kV TL (PATH) }\end{array}$ & $\begin{array}{l}\text { Loading }>100 \% \text { of } \\
\text { System Emergency }\end{array}$ & New 765 KV line/new 765 KV line \\
\hline
\end{tabular}




\begin{tabular}{|c|c|c|c|}
\hline Region & Name & Reason/Need & Description \\
\hline PJM_ROR & $\begin{array}{l}\text { Welton Springs - Mt Storm } \\
500 k V \text { TL (PATH) }\end{array}$ & $\begin{array}{l}\text { Loading }>100 \% \text { of } \\
\text { System Emergency }\end{array}$ & $\begin{array}{l}\text { Upgrade oper temp facil/reconductor } \\
500 \mathrm{KV} \text { line }\end{array}$ \\
\hline MISO_MI & $\begin{array}{l}\text { MCV - Tittabawasee } 345 \text { Ckt } 1 \\
\text { Reconductor }\end{array}$ & $\begin{array}{l}\text { Loading }>100 \% \text { of } \\
\text { System Emergency }\end{array}$ & $\begin{array}{l}\text { Reconductored Transmission Line }+2 \\
\text { Upgraded Bays }\end{array}$ \\
\hline MISO_MI & $\begin{array}{l}\text { MCV - Tittabawasee } 345 \text { Ckt } 2 \\
\text { Reconductor }\end{array}$ & $\begin{array}{l}\text { Loading }>100 \% \text { of } \\
\text { System Emergency }\end{array}$ & $\begin{array}{l}\text { Reconductored Transmission Line }+2 \\
\text { Upgraded Bays }\end{array}$ \\
\hline ENT & $\begin{array}{l}\text { New Sportman 345/161 kV third } \\
\text { auto }\end{array}$ & $\begin{array}{l}\text { Loading }>100 \% \text { of } \\
\text { System Emergency }\end{array}$ & Add 345 kV Auto \\
\hline VACAR & Wake-Wommack 500kV TL & $\begin{array}{l}\text { Interconnect New } \\
\text { Generation }\end{array}$ & $\begin{array}{l}\text { Includes new transmission line, } 1 \text { new } \\
500 \mathrm{kV} \text { substation }\end{array}$ \\
\hline VACAR & $\begin{array}{l}\text { Cumberland-Wommack 500kV } \\
\text { TL }\end{array}$ & $\begin{array}{l}\text { Interconnect New } \\
\text { Generation }\end{array}$ & $\begin{array}{l}\text { Includes new transmission line, } 1 \text { new } \\
500 \mathrm{kV} \text { substation }\end{array}$ \\
\hline VACAR & New Bern 500/230kV XFMR & $\begin{array}{l}\text { Interconnect New } \\
\text { Generation }\end{array}$ & New transformer \\
\hline VACAR & New Bern 500/230kV XFMR & $\begin{array}{l}\text { Interconnect New } \\
\text { Generation }\end{array}$ & New transformer \\
\hline VACAR & New Bern-Wommack 500kV TL & $\begin{array}{l}\text { Interconnect New } \\
\text { Generation }\end{array}$ & Includes New Transmission Line \\
\hline VACAR & Antioch 500/230 kV XFMR & $\begin{array}{l}\text { Loading }>100 \% \text { of } \\
\text { System Emergency }\end{array}$ & New transformer \\
\hline VACAR & Antioch 500/230 kV XFMR & $\begin{array}{l}\text { Loading }>100 \% \text { of } \\
\text { System Emergency }\end{array}$ & New transformer \\
\hline $\begin{array}{l}\text { NonRTO_Mid } \\
\text { west }\end{array}$ & $\begin{array}{l}\text { Upgrade Trimble Co to } \\
\text { Middletown } 345 \mathrm{kV}\end{array}$ & $\begin{array}{l}\text { Loading }>100 \% \text { of } \\
\text { System Emergency }\end{array}$ & Upgard Operating Temperature \\
\hline ENT & $\begin{array}{l}\text { New Lewis Creek to West } \\
\text { Conroe SS } 230 \mathrm{kV}\end{array}$ & $\begin{array}{l}\text { Loading }>100 \% \text { of } \\
\text { System Emergency }\end{array}$ & $\begin{array}{l}\text { Construct new } 230 \mathrm{kV} \text { Line and } 230 \\
\mathrm{kV} \text { substation at W. Conroe and } \\
\text { terminal at Lewis Creek }\end{array}$ \\
\hline ENT & $\begin{array}{l}\text { New } 230 / 138 / 13 / 8 \mathrm{kV} \text { three } \\
\text { winding transformer at Conroe } \\
\text { SS }\end{array}$ & $\begin{array}{l}\text { Loading }>100 \% \text { of } \\
\text { System Emergency }\end{array}$ & Add $230 \mathrm{kV}$ Auto \\
\hline ENT & $\begin{array}{l}\text { New West Conroe SS to Grimes } \\
230 \mathrm{kV}\end{array}$ & $\begin{array}{l}\text { Loading }>100 \% \text { of } \\
\text { System Emergency }\end{array}$ & $\begin{array}{l}\text { Construct new } 230 \text { kV Line and } 230 \\
\text { kV substation at Grimes }\end{array}$ \\
\hline ENT & $\begin{array}{l}\text { Upgrade West Conroe SS to } \\
\text { Conroe } 138 \mathrm{kV}\end{array}$ & $\begin{array}{l}\text { Loading }>100 \% \text { of } \\
\text { System Emergency }\end{array}$ & Upgrade 138 kV line \\
\hline ENT & New 345/230 kV auto at Grimes & $\begin{array}{l}\text { Loading }>100 \% \text { of } \\
\text { System Emergency }\end{array}$ & Add 345 kV Auto \\
\hline ENT & New Addis to Tiger 230 kV Ckt 2 & $\begin{array}{l}\text { Loading }>100 \% \text { of } \\
\text { System Emergency }\end{array}$ & $\begin{array}{l}\text { Construct new } 230 \mathrm{kV} \text { line and add } \\
\text { terminals at Addis and Tiger }\end{array}$ \\
\hline ENT & $\begin{array}{l}\text { Construct second Dowmeter to } \\
\text { Air Liquide Tap } 230 \mathrm{kV}\end{array}$ & $\begin{array}{l}\text { Loading }>100 \% \text { of } \\
\text { System Emergency }\end{array}$ & $\begin{array}{l}\text { Construct new } 230 \mathrm{kV} \text { line and add } \\
\text { terminals at Dowmeter }\end{array}$ \\
\hline ENT & $\begin{array}{l}\text { Upgrade Air Liquide Tap to } \\
\text { Chenango } 230 \mathrm{kV}\end{array}$ & $\begin{array}{l}\text { Loading }>100 \% \text { of } \\
\text { System Emergency }\end{array}$ & Upgrade $230 \mathrm{kV}$ line \\
\hline ENT & $\begin{array}{l}\text { Upgrade Chenango to Iberville } \\
230 \mathrm{kV} \text { line }\end{array}$ & $\begin{array}{l}\text { Loading }>100 \% \text { of } \\
\text { System Emergency }\end{array}$ & Upgrade $230 \mathrm{kV}$ line \\
\hline ENT & $\begin{array}{l}\text { Upgrade Iberville to Evergreen } \\
230 \mathrm{kV} \text { line }\end{array}$ & $\begin{array}{l}\text { Loading }>100 \% \text { of } \\
\text { System Emergency }\end{array}$ & Upgrade $230 \mathrm{kV}$ line \\
\hline MISO_IN & $\begin{array}{l}\text { 7WILSON } 345 \text { - 7REID } 345 \\
\text { Reconductor }\end{array}$ & $\begin{array}{l}\text { Loading }>100 \% \text { of } \\
\text { System Emergency }\end{array}$ & $\begin{array}{l}\text { Reconductored Transmission Line }+2 \\
\text { Upgraded Bays }\end{array}$ \\
\hline SOCO & $\begin{array}{l}\text { McGrau Ford - Hopewell 230kV } \\
\text { TL }\end{array}$ & $\begin{array}{l}\text { Loading }>100 \% \text { of } \\
\text { System Emergency }\end{array}$ & $\begin{array}{l}\text { 230kV Transmission Line, 230kV Bay } \\
\text { @ McGrau Ford \& Hopewell }\end{array}$ \\
\hline SOCO & Hopewell 230kV/115kV TL & $\begin{array}{l}\text { Loading }>100 \% \text { of } \\
\text { System Emergency }\end{array}$ & 230kV/115kV XFMR \\
\hline SOCO & Hopewell - Milton 230kV TL & $\begin{array}{l}\text { Loading }>100 \% \text { of } \\
\text { System Emergency }\end{array}$ & 230kV Transmission Line \\
\hline FRCC & $\begin{array}{l}\text { Re-conductor CURRY FD } 230.00 \\
\text { to STANTONW } 230.00\end{array}$ & $\begin{array}{l}\text { Loading }>100 \% \text { of } \\
\text { System Normal }\end{array}$ & Replace conductors \\
\hline FRCC & $\begin{array}{l}\text { Re-conductor SO WOOD } 230.00 \\
\text { to C CENTER } 230.00\end{array}$ & $\begin{array}{l}\text { Loading }>100 \% \text { of } \\
\text { System Normal }\end{array}$ & Replace conductors \\
\hline
\end{tabular}




\begin{tabular}{|c|c|c|c|}
\hline Region & Name & Reason/Need & Description \\
\hline FRCC & $\begin{array}{l}\text { Re-conductor TAFT } 230.00 \text { to C } \\
\text { CENTER } 230.00\end{array}$ & $\begin{array}{l}\text { Loading }>100 \% \text { of } \\
\text { System Normal }\end{array}$ & Replace conductors \\
\hline MISO_W & $\begin{array}{l}\text { Brookings County - Big Stone } \\
345\end{array}$ & $\begin{array}{l}\text { Interconnect New } \\
\text { Generation }\end{array}$ & New Transmission Line +2 Bays \\
\hline MAPP_CA & MYSLKRD-DUNLOP 230 kV TL & $\begin{array}{l}\text { Loading }>100 \% \text { of } \\
\text { System Emergency }\end{array}$ & Line, 2230 kVbays, \\
\hline MAPP_CA & DUNLOP-PONTON 230 kV TL & $\begin{array}{l}\text { Loading }>100 \% \text { of } \\
\text { System Emergency }\end{array}$ & Line, 2230 kVbays, \\
\hline MAPP_CA & RIEL 500/230 kV XFMR & $\begin{array}{l}\text { Loading }>100 \% \text { of } \\
\text { System Emergency }\end{array}$ & $\begin{array}{l}\text { One } 500 \mathrm{kV} \text { transformer, one } 500 \mathrm{kV} \\
\text { bay }\end{array}$ \\
\hline MISO_WUMS & $\begin{array}{l}\text { Oak Creek-Elm Rd 230-345kV } \\
\text { T884 XFMR Replacement }\end{array}$ & $\begin{array}{l}\text { Loading }>100 \% \text { of } \\
\text { System Emergency }\end{array}$ & Includes 1 new 345kV/230kV XFMR \\
\hline
\end{tabular}

